\title{
Health impact of the Volendam fire disaster
}

Citation for published version (APA):

Dorn, T. (2007). Health impact of the Volendam fire disaster. [Doctoral Thesis, Maastricht University]. NIVEL. https://doi.org/10.26481/dis.20070425td

Document status and date:

Published: 01/01/2007

DOI:

$10.26481 /$ dis.20070425td

Document Version:

Publisher's PDF, also known as Version of record

\section{Please check the document version of this publication:}

- A submitted manuscript is the version of the article upon submission and before peer-review. There can be important differences between the submitted version and the official published version of record.

People interested in the research are advised to contact the author for the final version of the publication, or visit the DOI to the publisher's website.

- The final author version and the galley proof are versions of the publication after peer review.

- The final published version features the final layout of the paper including the volume, issue and page numbers.

Link to publication

\footnotetext{
General rights rights.

- You may freely distribute the URL identifying the publication in the public portal. please follow below link for the End User Agreement:

www.umlib.nl/taverne-license

Take down policy

If you believe that this document breaches copyright please contact us at:

repository@maastrichtuniversity.nl

providing details and we will investigate your claim.
}

Copyright and moral rights for the publications made accessible in the public portal are retained by the authors and/or other copyright owners and it is a condition of accessing publications that users recognise and abide by the legal requirements associated with these

- Users may download and print one copy of any publication from the public portal for the purpose of private study or research.

- You may not further distribute the material or use it for any profit-making activity or commercial gain

If the publication is distributed under the terms of Article $25 \mathrm{fa}$ of the Dutch Copyright Act, indicated by the "Taverne" license above, 
Health impact of the Volendam fire disaster

Tina Dorn 
The study presented in this thesis was performed at the Netherlands Institute for Health Services Research (NIVEL), Utrecht, The Netherlands. The study was funded by the Public Health Department of the Dutch Ministry of Health, Welfare and Sport. Financial support for the printing of this thesis has been kindly provided by the Netherlands Institute for Health Services Research (NIVEL) and the Dutch Burns Foundation in Beverwijk.

Cover : Richard van Kruysdijk, Tina Dorn

Printing: Ponsen \& Looijen

ISBN 97-890-6905-8368

http://www.nivel.nl

nivel@nivel.nl

Telefoon 0302729700

Fax 0302729729

C2007 NIVEL, Postbus 1568, 3500 BN UTRECHT

All rights reserved. No part of this thesis may be reprinted or reproduced or utilized in any form or any electronic, mechanical, or other means, now known of hereafter invented, including photocopying and recording, or any information storage or retrieval system. Exceptions are allowed in respect of any fair dealing for the purpose of research, private study, or review. 


\title{
Health impact of the Volendam fire disaster
}

\author{
ACADEMISCH PROEFSCHRIFT \\ ter verkrijging van de graad van doctor aan \\ de Universiteit van Maastricht, \\ op gezag van de Rector Magnificus, Prof. mr. G.P.M.F. Mols \\ volgens het besluit van het College van Decanen, \\ in het openbaar te verdedigen \\ op woensdag 25 april 2007 om 12.00 uur \\ door \\ Tina Dorn \\ geboren te Speyer
}


Promotoren : Prof. dr. J. van der Zee (NIVEL)

Copromotor: Dr. C.J. IJzermans (NIVEL)

Beoordelingcommissie:

Prof. dr. G. Kok (voorzitter)

Prof. dr. W. van den Brink (Universiteit van Amsterdam)

Prof. dr. J.Th.M. van Eijk

Prof. dr. T. Fydrich (Humboldt-Universität Berlin)

Prof. dr. J.F.M. Melsemakers 
"Bij mij thuis in de vriendengroep, op mijn werk; alles is anders. Kijk iedereen heeft wel wat meegemaakt door de brand. Wat je ook zegt, het is ook nooit goed. Je kan niet meten wie het ergste heeft meegemaakt. ... Ja, wie bepaalt er nou wie er slachtoffer is. Het hele dorp is slachtoffer en ook weer niet. Dan vind je de ouders van wie een kind dood is het ergst, of jongeren die vingers missen of verbrand zijn in het gezicht. Maar ja, er zijn ook jongeren die niet kunnen slapen om wat ze gezien hebben die nacht. Is dat dan erg, zijn zij dan ook slachtoffer?"

M. Janssen, P. van der Velden, R. Kleber. Was alles maar weer normaal. Over Leven na de brand in Volendam. Instituut voor Psychotrauma, Zaltbommel, 2002 


\section{Contents}

$\begin{array}{lll}\text { Chapter } 1 & \text { Introduction } & 9\end{array}$

$\begin{array}{lll}\text { Chapter } 2 \text { Method and design } & 31\end{array}$

$\begin{array}{lll}\text { Chapter } 3 \text { Health problems primary victims } & 45\end{array}$

$\begin{array}{lll}\text { Chapter } 4 \text { Health problems secondary victims } & 63\end{array}$

$\begin{array}{lll}\text { Chapter } 5 \text { Hypertension in secondary victims } & 85\end{array}$

$\begin{array}{lll}\text { Chapter } 6 \text { Primary health care utilization } & 105\end{array}$

$\begin{array}{lll}\text { Chapter } 7 & \text { Benzodiazepine use } & 133\end{array}$

$\begin{array}{lll}\text { Chapter } 8 & \text { Discussion } & 153\end{array}$

$\begin{array}{ll}\text { Summary } & 177\end{array}$

$\begin{array}{ll}\text { Samenvatting } & 187\end{array}$

$\begin{array}{ll}\text { Literature } & 199\end{array}$

$\begin{array}{ll}\text { Dankwoord } & 215\end{array}$

$\begin{array}{ll}\text { About the author } & 221\end{array}$ 
Chapter

Introduction 
On New Year's Eve 2001, a fire ripped through a café-bar in Volendam, a former fishing village about 20 kilometers northeast of Amsterdam on the inland IJsselmeer Sea. The three-storey building, which had a bar and café on each floor, was one of the most popular meeting places for the town's youth population. The fire resulted in one of the worst mass burn incidents in recent Dutch history.

The disaster began at around midnight on the top floor of the building as hundreds of young revelers were ringing in the New Year. According to official figures, about 350 people were in the café when the fire broke out (1). The blaze was triggered when party-goers lit sparklers, igniting lowhanging, fir-tree ceiling decorations. The flames spread quickly and the burning material fell on to the crowd. Thick smoke and darkness fed panic as the electrical lighting failed and emergency exits became difficult to find. While many escaped by smashing windows and jumping from the top floor, others were trampled in the chaos.

Victims were sheltered and cooled in neighboring bars and houses before the first ambulances arrived at the scene (2). This made it difficult to accurately estimate the number of casualties. The arriving ambulances were besieged by the injured and relatives who had rushed to the scene, desperate for help (3). Transportation of victims was further complicated by the site's location at a narrow embankment on the waterfront. Later that night, field tents were erected for mass casualty treatment, and victims were transported to the hospitals on a larger scale. Four people died at the scene, and another ten succumbed to the effects of their severe injuries during the subsequent days and months. In total, 241 victims were seen in hospital, of whom 112 in intensive care units (4). Seventy eight patients were transported to specialized burn centers in the Netherlands, Belgium and Germany (5). Most victims were teenagers. The youngest victim was only 13 years old.

Soon after the fire, public prosecutors launched an inquiry to determine if fire regulations had been violated. This resulted in the conviction of the bar owner. Elements of human error and negligence were apparent in various aspects. First of all, too many people had been admitted to the bar that night, 
leading to serious overcrowding. Second, the ceiling decorations had not been treated to make them flame-resistant. Furthermore, emergency exits were either not visible or were blocked. Also, the windows on the top floor could not be used as exits since they were secured with iron bars. In addition, staircases behind the two emergency doors on the upper floors leading to the outside of the building were absent.

It comes as no surprise that many felt that the fire and its horrific consequences could have been avoided if fire regulations had been properly enforced by the municipality and adhered to by the proprietor. The legal proceedings and the search for those responsible led to considerable distress and turmoil in the community. Although a relatively small-scale incident when compared to other disasters, the Volendam fire aroused strong public interest. There was considerable media coverage, raising public awareness and financial support for the victims.

The tragedy in Volendam touched virtually everyone in the town as the dead and injured were all local people. After the fire, the people of Volendam not only had to cope with the loss of class-mates, friends, or family members, they were also confronted on a daily basis with the handicapped and disfigured victims (6). In this context, it is important to note that Volendam stands out as a very close-knit community in terms of social relations and kinship ties (7). Volendam is a Catholic enclave in the Protestant North-West of the country. Owing to its cultural isolation in the past and the hardships experienced when Volendam was still a fishing village on the rough Zuiderzee, Volendam evolved into a community of selfreliant people who tend to live out their lives in their home town. This strong social cohesion is also reflected in official census figures, which identify Volendam as the municipality with the lowest mobility in the entire country (8). 


\section{The Volendam fire - a disaster?}

The Dutch public at large considered the fire in Volendam to be a national tragedy and soon spoke of it as a 'disaster'. A significant factor in the perception of the incident as such was the age of the victims. The victims were all teenagers whose lives seemed to have just started. Another, related, factor was identification. Outsiders could easily identify with the pain of those mourning the deaths of the young people. They could share in the rage and shock of those who had lost their loved ones due to the seemingly negligent and reckless attitude of the bar owner who had been ignoring the recommendations of inspectors for years. And they could identify with the horrors experienced by those whose children and friends suffered serious burns. Part of this identification involves an assumption of risk (9). The fact that these youngsters did not have a responsible role in their fate offers far greater scope for identification than in the case of victims who have consciously accepted unnecessary risks. A further element that influences the perception of the incident as a public tragedy is the visibility of suffering. In Volendam, the prolonged suffering of those who are scarred for life will always remain evident.

While it is clear that the Volendam fire was perceived by public opinion to be a disaster, it remains to be determined whether this view would also be shared by the research community. This issue will be addressed below. In a first step, central themes found in scientific definitions of disaster will be presented. In a second step, the Volendam fire will be reviewed in the light of these themes.

\section{Central themes in disaster research}

Various definitions and taxonomies of disaster exist, stemming from disciplines as varied as sociology, medicine, psychology, organizational sciences or public health (10). Although the debate is interesting, it is beyond the scope of this study to dwell on all the controversies in the field. Rather, the focus will be on those themes that are usually shared by most definitions. One of these central themes is that disasters cause extensive losses to many people simultaneously; another is that they occur on a scale that overtaxes existing resources. Finally, disasters are generally categorized 
(according to their causes) into human-generated, man-made disasters and natural disasters (11). Whereas man-made disasters have an element of human intent, negligence or error, natural disasters stem from geophysical sources such as earthquakes, hurricanes or floods.

As the following section will demonstrate, the fire in Volendam has two features which mark it as a disaster. First, it was a sudden, unexpected event which overwhelmed the local medical resources. Second, it was experienced collectively and had a profound impact on the community and on social relations among residents. Finally, because the fire was caused by human error and neglect, it can be categorized as a man-made disaster.

\begin{abstract}
A sudden, unexpected event which overwhelmed local medical resources
Disasters are often seen as unexpected or uncontrollable events which overwhelm our ability to cope or adapt (12). In Volendam, this is certainly true in the psychological sense, since the victims were exposed to life-threat, horrible injuries and grotesque scenes. But it also applies in the organizational sense. When compared to other indoor fires, the Volendam fire was characterized by the large number of severely burned victims who managed to escape the café, and a low percentage of victims who died at the scene (13). Due to the high number of severe injuries, the local medical resources were overwhelmed, necessitating transports of severely burned patients to hospitals abroad. To conclude, the fire occurred on a scale that could not be managed with existing community resources and required outside help - a feature included in almost all definitions of disaster.
\end{abstract}

\title{
Community impact
}

Many definitions of disaster, especially sociological definitions, include social disruption as a defining characteristic (14). Disasters are also usually viewed as a collective experience, in contrast to 'personal' disasters such as sexual abuse or automobile accidents. In Volendam, a number of local young people suffered serious burns simultaneously. Many others were involved as witnesses, helpers, survivors, relatives or friends, rendering the fire and its consequences a collective, shared experience. It is no surprise that the Volendam fire has been called a community disaster (15). The social impact of the fire is not only reflected in numerous mass media reports, but also in 
the community response to the fire. Within days after the fire, a local information and advice center, named 'Het Anker' ('The anchor'), was put into place to address the questions of victims and their families. A foundation was set up to support the financial interests and medical needs of the victims. Later, a local treatment center, the Medical Center 'Waterland Oost', was constructed in order to provide medical after-care for the victims. A volunteer-run buddy project was set up with the aim of providing social support to the fire victims (16). In short, numerous examples demonstrate the social impact the fire had on the community.

\section{Review of the literature}

The main objective of this thesis is to measure and describe the adverse health effects of the Volendam fire with the help of epidemiological methods. The aim of this chapter is to further establish the purpose of the study and to provide an overview of the research related to the topic.

It is more than obvious that disasters cause physical harm since they result in deaths, injuries or illnesses in the affected community. Besides the physical harm, disasters also have a profound psychosocial impact. The next section will therefore briefly outline what is known on disaster and psychological distress. Subsequently it will be discussed how psychological distress is related to physical health. This is followed by a review of the literature on other indoor fires. After this rather broad introduction, a classification of the Volendam disaster victims is attempted. Based on this classification, we will evaluate what kind of health problems are to be expected in the different groups. The chapter will conclude with the statement of the research topic and the research questions.

\section{Disaster and psychological distress}

A broad range of psychosocial problems has been associated with exposure to various disasters, including Posttraumatic Stress Disorder (PTSD), anxiety disorders, depression, psychosomatic complaints, substance abuse, domestic violence and divorce (12). Rubonis and Bickman concluded in a metaanalysis of controlled disaster studies (comparison group, pre-post-designs) 
that the literature indicates a $17 \%$ increase in the prevalence of psychopathology following disaster exposure (17). In addition, a recent review of the literature (18) showed that samples were more likely to be impaired if they were composed of minors rather than adults; were from developing rather than developed countries; or experienced mass violence (e.g., terrorism, shootings) rather than natural or technological disasters. Within adult samples, the likelihood of adverse outcomes (18) most consistently increased with more severe exposure, female gender, middle age, ethnic minority status, secondary stressors, prior psychiatric problems, and weak or deteriorating psychosocial resources.

\section{Psychological distress and physical health}

Psychological distress due to disasters may not only impact on mental health, but, as the following section will demonstrate, can also have physical health effects. Numerous links have been proposed which relate the experience of psychological distress to adverse physical health outcomes. In sum, five different reasons can be identified which explain how psychological distress is related to physical health.

First, stress and its emotional concomitants bring with them a number of physical symptoms (19). Anxiety can produce diarrhea, upset stomach, sweaty hands, shortness of breath, difficulty sleeping, poor concentration and general agitation. Depression can lead to fatigue, difficulty in performing daily activities, loss of appetite and sleep disturbances. Individuals may thus "mistake" the symptoms associated with mood disorders for physical problems (20;21).

Second, some individuals tend to express distress and conflict through bodily symptoms. When these people are going through stressful events, they are especially likely to perceive minor symptoms as more serious (22).

Third, many people are unwilling to admit to themselves that they have a psychological problem, believing that it is shameful to have mental health problems. Physical complaints are thus often perceived to be more legitimate than psychological ones and more likely to be reported or presented at the doctor's office. 
The fourth reason is that the stressful experience may give way to multiple physiological changes which increase susceptibility to disease (23-25). Early stress research demonstrated conclusively that stimuli that threaten an organism produce physiological responses involving the nervous and the endocrine system (26;27). Repeated stressors may thus lead to "wear and tear" on the system, and as a consequence raise the likelihood of disease $(23 ; 28)$.

A fifth and final reason for ill health is seen in altered health habits. People under stress report getting less sleep, being less likely to follow a healthy diet, consume more alcohol and use drugs more frequently $(29 ; 30)$. Stress can thus indirectly affect illness by altering a person's behavior patterns.

The effects of life stress have been studied using different approaches ranging from the study of major life events, daily hassles, chronic stress and strain in the workplace and the home (31). Besides this, more recent work has examined the health effects associated with traumatic stressors (32). The definition of a traumatic event, as it is currently provided by the DSM-IV, is based on the experience of an extreme stressor involving a threat to life or the prospect of serious injury; witnessing an event that involves the death or serious injury of another person; or learning of the violent death or serious injury of a family member or close friend (33). Traumatic stressors are extreme stressors for several reasons. Not only do they attack people's basic assumptions of safety, but they also occur unexpectedly and make excessive demands on an individual's resources, are beyond the realm for which coping strategies have been developed, and leave a powerful mental image that is easily evoked by cues associated with the event (34). Examples are combat or war-zone experiences, sexual abuse, disasters and serious accidents. In addition to mental health effects, adverse physical health outcomes have been reported in trauma survivors, including poor selfreported health status, a greater number of medical problems, increased morbidity and mortality and greater service utilization (35-37). 


\section{Literature on fire disasters}

In order to provide a match between the background literature and the topic of this thesis, in a final step, the literature was searched with the aim of finding publications on other fires with characteristics similar to the Volendam fire. This is not always easy since fire disasters can be caused by a wide range of circumstances. We therefore concentrate on the descriptions of other indoor fires, to the exclusion of other mass burn incidents such as wildfires, coal mine explosions or airplane crashes. Scientific publications are available for fires such as the Las Vegas Hotel Fire (38), the Disco Fire in Dublin $(39 ; 40)$, the Happy Land Social Club Fire (41), the Rhode Island Nightclub Fire (42;43), the Discotheque Fire in Buenos Aires (44) or the Bali Burn Disaster (45;46). All these studies concentrate on the organizational and medical management of burns during the immediate post-disaster phase, with primary victims as the major group of interest (see also for a review (13)).

An exception is the 1998 Gothenburg fire, which has many similarities to the Volendam fire (47-50). From a research perspective, the Gothenburg fire is the only fire in which information is provided beyond the acute postdisaster stage and where psychosocial effects were studied. This fire occurred in an old warehouse where nearly 400 teenagers had gathered for a disco party. In contrast to Volendam, the Gothenburg fire was caused by arson. As a consequence of the fire, 213 people were injured and 63 people died, a much larger death toll than in Volendam. Posttraumatic stress, school adjustment and performance were examined 18 months after the fire in a sample of 275 adolescents who survived the incident. Twenty-five percent of the participants met DSM-IV criteria for PTSD. Twenty-three percent of the participants reported having either dropped out of school or repeated a class because of the fire $(51 ; 52)$. In contrast to the Volendam victims, many of the victims in Gothenburg were of immigrant descent, with a history of stressful or traumatic life events. In this sample, it is therefore difficult to disentangle the effects of the fire and the effects of prior exposure to psychological trauma. Moreover, the authors do not report on the type of injuries the adolescents had suffered and it is unclear how many burn victims were among the respondents. 
The Volendam fire itself has been the subject of previous investigations as well. Reijneveld and colleagues evaluated the impact of the fire based on questionnaires. Coincidentally, 15 months before the disaster some of the primary victims and many of their schoolmates had completed the questionnaires which were initially distributed in order to evaluate a school health promotion program. This circumstance provided the opportunity for pre-post comparisons. Post-disaster assessments were carried out twice - the first assessment 5 months after the fire (53), the second 12 months after the fire (54). Data were based on an initial sample of 91 Volendam adolescents and 643 controls from two control schools outside Volendam.

The first study showed that Volendam adolescents had larger increases in clinical scores than controls for total problems as measured by the Youth Self-Report (YSR) as well as for excessive alcohol use, but not for smoking or use of marijuana, ecstasy, and sedatives. The second assessment 12 months after the disaster demonstrated differences between controls and Volendam adolescents in regard to excessive drinking only (54). Reijneveld and colleagues did not find evidence for a relationship between the degree of disaster exposure and mental health effects, since the results were mostly similar in victims and their classmates. The sample consisted of only 14 primary victims (those who had been present in the café) and 77 secondary victims (the classmates), however, which rendered the assessment of a differential impact difficult.

\section{A classification of victims}

In the past, disaster victims were often classified by the extent to which they suffered personal injury and sickness, bereavement or property loss (55-57). Because of the 'ripple' effect of major incidents, many individuals may be classified as victims even though they were not at the 'epicenter' of the disaster. 
In Volendam, disaster victims can be classified into several categories according to the type of exposure to the disaster.

(1) Those who were in the burning building are the primary victims. Within this category, a subdivision can be made into victims who suffered a burn trauma and those who did not.

(2) Family members of primary victims are considered to be the secondary victims since they are psychologically closest to the primary victims.

(3) Tertiary victims are members from the same community who maintain multiple social ties with primary and/or secondary victims.

In sum, the basic assumption made in this thesis is that health problems of the different groups will depend on the degree and type of losses they experienced. In the next section we will therefore address the question as to which type of health problems are to be expected in which victims. In addition, it will shed light on additional theoretical concepts underlying these expectations.

\section{Primary victims}

Although life event researchers view disasters as 'natural experiments' in which large numbers of people are simultaneously exposed to one extreme stressor, the link between physical illness and life stress is difficult to establish in primary victims of disaster (58). The picture is complicated by the fact that the physical morbidity seen in primary victims is partly attributable to the consequences of physical injuries suffered during the disaster. Due to this, it can be difficult to disentangle the psychological and physical effects of the event. In the context of this thesis, it is therefore essential to distinguish primary victims with burns from primary victims without burns.

\section{Victims with burns}

Burns are thermal injuries of the skin which often require prolonged treatment. Besides the skin, the respiratory system may be affected due to inhalation of hot air and smoke. After wound healing has occurred, numerous reconstructive operations may follow, depending on the seriousness and size of the burn. Disfigurement is one of the most obvious consequences of a burn, but also functional limitations can prevail when scar 
tissue restricts the mobility of joints. Sometimes, amputations are unavoidable. The skin of the fingers, for example, is thin and can easily be deeply burned. In that case, the amputation of fingers may be the only solution. In brief, there are numerous physical consequences of burns which require medical attention.

Besides the physical trauma, burns have a far-reaching psychosocial impact. According to literature reviews, depression and posttraumatic stress disorder (PTSD) are prevalent in 13-23\% of cases and 13- $45 \%$ of the cases, respectively (59). It is therefore obvious that burn patients have special mental health care needs. Due to the debilitating and long-term effect of burn injuries, it is expected that victims who suffered burns in the Volendam fire will be in worse physical and mental health when compared to those victims who survived the fire without burn injuries.

\section{Victims without burns}

In contrast to primary victims with burns, victims without burns have been subjected to "psychological trauma only". Primary victims without burns might suffer from mental health consequences due to the witnessing of grotesque scenes at the site and the life threat they have experienced. In addition to this, it is expected that the disruption to the social networks of these young people has a distressing effect. A positive relationship between distress and physician utilization has been reported in many studies (22;6062) and it is expected that this effect will also observed in the current research. Besides this, certain physical health problems have been found to increase after disasters in disaster-affected adolescent populations when compared to control subjects (63), in particular musculoskeletal problems. A final assumption is that the effects of the fire are only transient in the majority of adolescents without burns. This is in accordance with the general literature on disasters which considers the first year after the disaster to be the peak time of effects (18). 


\section{Secondary victims}

Secondary victims are defined as the family members of primary victims. The current thesis mainly concentrates on health effects in parents of disaster victims. Within this category, several subgroups can be distinguished; these are bereaved parents, parents of victims with burns, and parents of victims without burns.

\section{Parents of victims without burns}

A theoretical concept that helps to define the area of interest is the term 'secondary traumatic stress'. This term has been coined to describe adverse effects upon family members and friends whose lives are closely associated with those of trauma survivors $(64 ; 65)$. Secondary traumatic stress may result from knowing about a traumatic event experienced by a significant other or from wanting to help the traumatized person. Related concepts are vicarious traumatization, compassion fatigue or empathic strain. There is no doubt that trauma experienced by one member can impact negatively on the family system (66). In Volendam, the primary victims were all teenagers and the parents of the victims had to deal with a number of stressful experiences after the disaster. The literature on secondary traumatic stress has largely focused on the development of symptoms of posttraumatic stress in family members, however, and it is unclear whether secondary exposure may lead to other conditions as well. In the context of this thesis, we therefore expect that the parents of victims without burns also show increases in mental health care utilization and a higher prevalence of mental health problems, especially during the acute phase after the disaster. In order to capture potential adverse physical health outcomes, the health problems of this parent group are therefore examined in the same way as for parents of victims with burns.

\section{Parents of victims with burns}

Burn injuries not only place severe demands on the coping resources of the patients, but also on their families $(67 ; 68)$. The burden of care for children with burns generally falls upon parents who have to balance the child's health care needs with those of other family members and work commitments (69). In addition, parents can experience considerable anxiety about the child's future well-being. The literature on pediatric chronic illness 
supports the idea that caring for a medically fragile child or adolescent has implications for the health of parents (70-72). However, only a few research studies have examined the health status of parent caregivers of burn victims. All described mental health consequences (i.e. depression, anxiety, posttraumatic stress symptoms) (73-79). Only one publication examined physical health consequences in family members of burn patients. It demonstrated that immune function in spouses and parents of burn patients was suppressed 72 hours after the admission of the burn patient and improved two to five weeks later, thus indicating only short-term effects (80). Our study provides the opportunity to examine both mental and physical health problems in parents of burn victims, consequently adding to a knowledge base which is still rather meager.

\section{Parents who lost a child}

One last group of parents deserves consideration, namely those parents who have lost a child as a consequence of the fire. It is never in the natural order of things for a child to die before his or her parents, and the impact can be especially intense when the death is sudden. Research has conclusively demonstrated that the circumstances of deaths which are unexpected, sudden and untimely are likely to lead to a higher risk of bereavement complications (81). Complications may include the development of depressive or anxiety disorders, but a deterioration of immune function and an increased risk for physical disorders has also been documented in bereaved persons (82-85). Based on the literature, it is expected that the parents who lost a child due to the fire in Volendam will be in worse mental and physical health than parents who were not bereaved.

\section{Tertiary victims}

As stated above, other community members who were directly involved in the fire, are considered tertiary victims in this study. Since it cannot be ruled out that the Volendam fire did have an impact on the health and well-being of community members, controls from outside Volendam will be used wherever possible. Although Volendam was in severe shock after the disaster and the consequences of the fire led to considerable unrest in the community, it is not expected that this will result in substantial health 
problems in community controls. In general, only short-lived effects are expected in this group if at all.

\section{Statement of the research topic and research questions}

As outlined above, it is assumed that there are different degrees of exposure to the disaster which are related to specific types of losses. Therefore, a distinction is made between victims with and without burns (primary victims), their family members (secondary victims) and other community members (tertiary victims). In addition, it is hypothesized that there is a relationship between these exposures and the health of individuals. Health effects in the population under study can be operationalized in different ways. Since the current study is based on the registrations of local Family Practitioner offices and pharmacies, it is logical that the study of health effects is determined by the type of data captured in these electronic registrations.

In essence, this study aims to answer three main questions:

1. How does the Volendam fire influence the health of the population under study?

2. What is the influence of the Volendam fire on primary health care utilization and medication use?

3. Is there a relationship between the degree of disaster exposure and the observed health effects?

The first question deals with the health problems of primary, secondary and tertiary victims. As the above literature review demonstrates, it is a wellknown fact that mental health problems can increase after disasters, but physical health problems in survivors of psychological trauma have been less often researched. Specific assumptions concerning the type of health problems can be made in the case of victims with burns, since their health problems are determined to a great extent by the burn trauma they suffered. In all other groups, it is difficult to make assumptions on what kind of physical health problems are to be expected. Therefore, a broad spectrum of physical health problems will be examined simultaneously. 
In order to answer the second question, two types of outcomes will be considered, that is health care utilization (operationalized as the number of contacts in family practice), and the utilization of psychotropic medications. In the case of the latter outcome, a specific type of psychotropic medication, namely benzodiazepines was chosen. These medications were selected because anxiety and sleep problems are very common after disasters. Therefore, benzodiazepines are most likely to have been prescribed on a large scale after the fire.

The third question is based on the assumption that in Volendam, there are groups with varying degrees of exposure to the disaster. In primary victims, exposure is assumed to be highest in victims with burns, because these youngsters suffered from a combination of physical and psychological trauma, followed by victims who survived without burns. In secondary victims, the severity of adversity is hypothesized to be highest in those parents whose children suffered burns, followed by parents of victims who were present during the fire but survived without burns. Bereavement will be considered as a risk factor for adverse outcomes. Community controls, finally, are assumed to have the least exposure when compared to other groups in Volendam.

\section{Outline of the thesis}

This thesis contains a series of five studies, dealt with in separate chapters. Chapter 3 focuses on the morbidity of the fire victims. Chapter 4 examines the same outcomes in the parents of these victims. Chapter 5 reports on the incidence of new hypertension in parents of fire victims. Chapter 6 investigates the contact frequencies of victims and their family members in primary care. Chapter 7 addresses the question whether benzodiazepines have been adequately prescribed in the post-disaster phase. The concluding chapter (chapter 8) attempts to integrate the findings presented in the separate chapters and discusses possible perspectives for future research. 


\section{References}

1. Commissie Onderzoek Cafébrand (Commissie Alders). Cafébrand Nieuwjaarsnacht Eindrapport. 2001. [New Year's Eve café fire. Final Report]

2. van Vugt AB. [Disaster medicine: lessons from Enschede and Volendam]. Ned Tijdschr Geneeskd 2001; 145(48):2309-2312.

3. Welling L, van Harten SM, Patka P, Bierens JJ, Boers M, Luitse JS et al. The café fire on New Year's Eve in Volendam, the Netherlands: description of events. Burns 2005; 31(5):548-554.

4. van Harten SM, Welling L, Perez RS, Patka P, Kreis RW. Management of multiple burn casualties from the Volendam disaster in the emergency departments of general hospitals. Eur J Emerg Med 2005; 12(6):270-274.

5. Pirson J, Degrave E. Aeromedical transfer to Belgium of severely burned patients during the initial days following the Volendam fire. Mil Med 2003; 168(5):360-363.

6. Janssen M, van der Velden P, Kleber R. Was alles maar weer normaal. Over leven na de brand in Volendam. Zaltbommel: Instituut voor Psychotrauma, 2002.

7. Cachet A, Daemen HHFM, Ringeling AB, Schaap L. Het derde klaphek voorbij. Een analyse van de Volendamse bestuurscultuur. Rotterdam: Centre for Local Democracy, Erasmus Universiteit Rotterdam, 2001.

8. Centraal Bureau voor de Statistiek. Gemeente op maat - Edam-Volendam. Voorburg: CBS, 2004.

9. Doka KJ. What makes a tragedy public? In: Lattanzi-Licht M, Doka KJ, editors. Living with grief: Coping with public tragedy. New York: Brunner-Routledge, 2003; 3-13.

10. Tierney KJ. Controversy and consensus in disaster mental health research. Prehospital and Disaster Medicine 2000; 15(4):181-187.

11. Noji EK. Disasters: introduction and state of the art. Epidemiol Rev 2005; 27:3-8.

12. Norris FH. Psychosocial consequences of disaster. PTSD Research Quarterly 2002; 13(2):18.

13. Welling L, van Harten SM, Patka P, Bierens JJ, Boers M, Luitse JS et al. Medical management after indoor fires: a review. Burns 2005; 31(6):673-678.

14. Barton AH. Communities in disaster: A sociological analysis of collective stress situations. Garden City, NY: Doubleday, 1969.

15. Ellemers JE. Rampen in Nederland. [Disasters in the Netherlands] Sociologische Gids 2001; 48(3):231-252.

16. Klein Beernink M. Support in Volendam. Houten: Bohn Stafleu van Loghum, 2006.

17. Rubonis AV, Bickman L. Psychological impairment in the wake of disaster: the disasterpsychopathology relationship. Psychol Bull 1991; 109:384-399.

18. Norris FH, Friedman MJ, Watson PJ. 60,000 disaster victims speak: Part II. Summary and implications of the disaster mental health research. Psychiatry 2002; 65(3):240-260.

19. Pennebaker JW. Accuracy of symptom perception. In: Baum A, Taylor SE, editors. Handbook of psychology and health. New York: Erlbaum, 1983: 189-218. 
20. Kroenke K, Spitzer RL, Williams JB, Linzer M, Hahn SR, deGruy FV, III et al. Physical symptoms in primary care. Predictors of psychiatric disorders and functional impairment. Arch Fam Med 1994; 3(9):774-779.

21. Kroenke K. Patients presenting with somatic complaints: epidemiology, psychiatric comorbidity and management. Int J Methods Psychiatr Res 2003; 12(1):34-43.

22. Miranda J, Perez-Stable EJ, Munoz RF, Hargreaves W, Henke CJ. Somatization, psychiatric disorder, and stress in utilization of ambulatory medical services. Health Psychol 1991; 10(1):46-51.

23. Dougall AL, Baum A. Psychoneuroimmunology and trauma. In: Green BL, Schnurr PP, editors. Trauma and health: Physical health consequences of exposure to extreme stress. Washington, DC: American Psychological Association, 2004: 129-155.

24. Herbert TB, Cohen S. Stress and immunity in humans: a meta-analytic review. Psychosom Med 1993; 55(4):364-379.

25. McEwen BS. The neurobiology of stress: from serendipity to clinical relevance. Brain Res 2000; 886(1-2):172-189.

26. Selye H. The stress of life. New York: McGraw-Hill, 1956.

27. Cannon WB. The wisdom of the body. New York: Norton, 1932.

28. Ford DE. Depression, trauma, and cardiovascular health. In: Green BL, Schnurr PP, editors. Trauma and health: Physical health consequences of exposure to extreme stress. Washington, DC: American Psychological Association, 2004; 73-97.

29. Ng DM, Jeffery RW. Relationships between perceived stress and health behaviors in a sample of working adults. Health Psychol 2003; 22(6):638-642.

30. Rheingold AA, Acierno R, Resnick HS. Trauma, posttraumatic stress disorder, and health risk behaviors. In: Schnurr PP, Green BL, editors. Trauma and health: Physical health consequences of exposure to extreme stress. Washington, DC: American Psychological Association, 2004; 217-244.

31. Taylor SE. What is stress? In: Taylor SE, editor. Health psychology. New York: McGrawHill, 1995; 219-296.

32. Schnurr PP, Green BL. Trauma and health: Physical health consequences of exposure to extreme stress. Washington, DC: American Psychological Association, 2004.

33. American Psychiatric Association. Diagnostic and statistical manual of mental disorders (4th ed.). Washington, DC. American Psychiatric Association, 2000.

34. Hobfoll SE. Traumatic stress: A theory based on rapid loss of resources. Anxiety Research 1991; 4(3):187-197.

35. Schnurr PP, Jankowski MK. Physical health and post-traumatic stress disorder: review and synthesis. Semin Clin Neuropsychiatry 1999; 4(4):295-304.

36. Green BL, Kimerling R. Trauma, posttraumatic stress disorder, and health status. In: Green BL, Schnurr PP, editors. Trauma and health: Physical health consequences of exposure to extreme stress. Washington, DC: American Psychological Association, 2004; 13-42. 
37. Walker EA, Newman E, Koss MP. Costs and health care utilization associated with traumatic experiences. In: Green BL, Schnurr PP, editors. Trauma and health: Physical health consequences of exposure to extreme stress. Washington, DC: American Psychological Association, 2004; 43-69.

38. Munninger K, Ravenholt O. Lessons from Las Vegas: the MGM Hotel fire. JEMS 1981; 6(2):37-40.

39. Sadler C. Accident and emergency: the St Valentine's day disaster. Nurs Mirror 1982; 154(20):14-16.

40. Duignan JP, McEntee GP, Scully B, Corrigan TP. Report of a fire disaster-management of burns and complications. Ir Med J 1984; 77(1):8-10.

41. Gill JR, Goldfeder LB, Stajic M. The happy land homicides: 87 deaths due to smoke inhalation. J Forensic Sci 2003; 48(1):161-163.

42. Mahoney EJ, Harrington DT, Biffl WL, Metzger J, Oka T, Cioffi WG. Lessons learned from a nightclub fire: institutional disaster preparedness. J Trauma 2005; 58(3):487-491.

43. Dacey MJ. Tragedy and response- the Rhode Island nightclub fire. N Engl J Med 2003; 349(21):1990-1992.

44. Ramos G, Flageat G, Queiroz G, Nacif G, Fiorentino R, Arata A et al. Massive Hospital Admission of Patients with Respiratory Failure Resulting from Smoke Inhalation Injury: The Cromagnon Republic Tragedy. J Burn Care Res 2006; 27(6):842-847.

45. Edgar DW, Wood F, Goodwin-Walters A. First response, rehabilitation, and outcomes of hand and upper limb function: survivors of the Bali bombing disaster. A case series report. J Hand Ther 2006; 19(3):283-297.

46. Kennedy PJ, Haertsch PA, Maitz PK. The Bali burn disaster: implications and lessons learned. J Burn Care Rehabil 2005; 26(2):125-131.

47. Brandsjo K, Hedelin A, Lundin T, Lundalv J. KAMEDO Report No. 75: Fire Catastrophe in Gothenburg 29-30 October 1998. Prehospital Disaster Med 2005; 20(4):258-261.

48. Cassuto J, Tarnow P. The discotheque fire in Gothenburg 1998. A tragedy among teenagers. Burns 2003; 29(5):405-416.

49. Tarnow P, Gewalli F, Cassuto J. Fire disaster in Gothenburg 1998-surgical treatment of burns. Burns 2003; 29(5):417-421.

50. Gewalli F, Fogdestam I. Triage and initial treatment of burns in the Gothenburg fire disaster 1998. On-call plastic surgeons' experiences and lessons learned. Scand J Plast Reconstr Surg Hand Surg 2003; 37(3):134-139.

51. Broberg AG, Dyregrov A, Lilled L. The Goteborg discotheque fire: posttraumatic stress, and school adjustment as reported by the primary victims 18 months later. J Child Psychol Psychiatry 2005; 46(12):1279-1286.

52. Dyregrov A, Frykholm AM, Lilled L, Broberg AG, Holmberg I. The Goteborg discotheque fire, 1998. Scand J Psychol 2003; 44(5):449-457.

53. Reijneveld SA, Crone MR, Verhulst FC, Verloove-Vanhorick SP. The effect of a severe disaster on the mental health of adolescents: a controlled study. Lancet 2003; 362(9385):691696. 
54. Reijneveld SA, Crone MR, Schuller AA, Verhulst FC, Verloove-Vanhorick SP. The changing impact of a severe disaster on the mental health and substance misuse of adolescents: follow-up of a controlled study. Psychol Med 2005; 35:367-376.

55. Dohrenwend BP, Dohrenwend BS, Warheit GJ, Bartlett GS, Goldsteen RL, Goldsteen K et al. Stress in the community: a report to the President's Commission on the Accident at Three Mile Island. Ann N Y Acad Sci 1981; 365:159-174.

56. Cohen RE, Ahearn FL. Handbook for mental health care of disaster victims. Baltimore: John Hopkins University, 1980.

57. Taylor A. A taxonomy of disasters and their victims. Journal of Psychosomatic Research 1987; 31(5):535-544.

58. McFarlane AC. The effects of stressful life events and disasters: research and theoretical issues. Aust N Z J Psychiatry 1985; 19(4):409-421.

59. Van Loey NE, Van Son MJ. Psychopathology and psychological problems in patients with burn scars: epidemiology and management. Am J Clin Dermatol 2003; 4(4):245-272.

60. Tessler R, Mechanic D, Dimond M. The effect of psychological distress on physician utilization: a prospective study. J Health Soc Behav 1976; 17(4):353-364.

61. Cameron L, Leventhal EA, Leventhal H. Seeking medical care in response to symptoms and life stress. Psychosom Med 1995; 57(1):37-47.

62. Gillock KL, Zayfert C, Hegel MT, Ferguson RJ. Posttraumatic stress disorder in primary care: prevalence and relationships with physical symptoms and medical utilization. Gen Hosp Psychiatry 2005; 27(6):392-399.

63. Dirkzwager AJ, Kerssens JJ, Yzermans CJ. Health problems in children and adolescents before and after a man-made disaster. J Am Acad Child Adolesc Psychiatry 2006; 45(1):94103.

64. Figley CR. Burnout in families: The systemic costs of caring. Boca Raton, FL, US: CRC Press, 1998.

65. Figley CR. Burnout as systemic traumatic stress: A model for helping traumatized family members. In: Figley CR. The systemic costs of caring. Boca Raton, FL, US: CRC Press, 1998; 15-28.

66. Barnes MF. Understanding the secondary traumatic stress of parents. In: Figley CR. The systemic costs of caring. Boca Raton, FL, US: CRC Press, 1998; 75-89.

67. Watkins PN, Cook EL, May SR, Still JM, Jr., Luterman A, Purvis RJ. Postburn psychologic adaptation of family members of patients with burns. J Burn Care Rehabil 1996; 17(1):7892.

68. Tarnowski KJ, Brown RT. Burn injuries. In: Goreczny AJ, Hersen M, editors. Handbook of pediatric and adolescent health psychology. Boston: Allyn and Bacon, 1999; 115-126.

69. Blakeney P, Moore P, Broemeling L, Hunt R, Herndon DN, Robson M. Parental stress as a cause and effect of pediatric burn injury. J Burn Care Rehabil 1993; 14(1):73-79.

70. Vedhara K, McDermott MP, Evans TG, Treanor JJ, Plummer S, Tallon D et al. Chronic stress in nonelderly caregivers: psychological, endocrine and immune implications. J Psychosom Res 2002; 53(6):1153-1161. 
71. Vedhara K, Shanks N, Anderson S, Lightman S. The role of stressors and psychosocial variables in the stress process: a study of chronic caregiver stress. Psychosom Med 2000; 62(3):374-385.

72. Kuster PA, Merkle CJ. Caregiving stress, immune function, and health: implications for research with parents of medically fragile children. Issues Compr Pediatr Nurs 2004; 27(4):257-276.

73. Rizzone LP, Stoddard FJ, Murphy JM, Kruger LJ. Posttraumatic stress disorder in mothers of children and adolescents with burns. J Burn Care Rehabil 1994; 15(2):158-163.

74. LeDoux J, Meyer WJ, III, Blakeney PE, Herndon DN. Relationship between parental emotional states, family environment and the behavioural adjustment of pediatric burn survivors. Burns 1998; 24(5):425-432.

75. Hall E, Saxe G, Stoddard F, Kaplow J, Koenen K, Chawla N et al. Posttraumatic stress symptoms in parents of children with acute burns. J Pediatr Psychol 2006; 31(4):403-412.

76. Fukunishi I. Posttraumatic stress symptoms and depression in mothers of children with severe burn injuries. Psychol Rep 1998; 83(1):331-335.

77. Kent L, King H, Cochrane R. Maternal and child psychological sequelae in paediatric burn injuries. Burns 2000; 26(4):317-322.

78. Mason SA. Young, scarred children and their mothers - a short-term investigation into the practical, psychological and social implications of thermal injury to the preschool child. Part I: Implications for the mother. Burns 1993; 19(6):495-500.

79. Meyer WJ, Blakeney P, Moore P, Murphy L, Robson M, Herndon D. Parental well-being and behavioral adjustment of pediatric survivors of burns. J Burn Care Rehabil 1994; 15(1):62-68.

80. Shelby J, Sullivan J, Groussman M, Gray R, Saffle J. Severe burn injury: effects on psychologic and immunologic function in noninjured close relatives. J Burn Care Rehabil 1992; 13(1):58-63.

81. Stroebe W, Schut H. Risk factors in bereavement outcome: A methodological and empirical review. In: Stroebe MS, editor. Handbook of bereavement research: Consequences, coping, and care. Washington DC: American Psychological Association, 2001; 349-371.

82. Hall M, Irwin M. Physiological indices of functioning in bereavement. In: Stroebe MS, editor. Handbook of bereavement research: Consequences, coping, and care. Washington, DC: American Psychological Association; 2001; 473-492.

83. Rubin SS, Malkinson R. Parental response to child loss across the life cycle: Clinical and research perspectives. In: Stroebe MS, editor. Handbook of bereavement research: Consequences, coping, and care. Washington DC: American Psychological Association, $2001 ; 219-240$.

84. Li J, Precht DH, Mortensen PB, Olsen J. Mortality in parents after death of a child in Denmark: a nationwide follow-up study. Lancet 2003; 361(9355):363-367.

85. Lehman DR, Wortman CB, Williams AF. Long-term effects of losing a spouse or child in a motor vehicle crash. J Pers Soc Psychol 1987; 52(1):218-231. 
Chapter

Method and design

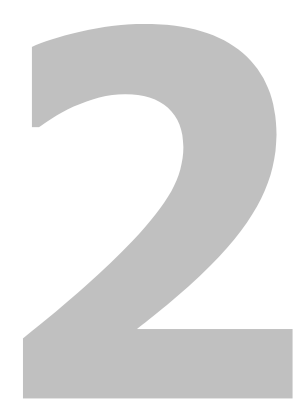


The following section will provide further detail on the method and design of this thesis. First, some general aspects of epidemiological methods in disaster settings will be discussed. Second, the setting in which the study was performed will be described. Third, more detail will be provided on the use of computer-based registrations. The remaining paragraphs will address the selection of cohorts, their representativeness, and the assessment of outcomes. 


\section{The use of epidemiological methods in disasters}

The overall objective of disaster epidemiology is to measure scientifically and describe the health effects of disasters and the factors contributing to these effects. The results of such investigations permit an assessment of the needs of disaster-affected populations, efficiently match resources to needs, prevent further adverse health effects, evaluate relief effectiveness, and make provision for future disasters (1). The uses of epidemiology in disaster situations have been reviewed in a number of reports, and periodic updates on the status of this discipline have appeared every few years $(2 ; 3)$. From these reviews, it becomes apparent that disaster epidemiologists face numerous problems. Due to the mainly unexpected and chaotic nature of disasters, it is difficult to apply epidemiological techniques in such a context. The following problems are therefore common in disaster research:

1. The size of the population at risk (also referred to as "denominator") can be difficult to obtain. Denominator data are required to calculate rates and permit comparisons of morbidity between populations that differ in size and composition.

2. Pre-disaster data are rarely available, which complicates the (causal) interpretation of effects.

3. It can be difficult to sample exposed and unexposed subjects representative of the community under study. In order to guarantee generalizability to the entire population, a careful selection of cohorts is necessary, however.

4. In addition to practical hurdles, collecting data for research purposes can place an extra burden on the victims who are in a state of emotional stress. If survey methods such as interviews and questionnaires are used, the return rates are much lower than in surveys in non-disaster settings (3).

Practically all the above described problems can be tackled by the use of existing electronic information systems of health care providers. In highly regulated primary care systems, where access to specialists is coordinated by a family practitioner and the majority of health problems are dealt with in primary care, the denominator problem does not affect the interpretation of study results. If patients are registered with one primary care physician at a 
time and collect their medications at only one designated pharmacy, the population under study is easily determined through the patient list which is kept by the physician. If these systems are operational already before the event, they can be used to generate information on pre-disaster health. One final advantage is that (anonymous) monitoring of larger population groups is possible which is less burdensome to victims. This approach also helps to exclude selection bias (due to non-response) and recall bias which often limit the interpretation of survey results. The data collection for the current thesis was based on the electronic registrations of family practitioners. In a next step, the setting in which the data were collected will be described.

\section{Setting}

The data for this study were collected at the practices of Family Practitioners (FPs). Within the Dutch health care system, FPs hold a key position. Access to specialist care is limited by the gate keeping function of the FP. This means that, in general, patients cannot seek specialist care without a referral by their family doctor, who is designated the sole primary care physician in the health care system, as opposed to other countries, where also general internists, pediatricians and gynecologists may serve as primary care providers. Family practitioners keep fixed patient lists and persons can be registered with one FP only. In the Netherlands, approximately $90 \%$ of the patients' health problems are addressed by the FP (4). Over a period of one year, more than $75 \%$ of the Dutch population will see their family doctor at least once, and more than $90 \%$ at least once every 3 years (5). Until 2006, the majority of Dutch patients were insured by public health insurance funds, compulsory for any citizen with an annual income below a yearly adjusted specific level ( $60 \%$ of the population). The remaining patients were privately insured (6). 


\section{Use of computer-based patient records}

In principle, the computer-based patient record is an electronic version of the paper-based patient record and is integrated into an information system $(7 ; 8)$. The information systems of family practitioners provide the option of coding diagnoses and findings according to the International Classification of Primary Care (ICPC), resulting in well-structured, standardized data (9). The information systems also contain functions for maintaining age-gender registration of all patients in the practice, demographic data, including health insurance data and information on the group of people who form a household. Besides electronic record keeping, the information system supports the administrative and financial aspects of running a practice (10).

In the Netherlands, family practitioners can choose among several competing registration systems. In our case, all participating practices made use of the Medicom computer system. This circumstance had two major advantages: First of all, several FP practices were part of the same system. Patient records were therefore accessible to all practitioners belonging to different practices. If a patient changed from one practice to another, or is seen on one occasion by another doctor, the patient records did not have to be transferred. The medical history was still linked to the same patient identification number. This way, continuity of record keeping was guaranteed. Secondly, in Medicom, all prescription information was collected centrally in one database. The pharmacies were connected to the family practice registration system and relied on the same patient identification numbers. Consequently, not only did we know what had been prescribed, but also who had received it because all patient information included in the FP record (exposure status of patient, age, gender, insurance type etc.) could be linked to the pharmacy record. Since the pharmacy records were used for billing purposes, the registrations were near-complete and provided high quality data. All items which had been dispensed (prescription and non-prescription drugs) were contained in the database. 


\section{Design}

The study design was a combination of prospective and retrospective cohort designs (11). Baseline measurements of health were ascertained from past FP records (retrospectively), and measurement of outcomes continued into the future (prospectively). The study period covered one-year pre-disaster and four years post-disaster (January 1, 2000 until January 1, 2005).

\section{Selection of cohorts}

In general, a distinction can be made between victims who were killed or injured, and survivors who were, at least physically, unscathed. "Hidden victims" encompassed family members or others who experienced loss in a disaster. As already outlined, we therefore distinguish primary victims (victims who were present during the fire, with and without burns), secondary victims (family members of primary victims) and tertiary victims (community members).

\section{Sampling of victims and their family members}

During the initial phase of the study, the family doctors indicated whether an adolescent had been present during the fire or not. By making use of the electronic patient records, it was possible to identify family members who were living at the same address as a fire victim. In order to protect the privacy of the patients, address information was coded into a so-called household number. This household number could then be used to determine cohabitation of family members.

\section{Sampling of community controls}

In this group, Volendam residents were included who did not live with one of the primary victims. We first identified those Volendam residents who did not live with one of the primary victims. In a second step, we selected all households with at least one parent and at least one child aged 13-21 years on January 1st, 2001. In order to make sure that the group was comparable in age structure, in a third step, we selected only those households with children aged 0-30 years and adults aged 36-64. 


\section{Representativeness}

In Volendam, there were four FP practices. Three of these contributed to the study. It was estimated that, at the time of the fire, approximately 350 people were present in the café. 321 survivors were registered across the four Volendam FP practices. 286 of the survivors belonged to the three participating practices. In addition, the 14 adolescents who lost their lives due to the fire were all enrolled with the participating practices (table 2.1). Our study thus captures 300 primary victims and their immediate family members. This accounts for approximately $86 \%$ of the total group of primary victims.

Table 2.1: Distribution of victims (survivors and deceased) and their family members (parents and siblings) across participating and non-participating practices

\begin{tabular}{lrrr}
\hline & Participating practices & Non-participating practice & Total \\
\hline Servivors & 286 & 35 & 321 \\
Deceased & 14 & 0 & 14 \\
Parents & 499 & 62 & 561 \\
Siblings & 303 & 41 & 344 \\
\hline
\end{tabular}

Patients registered with the participating and non-participating practices were comparable regarding the distribution of gender. In the participating practices, fewer patients (parents and siblings) had private insurance when compared to the non-participating practice (table 2.2). 
Table 2.2: Distribution of victims (survivors and deceased) and their family members (parents and siblings) across participating and non-participating practices - gender and insurance type

\begin{tabular}{lcr}
\hline & Participating practices & Non participating practice \\
\hline $\begin{array}{l}\text { Survivors } \\
\text { \% female }\end{array}$ & 39.5 & 37.1 \\
\% privately insured & 19.6 & 22.9 \\
& & \\
$\begin{array}{l}\text { Deceased } \\
\% \text { female }\end{array}$ & 35.7 & - \\
\% privately insured & 42.6 & - \\
Parents & & 51.6 \\
\% female & 52.3 & 46.8 \\
\% privately insured & 39.1 & \\
Siblings & & \\
\% female & & 46.3 \\
\% privately insured & & 43.9 \\
\hline
\end{tabular}

In terms of age, there were no differences between patients enrolled with the participating and the non-participating practices, with the exception of siblings in the participating practices who are younger than siblings in the non-participating practices (table 2.3).

Table 2.3: Distribution of victims (survivors and deceased) and their family members (parents and siblings) across participating and non-participating practices - age on January 1st, 2001

\begin{tabular}{lrr}
\hline & $\begin{array}{r}\text { Participating } \\
\text { practices }\end{array}$ & $\begin{array}{r}\text { Non-participating } \\
\text { practice }\end{array}$ \\
\cline { 2 - 3 } \cline { 3 - 3 } Mean (std) & Mean (std) \\
\hline Survivors & $17.3(2.5)$ & $17.7(2.4)$ \\
Deceased & $17.2(3.5)$ & - \\
Parents & $46.2(4.6)$ & $46.2(3.3)$ \\
Siblings & $16.2(5.0)$ & $14.3(4.1)$ \\
\hline
\end{tabular}


In the non-participating practice, 30 out of 35 primary victims suffered burns; in the participating practices the figure was 162 out of 286 primary victims. The total burned surface area of burn victims was comparable in victims enrolled with the participating and non-participating practices (13.4\% and $14.9 \%$ respectively). The same applied for the number of days spent in hospital in the year 2001 (22.7 and 20.1 days respectively).

\section{Assessment of outcomes}

The outcomes reported in this thesis were extracted from both family practice and pharmacy records. The electronic records provided data on health problems presented to the doctor and the number of contacts per patient with the practice. The pharmacy records gave an indication of the number and type of prescription items per patient.

\section{Health problems}

Health problems were coded according the International Classification of Primary Care (9). ICPC is a two-axis system (table 2.4 and 2.5). The first axis, primarily oriented toward body systems (the tracts), is coded by a letter. The second axis, the component, is coded by digits. The component axis contains seven code groups. To give an example, the diagnosis pneumonia would be coded R81 ( $\mathrm{R}$ for respiratory tract and 81 for the diagnostic component). Since the present study is primarily interested in morbidity, only the components 1-29 (symptoms and complaints) and 70-99 (diagnoses) were analyzed. 
Table 2.4: The two-axial ICPC - First axis: organ system

\begin{tabular}{ll}
\hline Code & Organ System \\
\hline A & General and unspecified \\
B & Blood \\
D & Digestive \\
F & Eye \\
H & Ear \\
K & Circulatory \\
L & Musculoskeletal \\
N & Neurological \\
P & Psychological \\
R & Respiratory \\
S & Skin \\
T & Endocrine and metabolic \\
U & Urology \\
W & Pregnancy and family planning \\
X & Female reproductive system \\
Y & Male reproductive system \\
Z & Social problems \\
\hline
\end{tabular}

Table 2.5: The two-axial ICPC - second axis: components

\begin{tabular}{ll}
\hline Code & Component \\
\hline $1-29$ & Symptoms and complaints \\
$30-49$ & Diagnostic screening and prevention \\
$50-59$ & Treatment and medication \\
$61-61$ & Test results \\
62 & Administrative \\
$63-69$ & Other \\
$70-99$ & Diagnoses \\
\hline
\end{tabular}

\section{Number of contacts with the Family Practitioner}

For every patient, it was known on which date he or she had contacted the doctor's office. A contact was defined as any contact with the family doctor's office which had been recorded in the registration system. These contacts included direct consultations with the FP, consultations by telephone, or contacts with the auxiliary assistant. 


\section{Prescriptions}

All prescription items were coded according to the Anatomical Therapeutic Chemical (ATC) Classification System issued by the WHO's Collaborating Centre for Drug Statistics Methodology (12). This classification system divides drugs into different groups according to the organ or system on which they act and/or therapeutic and chemical characteristics. It is broadly accepted as an international standard for drug utilization research (10).

\section{Overview of outcomes and study groups}

Table 2.6 provides an overview of which kind of outcomes were studied in which groups. The last row in table 2.6 mentions controls from communities other than Volendam. These controls were used in order to be able to shed light on developments in the general Dutch population. More detail on these groups will be provided in the specific chapters. One final note concerns the parents who lost a child due to the disaster, a relatively small $(n=27)$, but important group. Bereavement in parents will therefore was studied as a risk factor for increased health care utilization, benzodiazepine use and hypertension. The reader will also notice that not all studies cover the same time period. This is due to the fact that follow-up data were available successively (table 2.7).

Table 2.6: Overview of outcomes and study groups

\begin{tabular}{|c|c|c|c|c|}
\hline & \multicolumn{4}{|c|}{ Outcome measure } \\
\hline & $\begin{array}{l}\text { Health } \\
\text { problems }\end{array}$ & $\begin{array}{l}\text { Hyper- } \\
\text { tension }\end{array}$ & $\begin{array}{l}\text { Primary health } \\
\text { care utilization }\end{array}$ & $\begin{array}{l}\text { Benzodiazepine } \\
\text { use }\end{array}$ \\
\hline \multicolumn{5}{|l|}{ Primary victims } \\
\hline Victims with burns & $\mathrm{x}$ & & $\mathrm{x}$ & \\
\hline Victims without burns & $x$ & & $x$ & \\
\hline \multicolumn{5}{|l|}{ Secondary victims } \\
\hline Parents & $x$ & $x$ & $x$ & $x$ \\
\hline Siblings & & & $x$ & \\
\hline \multicolumn{5}{|l|}{ Tertiary victims } \\
\hline Community controls Volendam & $x$ & $x$ & $x$ & $x$ \\
\hline Controls outside Volendam & & & $x$ & $x$ \\
\hline
\end{tabular}


Chapter 2

Table 2.7: Outcomes according to study period, data source and chapter number

\begin{tabular}{|c|c|c|c|c|}
\hline & \multicolumn{4}{|c|}{ Outcome measure } \\
\hline & $\begin{array}{l}\begin{array}{l}\text { Health } \\
\text { problems }\end{array} \\
\end{array}$ & $\begin{array}{l}\text { Hyper- } \\
\text { tension }\end{array}$ & $\begin{array}{l}\text { Primary health } \\
\text { care utilization }\end{array}$ & $\begin{array}{l}\text { Benzodiazepine } \\
\text { use }\end{array}$ \\
\hline Years covered & $2000-2004$ & 2000-2004 & $2000-2003$ & 2000-2003 \\
\hline Data source & FP & $\begin{array}{l}\text { FP and } \\
\text { pharmacy }\end{array}$ & FP & $\begin{array}{l}\text { FP and } \\
\text { pharmacy }\end{array}$ \\
\hline Chapter number & 3,4 & 5 & 6 & 7 \\
\hline
\end{tabular}

FP: registrations of family practitioners 


\section{References}

1. Noji EK. Disaster epidemiology and disease monitoring. J Med Syst 1995; 19(2):171-174.

2. Norris FH. Disaster research methods: past progress and future directions. J Trauma Stress 2006; 19(2):173-184.

3. Logue JN, Melick ME, Hansen H. Research issues and directions in the epidemiology of health effects of disasters. Epidemiol Rev 1981; 3:140-162.

4. van der Lei J, Duisterhout JS, Westerhof HP, van der DE, Cromme PV, Boon WM et al. The introduction of computer-based patient records in The Netherlands. Ann Intern Med 1993; 119(10):1036-1041.

5. Okkes IM, Groen A, Oskam SK, Lamberts H. Advantages of long observation in episodeoriented electronic patient records in family practice. Methods Inf Med 2001; 40(3):229-235.

6. WHO Regional Office for Europe. Highlights on health in the Netherlands. Copenhagen: 1997.

7. Metsemakers JF, Knottnerus JA, van Schendel GJ, Kocken RJ, Limonard CB. Unlocking patients' records in general practice for research, medical education and quality assurance: the Registration Network Family Practices. Int J Biomed Comput 1996; 42(1-2):43-50.

8. Metsemakers JF, Hoppener P, Knottnerus JA, Kocken RJ, Limonard CB. Computerized health information in The Netherlands: a registration network of family practices. Br J Gen Pract 1992; 42(356):102-106.

9. Lamberts H, Wood M. International Classification of Primary Care. Oxford: Oxford University Press, 1987.

10. van Bemmel JH, Musen MA. Handbook of Medical Informatics. Houten: Bohn Stafleu Van Loghum, 1997.

11. Gordis L. Epidemiolgy. Philadelphia: Saunders, 2000.

12. WHO Collaborating Centre for Drug Statistics Methodology. Anatomical Therapeutic Chemical (ATC) Classification System. http://www.whocc.no/atcddd/. Accessed 1-1-2006. 
Chapter 2 


\section{Chapter}



\section{Health problems primary victims}

This chapter has been submitted as:

Dorn $T$

Yzermans CJ

Schilder A

Spreeuwenberg PM

Van der Zee J

The long-term impact of a major fire disaster on the physical and mental health of adolescents - evidence from a record-based cohort study

Journal of Traumatic Stress 


\begin{abstract}
This prospective cohort study investigates the health consequences of a fire disaster. Data were extracted from electronic medical records, covering one year pre-fire and four years post-fire. Three cohorts of adolescents were followed-up over time, including those who were exposed to physical and psychological trauma (victims with burns, $n=162$ ), those exposed to psychological trauma only (victims without burns, $n=124$ ), and a cohort of unexposed community controls $(n=1,487)$. The study shows that burn victims require medical attention for years, but it does not provide evidence for adverse long-term physical health effects in those who have survived without burns. Mental health problems, however, are long-standing in adolescent disaster survivors - irrespective of the presence of physical injuries.
\end{abstract}




\section{Introduction}

Disasters are experienced collectively, and they typically overwhelm our capacity to cope or adapt $(1 ; 2)$. Despite their tragic consequences, disasters permit the study of the health consequences of stressful events in large groups of people who all have been exposed to the same stressor at the same moment in time (3). Disaster-related stress has a great impact on peoples' lives, is intimately linked with mental health, and is very possibly related to many physical health problems as well (4-9). The idea that psychological trauma is related to physical health problems is also supported by recent literature reviews on traumatic stress which show that individuals exposed to traumatic stress report a poorer health status than comparable, nonexposed individuals (10-12).

In the past, several recommendations were made with respect to the field of disaster research $(6 ; 13 ; 14)$. One of these recommendations was to put more effort into the study of health effects in younger populations affected by disaster. In younger age groups, so far, most of the research has addressed mental health effects, concentrating on Posttraumatic Stress Disorder (PTSD) and depressive reactions (15-23), whereas studies on physical health effects are rather scarce. A prospective study by Dirkzwager et al., for example, demonstrated that disaster-affected adolescents showed, besides psychological problems, larger increases of musculoskeletal problems one year after the disaster when compared to control subjects (24). During the second year after the disaster, the effects had disappeared, however.

The current study describes the long-term health effects of a major fire which occurred in a café-bar, in Volendam, the Netherlands, on New Year's Eve 2000. Volendam is a former fishing village and a close-knit community with approximately 20,000 inhabitants. The bar was a popular meeting place for the town's young people. When the fire began at the top floor of the three-storey building, the bar was seriously overcrowded. The blaze was triggered around midnight when party-goers lit sparklers which ignited low-hanging ceiling decorations. As a consequence of the fire, four young people died at the scene and a further ten died in hospital. A total of 241 victims were treated in hospitals, of whom 112 in an intensive care unit (25). 
The impact on the mental health of Volendam adolescents was documented in two studies. Both studies compared pre-disaster baseline measurements with post-disaster assessments. For these two studies, baseline data were available due to routine data collections performed by local health authorities. The first post-disaster assessment was carried out 5 months after the fire (26), the second 12 months after the fire (27). Data were obtained through questionnaires and were based on samples of Volendam adolescents and controls from two control schools outside Volendam. The first study showed that Volendam adolescents had larger increases in clinical scores than controls for total problems - as measured by the Youth Self-Report (YSR) - and excessive use of alcohol; but not for smoking or use of marijuana, ecstasy, and sedatives. The second assessment 12 months after the disaster demonstrated differences between controls and Volendam adolescents in regard to excessive drinking only (27).

In addition, another publication on the Volendam disaster demonstrated that the fire caused a significant increase of health care utilization, not only in victims who had suffered burns, but also in those who had survived the incident without burns (28). The current study is part of the same research project. In order to complete the picture, it aims at investigating which kind of health problems underlie the reported increases in utilization.

What kind of health problems can be expected in this disaster-affected population? In victims who suffered burns during the disaster, health problems are most likely to be injury-related. In victims without burns, health problems may arise as a consequence of psychological trauma. In our case, it is the experience of life threat and the witnessing of grotesque scenes at the site which have the potential to induce psychological trauma. In order to separate the effects of psychological and physical trauma, the present study makes a distinction between adolescents who suffered burns during the disaster and others who survived without burns. As a control group, adolescents from the same community who were not directly involved in the fire are examined. 


\section{Method}

\section{Setting}

Volendam is a former fishing town located 20 miles north of Amsterdam, and has about 20,000 inhabitants. The community is close-knit and mobility is low. The population is served by four family practices. In the Netherlands, family practitioners (FPs) have a key position as gatekeepers to specialist care, which is only accessible after referral by a family practitioner. Accordingly, most contacts between the public at large and the health care system take place in family practice. Dutch FPs have fixed patient lists and patients are registered with one FP only (29). Each family practitioner keeps a registration system which allows him to record different medical events and requests for help. Basically, there are no financial barriers for patients to FP care. The health care system is organized on an insurance basis. Until 2006, two types of health insurance existed in the Netherlands - public and private insurance. Patients with an annual income below a specific level were insured through public insurance; above this level, patients were privately insured. Insurance type can thus be used as an indicator for the socio-economic status of the patient. The use of automated registrations is well established in Dutch family practice. In our study, all FPs classified their patients' health problems according to the International Classification of Primary Care (ICPC). The ICPC is an internationally endorsed classification system which is compatible with the ICD-10 (30). It is divided into several chapters, each dealing with one organ system (e.g. cardiovascular, musculoskeletal, gastrointestinal). The registrations were already operational before the fire occurred, allowing for pre-post comparisons.

\section{Sampling of victims}

According to official estimates, about 300-350 people were in the building at the time of the fire. Within one month of the incident, all four local family practices were contacted with the request to identify in their records those patients who had been present during the fire. The family practices identified 335 patients in their registrations. One family practice was not yet using electronic registration. This led to a total of three practices participating. The 335 patients originally identified in the family practices 
were distributed among participating and non-participating practices as follows: 286 of the survivors and the 14 deceased victims belonged to the participating practices, and 35 survivors were registered with the nonparticipating practice. Characteristics of the survivors enrolled in the nonparticipating practice $(n=35)$ were compared with those of the survivors enrolled with the participating practices $(n=286)$. The survivors included in the final study sample did not significantly differ from non-participants with respect to burn size, number of days in hospital, gender, age or insurance status. Survivors with burn injuries $(n=162)$ had a mean total burned surface area of $14.9 \%(\mathrm{SD}=17.1)$ and spent, on average, 34.2 days in hospital during the first 12 months after the disaster $(\mathrm{SD}=59.3)$.

\section{Sampling of community controls}

From the patient lists of the three participating FP practices, we selected all those who still lived with their parents, aged 13-23 at baseline, who had not been present during the fire. Siblings of disaster victims were excluded from this cohort. This results in a sample of 1,487 patients. All cohorts are mutually exclusive.

\section{Assessment of health problems}

The assessment of health problems is based on the electronic patient records of family practitioners. Mental health problems are defined as problems belonging to the ICPC-chapters $\mathrm{P}$ (psychological) and $\mathrm{Z}$ (social). In addition, physical health problems as summarized in the ICPC-chapters L (musculoskeletal), R (respiratory), D (gastrointestinal) and S (dermatological) are analyzed. These chapters are selected for analysis due to their high prevalence. As another outcome measure, the sum of physical health problems across ICPC-chapters is determined.

\section{Time periods}

Five different time periods are distinguished: (1) the 12 month period prior to the fire (year 2000), (2) 0-12 months post-fire (year 2001), (3) 13-24 months post-fire (year 2002), (4) 25-36 months post-fire (year 2003) and (5) 37-48 months post-fire (year 2004). If a patient presents the same health problem several times in a year, it is counted as one problem. Patients who did not contact the FP for health problems in a year receive a count of zero. Patients 
who were not, or only partly, enrolled during a given period (e.g. due to death or relocation) are excluded from the analysis.

\begin{abstract}
Analyses
Patient characteristics are compared using one-way ANOVA or chi-square tests (table 3.1). The multivariate analysis is based on logistic regression models. In order to account for the repeated measurements in our study, a multilevel framework is chosen, with person and measurement occasion as levels (31). The outcome measure in the regression analysis was the presence or absence of a health problem (musculoskeletal, gastrointestinal, dermatological, respiratory, or mental; coded 1 if present, and 0 if absent). The predictors were introduced into the models as follows. The three cohorts (victims with burns, victims without burns and controls) were modeled by one dummy each (model without intercept). Interaction terms of group and time (group*year 2001, group*year 2002, group*year 2003 and group*year 2004) were used for modeling the deviation from the year prefire. All regression model were adjusted for the influence of covariates (age, gender, family practice and insurance type) which had been centered around their means before introducing them into the equation.
\end{abstract}

Table 3.3 reports the results of five regression analyses (one for each health problem). These analyses provide two types of information. First, they provide information on within-group-comparisons. Second, they inform on between-group-comparisons. In table 3.3, significant within-groupcomparisons are printed in bold (presented as odds ratios and 95\% confidence intervals). An odds ratio above 1 indicates that within the group, the likelihood for presenting the health problem was higher than in the year pre-fire (the year 2000). An odds ratio below 1 indicates that, within the group, the likelihood for presenting the health problems was lower than in the year pre-fire. Between-group-comparisons were based on the calculation of contrasts. These contrasts test whether the post-fire increase (or decrease) observed in one group is statistically different form the post-fire increase (or decrease) seen in another group. If contrasts yielded significant results (alpha $=0.05)$, they were marked with indices ( $\ddagger$, + ; see legend table 3.3). 


\section{Results}

Table 3.1 provides the background characteristics of victims with burns, victims without burns and community controls. Victims with burns were more often male and younger than victims without burns. Victims without burns were comparable to community controls with respect to gender and age, but were less often privately insured when compared to controls. Table 3.2 provides the percentage of patients per year who presented a health problem at the FP practice for victims with burns, victims without burns and controls, respectively. Table 3.3 presents the results of the multivariate analysis. The following paragraphs first describe the changes within one group in the course of time. Then the difference between groups is reported.

Table 3.1: Background characteristics of victims with burns, victims without burns, and community controls

\begin{tabular}{lrrrrr}
\hline & $\begin{array}{r}\text { With } \\
\text { burns }\end{array}$ & $\begin{array}{r}\text { Without } \\
\text { burns }\end{array}$ & $\begin{array}{r}\text { Community } \\
\text { controls }\end{array}$ & $\begin{array}{r}\text { Comparison } \\
\text { 'with burns' } \\
\text { vs. 'without } \\
\text { burns' }\end{array}$ & $\begin{array}{r}\text { Comparison } \\
\text { 'without burns' vs. } \\
\text { community } \\
\text { controls }\end{array}$ \\
\hline $\begin{array}{l}\text { Gender } \\
\text { Men (\%) }\end{array}$ & $107(66.0)$ & $66(53.2)$ & $809(54.4)$ & $*$ & n.s. \\
Women (\%) & $55(34.0)$ & $58(46.8)$ & $678(45.6)$ & & \\
Mean age (sd) & $16.9(2.1)$ & $17.8(2.9)$ & $17.5(2.9)$ & $* *$ & n.s. \\
& & & & & \\
Insurance & & & & & \\
$\begin{array}{l}\text { Private (\%) } \\
\text { Public (\%) }\end{array}$ & $34(21.0)$ & $22(17.7)$ & $413(27.8)$ & n.s. & \\
\hline
\end{tabular}

* Significant at $\mathrm{p}<0.05,{ }^{* *}$ significant at $\mathrm{p}<0.01$, n.s. not significant. 
Table 3.2: $\quad$ Number of patients (\%) with health problem

\begin{tabular}{|c|c|c|c|c|c|}
\hline & $\begin{array}{r}2000 \\
\text { (pre-fire) } \\
\end{array}$ & $\begin{array}{r}2001 \\
\text { (post-fire) } \\
\end{array}$ & $\begin{array}{r}2002 \\
\text { (post-fire) } \\
\end{array}$ & $\begin{array}{r}2003 \\
\text { (post-fire) } \\
\end{array}$ & $\begin{array}{r}2004 \\
\text { (post-fire) } \\
\end{array}$ \\
\hline \multicolumn{6}{|l|}{ Musculoskeletal } \\
\hline With burns & 48 (29.6) & $44(27.2)$ & 59 (36.6) & $68(42.2)$ & $63(39.1)$ \\
\hline Without burns & $52(41.9)$ & 69 (55.6) & $63(51.2)$ & $46(37.4)$ & $61(49.6)$ \\
\hline Controls & 443 (29.8) & $449(30.2)$ & $460(31.7)$ & 449 (31.1) & $411(28.6)$ \\
\hline \multicolumn{6}{|l|}{ Gastrointestinal } \\
\hline With burns & $20(12.3)$ & $28(17.3)$ & $20(12.4)$ & $23(14.3)$ & $26(16.1)$ \\
\hline Without burns & $23(18.5)$ & $25(20.2)$ & $23(18.7)$ & $22(17.9)$ & $17(13.8)$ \\
\hline Controls & $165(11.1)$ & $179(12.0)$ & $161(11.1)$ & $196(13.6)$ & 157 (10.9) \\
\hline \multicolumn{6}{|l|}{ Dermatological } \\
\hline With burns & 57 (35.2) & 65 (40.1) & $76(47.2)$ & $66(41.0)$ & $63(39.1)$ \\
\hline Without burns & $59(47.6)$ & $56(45.2)$ & $58(47.2)$ & $46(37.4)$ & $43(35.0)$ \\
\hline Controls & $526(35.4)$ & $528(35.5)$ & 492 (33.9) & $487(33.8)$ & $435(30.2)$ \\
\hline \multicolumn{6}{|l|}{ Respiratory } \\
\hline With burns & $47(29.0)$ & $94(58.0)$ & $71(44.1)$ & $72(44.7)$ & $45(28.0)$ \\
\hline Without burns & $62(50.0)$ & $92(74.2)$ & $65(52.8)$ & $64(52.0)$ & $50(40.7)$ \\
\hline Controls & $446(30.0)$ & $477(32.1)$ & 459 (31.6) & $440(30.5)$ & $327(22.7)$ \\
\hline \multicolumn{6}{|l|}{ Mental } \\
\hline With burns & $2(1.2)$ & $33(20.4)$ & 17 (10.6) & $22(13.7)$ & $10(6.2)$ \\
\hline Without burns & $9(7.3)$ & $42(33.9)$ & 18 (14.6) & 13 (10.6) & $16(13.0)$ \\
\hline Controls & $49(3.3)$ & $98(6.6)$ & $89(6.1)$ & $96(6.7)$ & $80(5.6)$ \\
\hline
\end{tabular}

\section{Course of health problems in victims with burns}

During the first year after the fire, significantly more patients in the burns group present respiratory (OR 5.16, 95\% CI 3.21-8.29) and mental health problems (OR 88.59, 95\% CI 29.45-266.49) (table 3.3). During the second year after the fire, more patients in this group contact the FP for dermatological (OR 1.78, 95\% CI 1.14-2.77), respiratory (2.43, 95\% CI 1.52-3.89) and mental health problems (OR 20.82, 95\% CI 6.93-62.59). In the third year post-fire, musculoskeletal (OR 2.01, 95\% CI 1.26-3.22), respiratory (OR 2.52, 95\% CI 1.57-4.02) and mental health problems (OR 34.47, 95\% CI 11.50-103.34) are presented more often in this group. Finally, in the fourth year, musculoskeletal (OR 1.71, 95\% CI 1.06-2.73) and mental health problems (OR $8.46,95 \%$ CI 2.77-25.83) remain more prevalent than before the fire. 


\section{Course of health problems in victims without burns}

In 2001, victims without burns show increased musculoskeletal (OR 2.01, 95\% CI 1.21-3.33) and respiratory problems (OR 4.13, 95\% CI 2.39-7.15) when compared to the preceding year. The largest increase in 2001 is seen with regard to mental health problems (OR 21.43, 95\% CI 11.47-40.05). After 2001, no physical health effects are observed, but mental health problems remain more prevalent during the second (OR 3.29, 95\% CI 1.73-6.25) and fourth year after the fire (OR 2.66, 95\% CI 1.39-5.10), but not during the third year.

\section{Course of health problems in community controls}

Controls demonstrate increases in only one of the four physical domains: more patients present with gastrointestinal problems during the third year after the fire when compared to the year pre-fire (OR 1.33, 95\% CI 1.07-1.66). The number of community controls presenting with mental health problems increases during the first (OR 2.82, 95\% CI 2.16-3.68), second (OR 2.51, 95\% CI 1.91-3.28), third (OR 2.85, 95\% CI 2.18-3.73) and fourth year after the fire (OR 2.14, 95\% CI 1.63-2.81).

\section{Comparison of course of health problems across different groups}

In 2001, victims without burns show significantly larger increases in musculoskeletal problems than victims with burns (table 3.3). Furthermore, victims with burns demonstrate greater increases in mental health problems in 2001 when compared to victims without burns. In addition, in the same year, victims without burns display larger increases of musculoskeletal, respiratory and mental problems when compared to controls. In the second year post-fire (2002), victims with burns exhibit bigger increases in respiratory and mental health problems when compared to victims without burns. In the third year post-fire (2003), victims with burns exhibit greater increases in musculoskeletal, dermatological, respiratory and mental problems when compared to victims without burns. Interestingly, in the second, third and fourth year after the fire, victims without burns do not significantly deviate from controls in any of the studied areas. In the fourth year post-fire, victims with burns only differ significantly from victims without burns in the case of dermatological problems. 


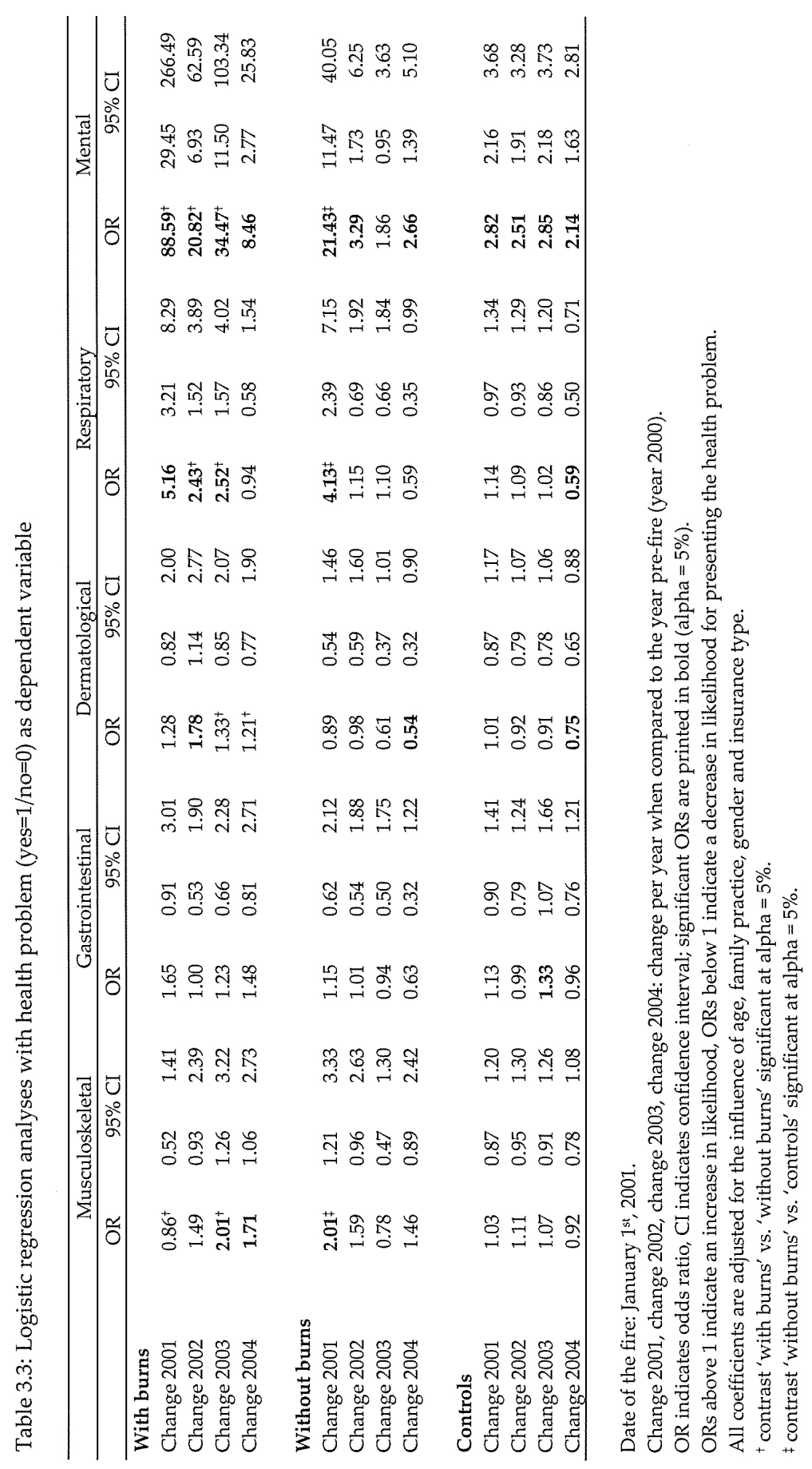




\section{Discussion}

Victims with burns - psychological and physical trauma combined

Our results demonstrate that victims with burns were in poorer mental and physical health for a number of years - when compared to those who survived the disaster without suffering burns. Victims with burns presented more respiratory problems, not only in the first year after the fire, but also during the second and third year post-disaster when compared to the year pre-fire. In addition to these quite persistent problems, increases in musculoskeletal (third and fourth year post-fire) and dermatological effects (second year post-fire) were observed. Respiratory and dermatological effects can be attributed to exposure to heat and smoke during the incident. Rather unexpected is the belated rise in musculoskeletal problems in this group. The most prevalent health problems in the third and fourth year post-disaster in victims with burns were low back pain and shoulder pain symptoms which cannot directly be explained by the presence of burns. Of all health problems, the mental health effects are the most pronounced and the most long-standing in this group. Even in the fourth year post-disaster, mental health problems are still elevated in victims with burns when compared to the year pre-fire. Since we assessed mental health problems in a primary care context, it is unclear whether the observed increases reflect a rise in incidence or a delay in coming forward for help.

Victims without burns - psychological trauma only

As a second group, we examined victims without burns. These adolescents were studied in order to shed light on the independent contribution of exposure to psychological trauma. Physical health effects in this group are limited to the first year post-disaster exclusively and they are only observed in the musculoskeletal and respiratory domains. An increased prevalence of musculoskeletal problems was also reported by the Dirkzwager study on the health of adolescents before and after the explosion of a fireworks depot in a residential area (24).

To aid interpretation, we additionally examined the most prevalent musculoskeletal complaints in victims without burns. During the first year post-fire, these were chest symptoms, neck problems and low back pain. It is 
possible that these problems are due to injuries inflicted when trying to flee the scene. It therefore remains uncertain whether the (short-term) increase in musculoskeletal problems seen in victims without burns is distress- or injury-related. Although short-term physical health effects exist, the study does not provide evidence for long-term physical health effects in those who survived the incident without suffering burns.

Two explanations can be offered for this finding. Either, adolescents are better protected against the physical effects of psychological trauma, or the time-frame of our study was too short to demonstrate long-term effects. Schnurr and colleagues emphasize that adverse physical health outcomes are often the product of cumulative, interactive effects of factors that alone (or in a short time frame) may have only minimal or transient effects that would be insufficient to induce disease (12). It is unclear, for example, if the trauma-exposed group has reacted with health-compromising coping strategies (e.g. excessive smoking, drinking or overeating) which might impact on health at later stages in life. Since behavioral mechanisms are seen as one of the primary pathways linking trauma to physical health, future studies of trauma-exposed adolescents should definitely assess these important mediators (32-35).

Although the current study did not provide evidence for long-term physical health effects in survivors without burns, an increased prevalence of mental health problems was observed during every single year post-disaster. During the first year post-disaster, the increase was the strongest and significantly larger than the increase seen in community controls. Assuming that not every adolescent who experiences emotional problems also seeks help with a family practitioner, our numbers most probably provide an underestimation of mental health problems in this group.

\section{Community controls}

Finally, the effects found in community controls should be discussed. In community controls, no substantial increases in physical health problems were found when compared to the pre-fire baseline. Since these adolescents were not exposed to the life-threatening fire themselves, no physical effects were expected either. After the disaster, the prevalence of mental health 
problems was higher in community controls than before the disaster, and this applies to every year after the fire. When compared to the increases seen in adolescents without burns, the increase in community controls is significantly higher during the first year of the study only. The study of Reijneveld et al. which was based on questionnaires distributed to Volendam adolescents predominantly included classmates of those who had been in the fire - a group largely identical to the 'community controls' in this chapter. From a methodological point of view, the Reijneveld study was very strict, since it included pre-disaster assessments and a control group of adolescents outside Volendam. The study found only short, but no longterm effects on mental health, although 12 months after the fire, excessive drinking was reported to be significantly higher in the Volendam youngsters than in a control group (27). A linkage of the two different data sources (medical records and questionnaires) was not attempted in our case, but our experience shows that it is advisable to obtain permission for record linkage from those who have participated in several investigations since it can aid the interpretation of results.

\section{Conclusion}

Having discussed the above findings, we move to a more general conclusion. The study contained in this chapter shows the advantages of record-based research, but also demonstrates its limitations. The way data were collected in this study allowed for the inclusion of a large, representative sample of disaster victims. Since the information was extracted from medical files, a continuous follow-up was possible and recall bias was minimized. Due to the fixed patients lists kept by the family practitioners, both attenders and non-attenders could be included in the study and selection bias could be excluded. This made it possible to estimate the prevalence of health problems from the primary care data. A major aim of our study was to consider mental and physical health problems simultaneously. The way physical health problems were operationalized in this research was therefore rather broad. A limitation of this approach is that due to the coding of health problems into ICPC-codes, it is difficult to distinguish between physical health problems resulting from psychological distress and those related to injuries. Future research is needed to shed more light on the mechanisms which link traumatic stress to physical health. One 
possibility is to collect data from medical files and to complement these data with other information sources. Although more burdensome to the victims, this would not only allow for a more fine-grained assessment of exposure and psychological distress reactions, but also for an assessment of additional variables which are mediators in the stress-illness relationship.

Despite these limitations, our study is a valuable contribution to the field of disaster research for two reasons. On the one hand, it is methodologically rigid since it includes pre-disaster assessments of health, a control group and has an extended follow-up period. On the other hand, it provides information for policy makers on the type and duration of health effects which can be expected in disaster-affected, adolescent populations. In sum, the current study not only calls attention to the fact that burn injuries require medical attention for years beyond the specialist setting, but also to the fact that mental health problems are long-standing in survivors - irrespective of the presence of physical injuries. 


\section{References}

1. Fullerton CS, Ursano RJ, Norwood AE, Holloway HH. Trauma, terrorism and disaster. In: Ursano RJ, Fullerton CS, Norwood AE, editors. Terrorism and disaster - individual and community mental health interventions. New York: Cambridge University Press, 2003; 122.

2. Noji EK. The nature of disaster: general characteristics and public health effects. In: Noji EK, editor. The public health consequences of disasters. New York: Oxford University Press, 1997; 3-20.

3. McFarlane AC. The effects of stressful life events and disasters: research and theoretical issues. Aust N Z J Psychiatry 1985; 19(4):409-421.

4. Norris F. Epidemiology of trauma: Frequency and impact of different potentially traumatic events on different demographic groups. J Consult Clin Psychol 1992; 60(3):409-418.

5. Norris FH. Psychosocial consequences of disaster. PTSD Research Quarterly 2002; 13(2):18.

6. Norris FH, Friedman MJ, Watson PJ. 60,000 disaster victims speak: Part II. Summary and implications of the disaster mental health research. Psychiatry 2002; 65(3):240-260.

7. Norris FH, Friedman MJ, Watson PJ, Byrne CM, Diaz E, Kaniasty K. 60,000 disaster victims speak: Part I. An empirical review of the empirical literature, 1981-2001. Psychiatry 2002; 65(3):207-239.

8. Hobfoll SE. The ecology of stress. Hemisphere: New York, 1988.

9. Hobfoll SE. Traumatic stress: A theory based on rapid loss of resources. Anxiety Research 1991; 4(3):187-197.

10. Boscarino JA. Posttraumatic stress disorder and physical illness: results from clinical and epidemiological studies. Ann N Y Acad Sci 2004; 1032:141-153.

11. Kimerling R, Clum G, McQuery J, Schnurr PP. PTSD and medical comorbidity. In: Ouimette P, et a, editors. Gender and PTSD. New York, NY, US: Guilford Press, 2002; $271-$ 302.

12. Schnurr PP, Jankowski MK. Physical health and post-traumatic stress disorder: review and synthesis. Semin Clin Neuropsychiatry 1999; 4(4):295-304.

13. Rubonis AV, Bickman L. Psychological impairment in the wake of disaster: the disasterpsychopathology relationship. Psychol Bull 1991; 109:384-399.

14. Logue JN, Melick ME, Hansen H. Research issues and directions in the epidemiology of health effects of disasters. Epidemiol Rev 1981; 3:140-162.

15. Bolton D, O'Ryan D, Udwin O, Boyle S, Yule W. The long-term psychological effects of a disaster experienced in adolescence: II: General psychopathology. J Child Psychol Psychiatry; 41(4):513-523.

16. Yule W, Bolton D, Udwin O, Boyle S, O'Ryan D, Nurrish J. The long-term psychological effects of a disaster experienced in adolescence: I: The incidence and course of PTSD. J Child Psychol Psychiatry 2000; 41(4):503-511. 
17. Giaconia RM, Reinherz HZ, Silverman AB, Pakiz B, Frost AK, Cohen E. Traumas and posttraumatic stress disorder in a community population of older adolescents. J Am Acad Child Adolesc Psychiatry 1995; 34(10):1369-1380.

18. Goenjian AK, Walling D, Steinberg AM, Karayan I, Najarian LM, Pynoos R. A prospective study of posttraumatic stress and depressive reactions among treated and untreated adolescents 5 years after a catastrophic disaster. Am J Psychiatry 2005; 162(12):2302-2308.

19. Goenjian AK, Molina L, Steinberg AM, Fairbanks LA, Alvarez ML, Goenjian HA et al. Posttraumatic stress and depressive reactions among Nicaraguan adolescents after hurricane Mitch. Am J Psychiatry 2001; 158(5):788-794.

20. Roussos A, Goenjian AK, Steinberg AM, Sotiropoulou C, Kakaki M, Kabakos C et al. Posttraumatic stress and depressive reactions among children and adolescents after the 1999 earthquake in Ano Liosia, Greece. Am J Psychiatry 2005; 162(3):530-537.

21. Silva RR, Alpert M, Munoz DM, Singh S, Matzner F, Dummit S. Stress and vulnerability to posttraumatic stress disorder in children and adolescents. Am J Psychiatry 2000; 157(8):1229-1235.

22. Silverman WK, La Greca AM. Children experiencing disasters: Definitions, reactions, and predictors of outcomes. In: La Greca AM, editor. Helping children cope with disasters and terrorism. Washington, DC: American Psychological Association, 2002; 11-33.

23. Broberg AG, Dyregrov A, Lilled L. The Goteborg discotheque fire: posttraumatic stress, and school adjustment as reported by the primary victims 18 months later. J Child Psychol Psychiatry 2005; 46(12):1279-1286.

24. Dirkzwager AJ, Kerssens JJ, Yzermans CJ. Health problems in children and adolescents before and after a man-made disaster. J Am Acad Child Adolesc Psychiatry 2006; 45(1):94103.

25. Welling L, van Harten SM, Patka P, Bierens JJ, Boers M, Luitse JS et al. The café fire on New Year's Eve in Volendam, the Netherlands: description of events. Burns 2005; 31(5):548-554.

26. Reijneveld SA, Crone MR, Verhulst FC, Verloove-Vanhorick SP. The effect of a severe disaster on the mental health of adolescents: a controlled study. Lancet 2003; 362(9385):691696.

27. Reijneveld SA, Crone MR, Schuller AA, Verhulst FC, Verloove-Vanhorick SP. The changing impact of a severe disaster on the mental health and substance misuse of adolescents: follow-up of a controlled study. Psychol Med 2005; 35:367-376.

28. Dorn T, Yzermans CJ, Kerssens JJ, Spreeuwenberg PM, van der Zee J. Disaster and subsequent healthcare utilization: a longitudinal study among victims, their family members, and control subjects. Med Care 2006; 44(6):581-589.

29. Boerma WGW, Fleming DM. The role of general practice in primary health care. London: World Health Organization, 1998.

30. Hofmans-Okkes IM, Lamberts H. The International Classification of Primary Care (ICPC): new applications in research and computer-based patient records in family practice. Fam Pract 1996; 13(3):294-302. 
31. Snijder TB, Bosker R. Multilevel analysis: an introduction to basic and advanced multilevel modeling. Thousand Oaks, CA: Sage, 1999.

32. Cartwright M, Wardle J, Steggles N, Simon AE, Croker H, Jarvis MJ. Stress and dietary practices in adolescents. Health Psychol 2003; 22(4):362-369.

33. Schnurr PP, Green BL. Understanding relationships among trauma, posttraumatic stress disorder, and health outcomes. In: Green BL, Schnurr PP, editors. Trauma and health: Physical health consequences of exposure to extreme stress. Washington, DC, US: American Psychological Association, 2004: 247-275.

34. Ng DM, Jeffery RW. Relationships between perceived stress and health behaviors in a sample of working adults. Health Psychol 2003; 22(6):638-642.

35. Wills TA, Sandy JM, Yaeger AM. Stress and smoking in adolescence: a test of directional hypotheses. Health Psychol 2002; 21(2):122-130. 


\section{Chapter}

\section{Health problems secondary victims}

This chapter has been accepted for publication and will be published as:

\section{Dorn $T$}

Yzermans $C J$

Spreeuwenberg PM

van der Zee J

Physical and mental health problems in parents of adolescents with burns a controlled, longitudinal study

Journal of Psychosomatic Research 


\begin{abstract}
Objective Caregiving has been described in the literature as a risk factor for ill health in the carer. This controlled, prospective study examines the course of physician-verified physical and mental health problems in parents of adolescent survivors of a mass burn incident.
\end{abstract}

Methods Health information was extracted from electronic medical records. Continuous data were available for one year before and four years after the fire. Cohorts comprised 273 parents of survivors with burns, 199 parents of survivors without burns and 1,756 controls. Post-fire increases in health problems were compared by means of logistic regression.

Results Parents of burn victims were more likely to present mental health problems during the first two years after the incident when compared to the baseline. Moreover, they were more likely to present cardiovascular health problems in every year following the disaster compared to the baseline. Increases observed in mental and cardiovascular health problems were significantly larger in parents of burn victims compared to controls. Risk factors for presenting mental health problems were female gender of the parent and a large burn size in the child. Lower socioeconomic status and female gender of the parent predicted cardiovascular health problems.

Conclusion Evidence gained in longitudinal studies informs on which health problems are most likely to develop in parental caregivers. In the interest of both parent and child, a family-oriented approach is proposed. 


\section{Introduction}

The literature on pediatric chronic illness supports the idea that caring for a medically fragile child or adolescent has implications for the health of parents (1). There are various examples of empirical investigations on the impact of childhood illness on the family, encompassing conditions such as cerebral palsy $(2 ; 3)$, physical disabilities $(4 ; 5)$, or sickle cell disease (6). A large body of research is available on parents of children with cancer. This literature indicates that distress reactions such as anxiety or depression are common in affected parents (7).

Although several studies on the mental health of parental caregivers exist, there has been little investigation of physical health outcomes $(8 ; 9)$. There is a long tradition of studying physical health outcomes in elderly caregivers (e.g. (10;11), but less is known on middle-aged parents who are caregivers of their children.

The current study deals with mental and physical health outcomes of parents of children with burns. As in other families with chronically ill children, the burden of care generally falls upon parents who attempt to balance the burn victim's health care needs with those of other family members and work commitments (12). Follow-up care can be very timeconsuming and painful for the patient. Procedures may include daily baths, dressing changes, exercises and wearing of splints and pressure garments (13). Next tot the caretaking role, parents must also resume family roles such as spouse, parent of the patient's siblings, housekeeper, cook and many others.

A look into the literature shows that studies on parents of burn victims are generally scarce. As in the research on other childhood diseases, mental health problems in parents (i.e. depression, anxiety, posttraumatic stress symptoms) or more often the subject of investigation when compared to physical health problems. With regard to mental health problems, the conclusions drawn in the literature are inconsistent. While most studies on parents of burn patients report adverse mental health outcomes (14-21), some do not demonstrate adverse effects $(12 ; 22)$. 
Regarding physical health problems, to our knowledge, there exists only one publication examining physical health consequences in family members of burn patients. It demonstrated that immune function in spouses and parents of burn patients was suppressed 72 hours after the admission of the burn patient and improved two to five weeks later, thus only indicating shortterm effects (14). Besides the lack of physical outcome measures, there are also some methodological concerns regarding the existing research on parents of burn victims. Samples are often small, drawn from specialty centers, and it is unclear whether parents who cope well are appropriately represented among the respondents. Finally, most studies are cross-sectional in design and lack pre-burn assessments, rendering causal inferences difficult.

The current population-based, prospective study tries to tackle some of these shortcomings. It aims at examining both physical and mental health outcomes in parents of adolescent burn victims, using data extracted from electronic medical records. The adolescents themselves were injured in a fire which occurred in an overcrowded pub in Volendam, the Netherlands on January 1st, 2001. The fire broke out around midnight as hundreds of young revelers were toasting the New Year. As a result, 14 young people lost their lives and about 240 were injured (23).

The purpose of the present study is to study physical and mental health outcomes in the parents of these adolescents during a period of four years after the incident. In addition, their outcomes are compared to those of other parents, using pre- and post-event data. In addition, gender, size of burn, socioeconomic characteristics of the family, and the number of children in the family who have been involved in the burn incident will be investigated as risk factors. Gender is of special interest since women traditionally have a caretaking role and often attempt to balance family members' needs. For this reason, women are assumed to be more vulnerable to stress within the family than men (24). Female gender as a risk factor has not been examined extensively, however, which is due to the fact that fathers are largely underrepresented in the existing research on parents of burn victims. The inclusion of socioeconomic characteristics seems logical as well, since lower socioeconomic status in general is associated with more ill-health than 
higher socioeconomic status (25). In addition, it is expected that effects in parents of children with burns will vary with the size of the burn. The total burned surface area (TBSA) of the child can be considered to be one of the most important injury characteristics and it is directly related to the rehabilitation efforts a child and its family have to undergo.

Specifically, the hypotheses of the study can be stated as follows:

1. During follow-up, the proportion of parents presenting with mental and physical health problems significantly increases in parents of adolescents with burns compared to the pre-fire baseline.

2. The largest post-fire increases are seen in parents of adolescents with burns, followed by parents of adolescents who have survived the fire without burns, and increases are smallest in controls.

3. The peak period of mental and physical health effects is observed during the first year after the fire. The share of parents presenting with mental health problems is expected to decline in the course of the years as adaptation occurs over time.

4. Parental mental and physical health problems vary according to the size of the burn of the child and parental socioeconomic status.

5. Mothers of adolescents with burns demonstrate larger increases in mental health and physical health problems than fathers of adolescents with burns.

\section{Method}

\section{Setting}

Volendam is a former fishing town located 20 miles north of Amsterdam, and has about 20,000 inhabitants. The community is close-knit and mobility is low. The population is served by four family practices. In the Netherlands, family practitioners (FPs) have a key position as gatekeepers to specialist care, which is only accessible after referral by a family practitioner. Accordingly, most contacts between the public at large and the health care system take place in family practice (approximately 90\%). Dutch FPs have fixed patient lists and patients are registered with one FP only (26). Basically, there are no financial barriers for patients to FP care. Until 2006, two types of 
health insurance existed in the Netherlands, public and private insurance. Patients with an annual income below a specific level were insured through public insurance; above this level, patients were privately insured (approximately $40 \%$ of the population). Insurance type can thus be used as an indicator for the socioeconomic status of the patient. The use of electronic registrations is well-established in Dutch family practice. In our study, all FPs classified their patients' health problems according to the International Classification of Primary Care (ICPC), an internationally endorsed classification system which is compatible with the ICD-10 (27;28). It is divided into several chapters, each dealing with one organ system (e.g. cardiovascular, musculoskeletal, gastrointestinal).

\section{Sampling of cohorts}

As a first step, it was necessary to identify those adolescents who had been present in the bar. According to official estimates, about 350 people were in the building at the time of the fire. The four FP practices were able to identify a total of 335 persons in their registrations (14 deceased adolescents and 321 survivors, with and without physical injuries). Thirty-five of the surviving victims were excluded from the study since they belonged to a practice which was not yet fully computerized. The characteristics of survivors enrolled in the non-participating practice $(n=35)$ were compared with those of survivors enrolled with the participating practices $(n=286)$. Survivors included in the final study sample did not significantly differ from non-participants with respect to burn size, number of days in hospital, gender, age or insurance status. Victims with burn injuries had a mean total burn surface area of $14.9 \%(\mathrm{SD}=17.1)$ and spent, on average, 34.2 days in hospital during the first 12 months after the disaster ( $S D=59.3)$. Victims with burns $(\mathrm{n}=162)$ had a mean age of $16.9(\mathrm{SD}=2.1)$, victims without burns $(n=124)$ were 17.8 years on average $(S D=2.9)$.

As a second step, we identified all cohabiting parents of the victims with the help of the electronic patient registration $(n=499)$. 27 of these parents were excluded because they had lost a child due to the fire - an experience different from the one we aimed to examine - resulting in a sample of 472 parents (273 parents of burn victims and 199 parents of unburned victims). These 472 parents were distributed among 249 family units. In 28 out of the 
249 affected family units included, more than one child had been present during the fire.

As a third step, we selected all parents from the three participating family practices with children aged 14-20 years who had not been trapped in the fire. These parents are referred to as 'community controls' $(n=1,756$, distributed among 952 family units).

\section{Assessment of health problems}

The assessment of health problems was based on the electronic patient records of family practitioners. Mental health problems were defined as problems belonging to the ICPC-chapters 'psychological' and 'social'. In addition, physical health problems as summarized in the ICPC-chapters 'cardiovascular', 'musculoskeletal', 'respiratory', 'gastrointestinal' and 'dermatological' were analyzed since they capture the most important areas of morbidity. If a patient presented a health problem at least once in a given period, the value of the outcome variable was one. Parents who did not contact the FP for the health problem in question in a given period, received a count of zero. Five different time periods were distinguished: the 12months period prior to the fire (year 2000), 0-12 months post-fire (year 2001), 12-24 months post-fire (year 2002), 25-36 months post-fire (year 2003) and 37-48 months post-fire (year 2004).

\section{Analyses}

For the analysis of health problems, logistic regression was used. In the current study, repeated measurements are nested within persons and persons are nested within couples. In order to account for this dependency of observations, a multilevel modeling approach was chosen (29), based on the MLwiN software package (available at http://www.cmm.bristol.ac.uk).

The outcome measure in the regression analysis was the presence or absence of a health problem (cardiovascular, musculoskeletal, gastrointestinal, dermatological, respiratory, or mental; coded 1 if present, and 0 if absent). The predictors were introduced into the models as follows. The three parent groups (parents of children with burns, parents of children without burns and controls) were modeled by one dummy each (model without intercept). 
Interaction terms of group and time (group*year 2001, group*year 2002, group*year 2003 and group*year 2004) were used for modeling the deviation from the year pre-fire. All regression model were adjusted for the influence of covariates (age, gender, family practice and insurance type) which had been centered around their means before introducing them into the equation.

Table 4.3 reports the results of 6 regression analyses (one for each health problem). These analyses provide two types of information. First, they provide information on within-group-comparisons. Second, they inform on between-group-comparisons. In table 4.3, significant within-groupcomparisons are printed in bold (presented as odds ratios and 95\% confidence intervals). An odds ratio above 1 indicates that within the group, the likelihood for presenting the health problem was higher than in the year pre-fire (the year 2000). An odds ratio below 1 indicates that, within the group, the likelihood for presenting the health problems was lower than in the year pre-fire. Between-group-comparisons were based on the calculation of contrasts. These contrasts test whether the post-fire increase (or decrease) observed in one group is statistically different form the post-fire increase (or decrease) seen in another group. If contrasts yielded significant results (alpha $=0.05)$, they were marked with indices ( $\#, \$,+$; see legend table 4.3 ).

Tables 4.4 and 4.5 provide the results of two additional regression analyses for which only the data of the parents of children with burns were used. These models examine the influence of risk factors for cardiovascular and mental health problems in parents of burned children. The outcome measure in the analysis reported in table 4 is mental health problems during the first two years after the fire (if mental health problems were present during at least one of the two years, the value of the outcome variable was 1; if absent, it was 0 ). The outcome measure in the analysis presented in table 4.5 is cardiovascular problems during the four years post-fire (if cardiovascular health problems were present during at least one of the four years, the value of the outcome variable was 1 ; if absent, it was 0 ). The decision to consider time windows different from the previous analysis was based on the findings reported in table 4.3 (cardiovascular effects were observed in every 
year post-disaster, while mental health effects were reported during the first two years post-disaster).

\section{Results}

Statistical group comparisons (ANOVA for continuous variables and chisquare tests for categorical variables) did not yield statistically significant differences between parents of burned children $(n=273)$, parents of unburned children $(n=199)$ and community controls $(n=1,756)$ with regard to gender and insurance type (table 4.1). Parents of burned children (mean age 45.7, standard deviation 4.2) were significantly older than parents of unburned children (mean age 46.7, standard deviation 5.0).

Table 4.1: Background characteristics of parents of victims with burns, parents of victims without burns and community controls

\begin{tabular}{lrrrrr}
\hline & $\begin{array}{r}\text { Parents of } \\
\text { burned } \\
\text { victims } \\
\mathrm{n}=273\end{array}$ & $\begin{array}{r}\text { Parents of } \\
\text { unburned } \\
\text { victims } \\
\mathrm{n}=199\end{array}$ & $\mathrm{n}=1.756$ & $\begin{array}{r}\text { Controls } \\
\text { 'burned' and } \\
\text { 'unburned' }\end{array}$ & $\begin{array}{r}\text { Comparison } \\
\text { 'unburned' } \\
\text { and controls }\end{array}$ \\
\hline $\begin{array}{l}\text { Gender } \\
\text { Men (\%) }\end{array}$ & $129(47.3)$ & $96(48.2)$ & $841(47.9)$ & $\mathrm{ns}$ & $\mathrm{ns}$ \\
Women (\%) & $144(52.7)$ & $103(51.8)$ & $915(52.1)$ & & \\
Mean age (std) & $45.7(4.2)$ & $46.7(5.0)$ & $46.7(4.8)$ & & $\mathrm{ns}$ \\
$\begin{array}{l}\text { Insurance } \\
\text { Private (\%) }\end{array}$ & $108(39.6)$ & $79(39.7)$ & $773(44.0)$ & $\mathrm{ns}$ & $\mathrm{ns}$ \\
Public (\%) & $165(60.4)$ & $120(60.3)$ & $983(56.0)$ & & \\
\hline
\end{tabular}

* Significant at $\mathrm{p}<0.05 ;$ ns not significant. 
Table 4.2 provides the number and percentage of parents with mental, musculoskeletal, respiratory, gastrointestinal and dermatological health problems. Considering mental health problems, parents of victims with burns showed larger increases from the pre-fire baseline than parents of victims without burns, with the increase being the strongest in the first year following the fire, the year 2001. Furthermore, cardiovascular health problems had increased in all three cohorts in the course of the four-year follow-up period. Although there were differences at baseline between groups, the strongest deviations from the baseline were seen in parents of victims with burns, followed by parents of victims without burns.

Table 4.2: $\quad$ Number of parents (\%) with health problem

\begin{tabular}{|c|c|c|c|c|c|}
\hline & $\begin{array}{r}2000 \\
\text { (pre-fire) } \\
\end{array}$ & $\begin{array}{r}2001 \\
\text { (post-fire) } \\
\end{array}$ & $\begin{array}{r}2002 \\
\text { (post-fire) } \\
\end{array}$ & $\begin{array}{r}2003 \\
\text { (post-fire) } \\
\end{array}$ & $\begin{array}{r}2004 \\
\text { (post-fire) }\end{array}$ \\
\hline \multicolumn{6}{|l|}{ Cardiovascular } \\
\hline Parents - burned & $29(10.6)$ & $47(17.2)$ & $63(23.3)$ & $63(23.3)$ & $58(21.6)$ \\
\hline Parents - unburned & $32(16.1)$ & 39 (19.6) & $41(20.7)$ & $38(19.2)$ & $45(22.7)$ \\
\hline Controls & $231(13.2)$ & $258(14.8)$ & $271(15.7)$ & $277(16.2)$ & $283(16.6)$ \\
\hline \multicolumn{6}{|l|}{ Musculoskeletal } \\
\hline Parents - burned & $117(42.9)$ & $127(46.5)$ & $132(48.9)$ & $129(47.8)$ & $136(50.6)$ \\
\hline Parents - unburned & $97(48.7)$ & $91(45.7)$ & $111(56.1)$ & $99(50.0)$ & $111(56.1)$ \\
\hline Controls & $719(40.9)$ & $726(41.5)$ & $716(41.6)$ & $721(42.2)$ & $744(43.6)$ \\
\hline \multicolumn{6}{|l|}{ Gastrointestinal } \\
\hline Parents - burned & $43(15.8)$ & $37(13.6)$ & $38(14.1)$ & $48(17.8)$ & $51(19.0)$ \\
\hline Parents - unburned & $32(16.1)$ & $42(21.1)$ & $38(19.2)$ & $37(18.7)$ & $25(12.6)$ \\
\hline Controls & $281(16.0)$ & $264(15.1)$ & $235(13.7)$ & $235(13.8)$ & $258(15.1)$ \\
\hline \multicolumn{6}{|l|}{ Dermatological } \\
\hline Parents - burned & $76(27.8)$ & $77(28.2)$ & $70(25.9)$ & $88(32.6)$ & $83(30.9)$ \\
\hline Parents - unburned & $61(30.7)$ & $73(36.7)$ & $69(34.8)$ & $56(28.3)$ & $69(34.8)$ \\
\hline Controls & $459(26.1)$ & $455(26.0)$ & $456(26.5)$ & $489(28.6)$ & $502(29.4)$ \\
\hline \multicolumn{6}{|l|}{ Respiratory } \\
\hline Parents - burned & $80(29.3)$ & $89(32.6)$ & $95(35.2)$ & $79(29.3)$ & $64(23.8)$ \\
\hline Parents - unburned & $61(30.7)$ & $51(25.6)$ & 75 (37.9) & $63(31.8)$ & $57(28.8)$ \\
\hline Controls & $469(26.7)$ & $492(28.1)$ & $468(27.2)$ & $449(26.3)$ & $423(24.8)$ \\
\hline \multicolumn{6}{|l|}{ Mental } \\
\hline Parents - burned & $26(9.5)$ & $70(25.6)$ & 49 (18.1) & $31(11.5)$ & $32(11.9)$ \\
\hline Parents - unburned & $26(13.1)$ & $31(15.6)$ & $11(5.6)$ & 25 (12.6) & $19(9.6)$ \\
\hline Controls & $202(11.5)$ & $208(11.9)$ & $190(11.0)$ & $164(9.6)$ & $171(10.0)$ \\
\hline
\end{tabular}

Date of the fire: January $1^{\text {st }} 2001$. 
Table 4.3: Logistic regression analyses with health problem (yes $=1 /$ no $=0$ ) as dependent variable

\begin{tabular}{|c|c|c|c|c|c|c|c|c|c|}
\hline \multirow{2}{*}{ Parents - burne } & \multicolumn{3}{|c|}{ Cardiovascular } & \multicolumn{3}{|c|}{ Musculoskeletal } & \multicolumn{3}{|c|}{ Gastrointestinal } \\
\hline & OR & \multicolumn{2}{|c|}{$95 \% \mathrm{CI}$} & OR & \multicolumn{2}{|c|}{$95 \% \mathrm{CI}$} & OR & \multicolumn{2}{|c|}{$95 \% \mathrm{CI}$} \\
\hline Change 2001 & 2.67 & 1.61 & 4.44 & 1.21 & 0.86 & 1.71 & $0.80^{\sharp}$ & 0.50 & 1.26 \\
\hline Change 2002 & $4.87^{\#}$ & 2.96 & 8.00 & 1.36 & 0.96 & 1.92 & 0.84 & 0.53 & 1.33 \\
\hline Change 2003 & $5.47^{\#}$ & 3.33 & 8.97 & 1.28 & 0.91 & 1.81 & 1.21 & 0.78 & 1.87 \\
\hline Change 2004 & 4.20 & 2.55 & 6.92 & 1.49 & 1.05 & 2.10 & 1.35 & 0.87 & 2.08 \\
\hline \multicolumn{10}{|c|}{ Parents - unburned } \\
\hline Change 2001 & 1.86 & 1.09 & 3.15 & 0.85 & 0.57 & 1.28 & $1.59^{\$}$ & 0.96 & 2.63 \\
\hline Change 2002 & 2.08 & 1.23 & 3.51 & 1.48 & 0.98 & 2.23 & 1.37 & 0.82 & 2.29 \\
\hline Change 2003 & 1.66 & 0.97 & 2.83 & 1.07 & 0.72 & 1.61 & 1.31 & 0.78 & 2.20 \\
\hline Change 2004 & 2.70 & 1.61 & 4.54 & 1.48 & 0.98 & 2.23 & 0.70 & 0.40 & 1.23 \\
\hline \multicolumn{10}{|l|}{ Controls } \\
\hline Change 2001 & $1.30^{+}$ & 1.07 & 1.57 & 1.03 & 0.90 & 1.19 & 0.91 & 0.76 & 1.09 \\
\hline Change 2002 & $1.46^{+}$ & 1.21 & 1.76 & 1.03 & 0.89 & 1.18 & 0.78 & 0.65 & 0.93 \\
\hline Change 2003 & $1.41^{+}$ & 1.16 & 1.70 & 1.06 & 0.92 & 1.21 & 0.79 & 0.66 & 0.95 \\
\hline \multirow[t]{3}{*}{ Change 2004} & $1.50^{+}$ & 1.25 & 1.82 & 1.14 & 0.99 & 1.31 & 0.91 & 0.76 & 1.09 \\
\hline & \multicolumn{3}{|c|}{ Dermatological } & \multicolumn{3}{|c|}{ Respiratory } & \multicolumn{3}{|c|}{ Mental } \\
\hline & OR & \multicolumn{2}{|c|}{$95 \% \mathrm{CI}$} & OR & \multicolumn{2}{|c|}{$95 \% \mathrm{CI}$} & OR & \multicolumn{2}{|c|}{$95 \% \mathrm{CI}$} \\
\hline \multicolumn{10}{|c|}{ Parents - burned } \\
\hline Change 2001 & 1.02 & 0.71 & 1.48 & 1.23 & 0.85 & 1.79 & $5.87^{\#}$ & 3.73 & 9.24 \\
\hline Change 2002 & 0.89 & 0.61 & 1.29 & 1.43 & 0.99 & 2.06 & $2.86^{\#}$ & 1.80 & 4.55 \\
\hline Change 2003 & 1.29 & 0.90 & 1.86 & 0.99 & 0.68 & 1.44 & 1.31 & 0.80 & 2.15 \\
\hline Change 2004 & 1.17 & 0.81 & 1.69 & 0.68 & 0.46 & 1.01 & $1.38^{\sharp}$ & 0.84 & 2.25 \\
\hline \multicolumn{10}{|c|}{ Parents - unburned } \\
\hline Change 2001 & 1.37 & 0.91 & 2.07 & 0.71 & 0.45 & 1.11 & 1.35 & 0.80 & 2.28 \\
\hline Change 2002 & 1.25 & 0.82 & 1.89 & 1.59 & 1.03 & 2.45 & $0.29^{\mathrm{s}}$ & 0.15 & 0.56 \\
\hline Change 2003 & 0.87 & 0.57 & 1.34 & 1.09 & 0.70 & 1.69 & 0.94 & 0.55 & 1.62 \\
\hline Change 2004 & 1.25 & 0.82 & 1.89 & 0.89 & 0.57 & 1.40 & 0.61 & 0.35 & 1.09 \\
\hline \multicolumn{10}{|l|}{ Controls } \\
\hline Change 2001 & 0.99 & 0.85 & 1. & 1.11 & 0.95 & 1.29 & $1.06^{+}$ & 0.87 & 1.28 \\
\hline Change 2002 & 1.02 & 0.87 & 1.18 & 1.03 & 0.88 & 1.20 & $0.92^{+}$ & 0.76 & 1.13 \\
\hline Change 2003 & 1.15 & 0.99 & 1.34 & 0.96 & 0.82 & 1.12 & $0.75^{+}$ & 0.61 & 0.92 \\
\hline Change 2004 & 1.21 & 1.04 & 1.40 & 0.86 & 0.74 & 1.01 & $0.80^{+}$ & 0.66 & 0.98 \\
\hline
\end{tabular}

Date of the fire: January 1st, 2001.

Change 2001, change 2002, change 2003, change 2004: change per year when compared to the year pre-fire (year 2000).

OR indicates odds ratio, CI indicates confidence interval; significant ORs are printed in bold (alpha $=5 \%$ ).

ORs above 1 indicate an increase in likelihood, ORs below 1 indicate a decrease in likelihood for presenting the health problem.

All coefficients are adjusted for the influence of age, family practice, gender and insurance type.

" comparison 'parents - burned' vs. 'parents - unburned' significant at alpha $=5 \%$.

$\$$ comparison 'parents - unburned' vs. 'controls' significant at alpha $=5 \%$.

+ comparison 'controls' vs. 'parents -burned' significant at alpha $=5 \%$. 
Table 4.3 presents the results of the multivariate analyses. The provided odds ratios indicate whether the likelihood for presenting a health problem has increased or decreased during the year in question. The confidence intervals indicate whether the finding is statistically significant or not (significant odds ratios are printed in bold). In parents of children with burns, significant post-fire increases were mainly observed in two areas, cardiovascular and mental health.

In the years 2001 (OR 2.67; 95\% CI 1.61-4.44), 2002 (OR 4.87; 95\% CI 2.968.00), 2003 (OR 5.47; 95\% CI 3.33-8.97) and 2004 (OR 4.20; 95\% CI 2.55-6.92), the likelihood for presenting a cardiovascular health problem was significantly increased in parents of children with burns when compared to the year pre-fire. Significant post-fire increases in cardiovascular health problems were also observed in parents of victims without burns and in controls. Between-group comparisons demonstrated that the post-fire increase of cardiovascular health problems observed in parents of burn victims was significantly larger than in parents of unburned victims during the year 2002 and 2003. In 2002, for example, the odds ratio for parents of victims with burns was 4.87 (95\% CI 2.96-8.00). In parents of victims without burns, it was 2.08 (95\% CI 1.23-3.51). These two odds ratios differ significantly from each other (table 4.3, marked by \#), meaning that the postfire increase in cardiovascular problems observed in parents of burn victims was significantly larger than in parents of victims without burns.

With regard to mental health problems, the analysis showed that after the fire, parents of burn victims were more likely to present mental problems during the year 2001 (OR 5.87; 95\% CI 3.73-9.24) and 2002 (OR 2.86; 95\% CI 1.80-4.55; table 4.3). When compared to community controls, parents of burn victims demonstrated larger post-fire increases in mental health problems in every year of the four-year follow-up period (marked by + ). When compared to parents of victims without burns, parents of burn victims demonstrated larger post-fire increases in mental health problems in 2001, 2002 and 2004, but not in 2003 (marked by \#). 
Table 4.4: Parents of children with burns: predictors of mental health problems during the first two years post-fire (logistic regression)

\begin{tabular}{lccr}
\hline & \multicolumn{3}{c}{ Mental } \\
\cline { 2 - 4 } & OR & \multicolumn{2}{c}{ \% CI } \\
\hline Post-fire (reference: pre-fire) & $\mathbf{4 . 8 2}$ & $\mathbf{2 . 0 9}$ & $\mathbf{1 1 . 1 0}$ \\
Female gender (reference: male) & 0.55 & 0.17 & 1.83 \\
Age (in years) & 1.02 & 0.90 & 1.16 \\
Public health insurance (reference: private) & 1.55 & 0.48 & 5.08 \\
Two children affected (reference: one child affected) & 1.34 & 0.27 & 6.61 \\
Total burn surface area of child (in percent) & 1.01 & 0.97 & 1.04 \\
Enrolled at practice 1 (reference: practice 3) & $\mathbf{0 . 1 3}$ & $\mathbf{0 . 0 3}$ & $\mathbf{0 . 5 8}$ \\
Enrolled at practice 2 (reference: practice 3) & 0.43 & 0.12 & 1.61 \\
Post-fire*Female gender & $\mathbf{9 . 8 7}$ & 3.93 & $\mathbf{2 4 . 8 4}$ \\
Post-fire* Public health insurance & 1.23 & 0.50 & 3.06 \\
Post-fire*Two children affected & 0.99 & 0.30 & 3.30 \\
Post-fire*Total burn surface area of child & $\mathbf{1 . 0 5}$ & $\mathbf{1 . 0 2}$ & $\mathbf{1 . 0 8}$ \\
\hline
\end{tabular}

Since most changes have been observed in the mental and cardiovascular health domains, additionally, predictors for these problems in parents of burn victims were examined (table 4.4 and 4.5). As already demonstrated in the previous analyses, the proportion of parents of children with burns who presented with mental health problems had significantly increased compared to the pre-fire baseline (OR 4.82; 95\% CI 2.09-11.10; table 4.4). Also, the proportion was lower in parents who were enrolled with practice 1 compared to the reference, practice 3 (OR 0.13; 95\% CI 0.03-0.58). As the interaction terms demonstrate, the post-fire increase in mothers was much stronger than the post-fire increase in fathers (OR 9.87; 95\% CI 3.93-24.84). Finally, the total burn surface area of the child significantly predicted if parents presented a mental health problem or not (OR 1.05; 95\% CI 1.021.08). In other words, the larger the burn, the higher the likelihood of parents presenting a mental health problem during the first two years post-fire.

In order to make sure that these associations between gender and mental health problems are specific to parents of burn victims, additional analyses were performed for the cohort of community controls (not in table). In this group, independent of the time of measurement, women were also more likely to present with mental health problems (OR 2.03, 95\% CI 1.47-2.81; not 
in table). In contrast to parents of burn victims, the interaction term (postfire ${ }^{*}$ female gender) indicated that the post-fire increase was larger in male controls than in female controls (OR 0.67, 95\% CI 0.45-1.00; not in table) and not vice versa as it was the case in parents of burn victims. The analysis also demonstrated the same practice effect as in the analysis of parents of children with burns (OR 0.43, 95\% CI 0.32-0.59; not in table).

Table 4.5: Parents of children with burns: predictors of cardiovascular health problems during the first four years post-fire (logistic regression)

\begin{tabular}{lrrr}
\hline & \multicolumn{3}{c}{ Cardiovascular } \\
\cline { 2 - 4 } & OR & \multicolumn{2}{c}{$95 \%$ CI } \\
\hline Post-fire (reference: pre-fire) & $\mathbf{1 1 8 . 2 7}$ & $\mathbf{5 0 . 2 8}$ & $\mathbf{2 7 8 . 2 0}$ \\
Female gender (reference: male) & 0.60 & 0.14 & 2.64 \\
Age (in years) & 1.05 & 0.88 & 1.25 \\
Public health insurance (reference: private) & 0.70 & 0.14 & 3.60 \\
Two children affected (reference: one child affected) & 0.47 & 0.04 & 5.34 \\
Total burn surface area of child (in percent) & 1.02 & 0.98 & 1.07 \\
Enrolled at practice 1 (reference: practice 3) & 0.31 & 0.04 & 2.55 \\
Enrolled at practice 2 (reference: practice 3) & 1.17 & 0.18 & 7.72 \\
Post-fire*Female gender & $\mathbf{6 . 3 5}$ & $\mathbf{2 . 0 9}$ & $\mathbf{1 9 . 2 8}$ \\
Post-fire*Public health insurance & $\mathbf{9 . 4 3}$ & $\mathbf{2 . 9 3}$ & $\mathbf{3 0 . 3 7}$ \\
Post-fire*Two children affected & 0.95 & 0.15 & 6.14 \\
Post-fire* Total burn surface area of child & 0.97 & 0.95 & 1.00 \\
\hline
\end{tabular}

Finally, the likelihood of presenting with a cardiovascular health problem during the four years of follow-up was investigated in parents of burn victims (table 4.5). Here, we also observed a significant post-fire increase in cardiovascular health problems (OR 118.27; 95\% CI 50.28-278.20). The effect is large in size since the pre-fire period is only one year compared to the post-fire period examined here, which is four years (the longer the observation period, the higher the likelihood of presenting with the problem). There were no significant differences regarding gender, insurance type, age or practice in this analysis. Two interaction terms were significant, however. First, mothers of burned children were more likely to present with a cardiovascular problem than fathers (OR 6.35; 95\% CI 2.09-19.28). Second, 
public health insurance significantly predicted the likelihood of presenting such a problem during follow-up (OR 9.43; 95\% CI 2.93-30.37). Since insurance type is determined by family income, it can be concluded that parents of children with burns from a lower socioeconomic background were more vulnerable than parents of children with burns from a higher socioeconomic background.

As in mental health problems, the control group was examined in an additional analysis (not in table). The interaction terms, which indicate that an increase is significantly larger in one group when compared to the reference group, demonstrated that female controls and controls with public insurance were not more likely to present with cardiovascular problems during the post-fire period when compared to male controls or controls with private insurance (post-fire ${ }^{*}$ female gender OR $1.11,95 \%$ CI $0.79-1.57$, and post-fire* public health insurance OR $0.90,95 \%$ CI 0.63-1.27, respectively; not in table).

\section{Discussion}

This chapter shows that the health of parents of adolescents with burns differed from the health of other parents in two main areas: cardiovascular and mental health problems. Whereas mental health problems were most pressing during the first and second year after burn injuries had been inflicted, cardiovascular health problems appeared to be at elevated levels in later years. As expected, the largest increases were observed in parents of victims with burns, followed by parents of victims without burns, and controls.

Despite the fact that we examined several physical health outcomes, no substantial effects on health problems in the gastrointestinal, respiratory, musculoskeletal or dermatological domains were found. Although evidence linking cardiovascular disease and exposure to psychological trauma is strong and has been found consistently across different populations and stressful events (30), it is difficult to determine why the physical effects mainly emerge in the cardiovascular domain. Cardiovascular diseases 
develop as a result of a number of risk factors, such as smoking, excessive drinking, high blood pressure and cholesterol, obesity, lack of physical activity and an unhealthy diet. It has been suggested that behaviors such as smoking, alcohol and drug use can operate as coping strategies which help to reduce feelings of stress in the short term, but damage health in the long term (31). Healthy life styles may thus deteriorate as a consequence of life stress and, in turn, increase the cardiovascular disease risk.

In addition, the physiological stress response in humans includes an increase in force to the vessel wall, with blood pressure peaks, vasoconstriction and exaggerated coagulation activation (32;33). In this case, wear and tear to the cardiovascular system may occur. The concept of 'allostatic load' has been coined to describe the cumulative physiological toll exacted on the body over time by efforts to adapt to life experiences (34). High allostatic load has been associated with declines in physical functioning and with an increased risk for cardiovascular disease (35;36). In addition, there is an abundant literature to demonstrate that the risk of coronary artery disease is elevated in subjects with depression, anxiety, exhaustion, worry, anger or hostility - a range of emotions one would also expect in the parents included in this study (37-40). To possibly corroborate the psychosocial mediators which link the experience of parenting a child with burns to adverse health outcomes, more research is warranted, however.

Another point of interest concerned the question as to which factors are related to mental and cardiovascular health problems in parents of burn victims. Female gender and a high burn surface area of the child predicted mental health problems in parents of burn patients, whereas cardiovascular health problems were associated with parental public health insurance and female gender, but not with the burn size of the child. The gender effect for mental and cardiovascular health problems observed in the current study is in line with previous findings (41). Traditionally, women have been assigned the role of caregiver, a role that may lead to increased stress levels. Norris and colleagues noted in their review of disaster studies that being a parent, especially a mother, was associated with higher distress (42). In addition, in the Netherlands, public health insurance is indicative for lower incomes. Lower socioeconomic status, in turn, is generally considered a risk factor for 
ill health and this association has also been reported for cardiovascular health $(25 ; 34)$.

\section{Strengths, weaknesses and limitations}

Our study has several strengths. First of all, physical health effects are generally under-researched outcomes when it comes to caregivers of medically fragile children. In addition, so far, no studies existed on the physical health of parents of children with burns. The present study has therefore made a contribution to a knowledge base which is still rather small. Furthermore, from a methodological point of view, the design of the study was strong. We prospectively examined changes in health problems within groups (changes over time) and changes in health problems between different groups of parents. The observation period was four years and baseline data were available for one year pre-event. The estimates of health problems are reliable since all health problems were physician-verified and are not biased by self-report. Also, the study is population-based. Since the research was based on pre-existing electronic registries, selection and recall bias are ruled out. This is an important advantage, since many samples included in previous research were drawn from specialty centers and tend to exclude those parents who are well in spite of the burn incident. Also, fathers are often underrepresented in comparable studies - a problem not present in the current research. It can thus be assumed that these findings are generally representative of parents of adolescents with burns.

In spite of these strengths, the study has some weaknesses and limitations. First, we were not able to measure other variables which also might negatively affect health. Examples are unhealthy life-styles and other negative life-events. Second, it should be noted that some parents included in the cohort of community controls may have been indirectly affected by the fire as they could belong to the extended families of the victims. This would lead to an underestimation of the differences found between groups, however, and not to an overestimation of effects. Third, as already mentioned, the study was based on electronic medical records, and mediating psychological variables were not assessed. These variables would help to shed more light on the underlying processes that lead to adverse physical health outcomes. Fourth, not every parent who experiences 
emotional problems may also seek help from a family practitioner. Our study therefore predominantly assesses physician utilization for mental health and not the actual prevalence of these problems. Finally, while a broad range of health outcomes was assessed simultaneously in this chapter, health problems have not yet been considered at a more fine-grained level. Other study results indicate, for example, that hypertension may be the most important disorder which contributes to the decrements in cardiovascular health found here at a more general level (44).

In conclusion, some practical implications should be noted. First, it is important to meet parental mental health needs and to guarantee appropriate monitoring of health in general and cardiovascular problems in particular. Second, it should not be forgotten that from a system's point of view, parents and children are interrelated $(45 ; 46)$ and that the well-being of the parent may also affect the outcomes of the child. Interestingly, in most studies of pediatric burn survivors, burn severity did not predict psychosocial adjustment of the child, but good family relationships did (47). In the interest of both the child and the parents, interventions should thus be directed at the family as a system.

\section{Acknowledgements}

This study was financially supported by the Dutch Ministry of Health. We thank all Volendam family practitioners for the provision of the data and Petra ten Veen for the management of the database. 


\section{References}

1. Barlow JH, Ellard DR. The psychosocial well-being of children with chronic disease, their parents and siblings: an overview of the research evidence base. Child Care Health Dev 2006; 32(1):19-31.

2. Brehaut JC, Kohen DE, Raina P, Walter SD, Russell DJ, Swinton M et al. The health of primary caregivers of children with cerebral palsy: how does it compare with that of other Canadian caregivers? Pediatrics 2004; 114(2):e182-e191.

3. Raina P, O'Donnell M, Rosenbaum P, Brehaut J, Walter SD, Russell D et al. The health and well-being of caregivers of children with cerebral palsy. Pediatrics 2005; 115(6):e626-e636.

4. Tong HC, Kandala G, Haig AJ, Nelson VS, Yamakawa KS, Shin KY. Physical functioning in female caregivers of children with physical disabilities compared with female caregivers of children with a chronic medical condition. Arch Pediatr Adolesc Med 2002; 156(11):1138-1142.

5. Tong HC, Haig AJ, Nelson VS, Yamakawa KS, Kandala G, Shin KY. Low back pain in adult female caregivers of children with physical disabilities. Arch Pediatr Adolesc Med 2003; 157(11):1128-1133.

6. Midence K, McManus C, Fuggle P, Davies S. Psychological adjustment and family functioning in a group of British children with sickle cell disease: preliminary empirical findings and a meta-analysis. Br J Clin Psychol 1996; 35(3):439-450.

7. Grootenhuis MA, Last BF. Adjustment and coping by parents of children with cancer: a review of the literature. Support Care Cancer 1997; 5(6):466-484.

8. Vedhara K, McDermott MP, Evans TG, Treanor JJ, Plummer S, Tallon D et al. Chronic stress in nonelderly caregivers: psychological, endocrine and immune implications. J Psychosom Res 2002; 53(6):1153-1161.

9. Vedhara K, Shanks N, Anderson S, Lightman S. The role of stressors and psychosocial variables in the stress process: a study of chronic caregiver stress. Psychosom Med 2000; 62(3):374-385.

10. Vitalino PP, Zhang J, Scanlan JM. Is caregiving hazardous to one's physical health? A meta-analysis. Psychol Bull 203; 129:946-972.

11. Kiecolt-Glaser JK, Dura JR, Speicher CE, Trask OJ, Glaser R. Spousal caregivers of dementia victims: longitudinal changes in immunity and health. Psychosom Med 1991; 53:345-62.

12. Blakeney P, Moore P, Broemeling L, Hunt R, Herndon DN, Robson M. Parental stress as a cause and effect of pediatric burn injury. J Burn Care Rehabil 1993; 14(1):73-79.

13. Tarnowski KJ, Brown RT. Burn injuries. In: Goreczny AJ, Hersen M, editors. Handbook of pediatric and adolescent health psychology. Boston: Allyn and Bacon, 1999; 115-126.

14. Shelby J, Sullivan J, Groussman M, Gray R, Saffle J. Severe burn injury: effects on psychologic and immunologic function in noninjured close relatives. J Burn Care Rehabil 1992; 13(1):58-63.

15. Rizzone LP, Stoddard FJ, Murphy JM, Kruger LJ. Posttraumatic stress disorder in mothers of children and adolescents with burns. J Burn Care Rehabil 1994; 15(2):158-163. 
16. LeDoux J, Meyer WJ, III, Blakeney PE, Herndon DN. Relationship between parental emotional states, family environment and the behavioural adjustment of pediatric burn survivors. Burns 1998; 24(5):425-432.

17. Hall E, Saxe G, Stoddard F, Kaplow J, Koenen K, Chawla N et al. Posttraumatic stress symptoms in parents of children with acute burns. J Pediatr Psychol 2006; 31(4):403-412.

18. Fukunishi I. Posttraumatic stress symptoms and depression in mothers of children with severe burn injuries. Psychol Rep 1998; 83(1):331-335.

19. Kent L, King H, Cochrane R. Maternal and child psychological sequelae in paediatric burn injuries. Burns 2000; 26(4):317-322.

20. Mason SA. Young, scarred children and their mothers - a short-term investigation into the practical, psychological and social implications of thermal injury to the preschool child. Part I: Implications for the mother. Burns 1993; 19(6):495-500.

21. El Hamaoui Y, Yalaalaoui S, Chihabeddine K, Boukind E, Moussaoui D. Depression in mothers of burned children. Arch Womens Ment Health 2006; 9:117-119.

22. Meyer WJ, Blakeney P, Moore P, Murphy L, Robson M, Herndon D. Parental well-being and behavioral adjustment of pediatric survivors of burns. J Burn Care Rehabil 1994; 15(1):62-68.

23. Welling L, van Harten SM, Patka P, Bierens JJ, Boers M, Luitse JS et al. The café fire on New Year's Eve in Volendam, the Netherlands: description of events. Burns 2005; 31(5):548-554.

24. Figley CR. Burnout in families: The systemic costs of caring. Boca Raton, FL, US: CRC Press; 1998.

25. Taylor SE, Repetti RL, Seeman T. Health psychology: what is an unhealthy environment and how does it get under the skin? Annu Rev Psychol 1997; 48:411-447.

26. Boerma WG, van der Zee J, Fleming DM. Service profiles of general practitioners in Europe. European GP Task Profile Study. Br J Gen Pract 1997; 47(421):481-486.

27. Wood M, Lamberts H, Meijer JS, Hofmans-Okkes IM. The conversion between ICPC and ICD-10. Requirements for a family of classification systems in the next decade. Fam Pract 1992; 9:340-8.

28. Hofmans-Okkes IM, Lamberts H. The International Classification of Primary Care (ICPC): new applications in research and computer-based patient records in family practice. Fam Pract 1996; 13(3):294-302.

29. Snijder TB, Bosker R. Multilevel analysis: an introduction to basic and advanced multilevel modeling. Thousand Oaks, CA: Sage, 1999.

30. Boscarino JA. Posttraumatic stress disorder and physical illness: results from clinical and epidemiological studies. Ann N Y Acad Sci 2004; 1032:141-153.

31. Schnurr PP, Green BL. Understanding relationships among trauma, posttraumatic stress disorder, and health outcomes. In: Green BL, Schnurr PP, editors. Trauma and health: Physical health consequences of exposure to extreme stress. Washington, DC, US: American Psychological Association, 2004: 247-275. 
32. Cannon WB, Mendenhall WL. Factors affecting the coagulation time of blood: IV. The hastening of coagulation in pain and emotional excitement. American Journal of Physiology 1914; 34:251-261.

33. McEwen BS. The neurobiology of stress: from serendipity to clinical relevance. Brain Res 2000; 886(1-2):172-189.

34. McEwen BS, Stellar E. Stress and the individual: mechanisms leading to disease. Arch Intern Med 1993; 153:2093-101.

35. Seeman TE, Singer BH, Rowe JW, Horwitz RI, McEwen BS. Price of adaptation-allostatic load and its health consequences. MacArthur studies of successful aging. Arch Intern Med 1997; 157(19):2259-2268.

36. Black PH, Garbutt LD. Stress, inflammation and cardiovascular disease. J Psychosom Res 2002; 52(1):1-23.

37. Phillips AC, Carroll D, Ring C, Sweeting H, West P. Life events and acute cardiovascular reactions to mental stress: a cohort study. Psychosom Med 2005; 67(3):384-392.

38. Pickering TG. Mental stress as a causal factor in the development of hypertension and cardiovascular disease. Curr Hypertens Rep 2001; 3(3):249-254.

39. Rozanski A, Blumenthal JA, Kaplan J. Impact of psychological factors on the pathogenesis of cardiovascular disease and implications for therapy. Circulation 1999; 99(16):2192-2217.

40. Brosschot JF, Gerin W, Thayer JF. The perseverative cognition hypothesis: a review of worry, prolonged stress-related physiological activation, and health. J Psychosom Res 2006; 60(2):113-124.

41. Dirkzwager AJ, Grievink L, van der Velden PG, Yzermans CJ. Risk factors for psychological and physical health problems after a man-made disaster. Prospective study. Br J Psychiatry 2006; 189:144-149.

42. Norris FH, Friedman MJ, Watson PJ. 60,000 disaster victims speak: Part II. Summary and implications of the disaster mental health research. Psychiatry 2002; 65(3):240-260.

43. Yzermans CJ, Donker GA, Kerssens JJ, Dirkzwager AJ, Soeteman RJ, Ten Veen PM. Health problems of victims before and after disaster: a longitudinal study in general practice. Int J Epidemiol 2005; 34:810-819.

44. Dorn T, Yzermans CJ, Guijt H, van der Zee J. Disaster-related stress as a prospective risk factor for hypertension in parents of adolescent disaster victims. American Journal of Epidemiology 2007; 165:410-417.

45. Figley CR. Burnout as systemic traumatic stress: A model for helping traumatized family members. In: Figley CR, editor. Burnout in families. The systemic costs of caring. Boca Raton, FL, US: CRC Press, 1998; 15-28.

46. Barnes MF. Understanding the secondary traumatic stress of parents. In: Figley CR, editor. Burnout in families. The systemic costs of caring. Boca Raton, FL, US: CRC Press, 1998: 7589.

47. Landolt MA, Grubenmann S, Meuli M. Family impact greatest: predictors of quality of life and psychological adjustment in pediatric burn survivors. J Trauma 2002; 53(6):1146-1151. 
Chapter 4 


\section{Chapter}



\section{Hypertension in secondary victims}

This chapter was published as:

\section{Dorn T}

Yzermans $C J$

Guijt $H$

van der Zee J

Disaster-related stress as a prospective risk factor for hypertension in parents of adolescent fire victims

American Journal of Epidemiology, 2007; 165(4):410-417 


\begin{abstract}
Life stress has been related to hypertension in various studies, but welldesigned research carried out in disaster settings is scarce. Moreover, most research focuses on the primary victims and disregards effects on their caregivers. In a prospective, population-based cohort study, the authors tested the hypothesis that parents of adolescents who had been involved in the Volendam, Netherlands, pub fire on January 1, $2001(n=418)$ were more at risk of developing hypertension than parents from the same community whose children had not been involved in the fire $(n=1,462)$. Only residents without prior evidence of hypertension were included. The follow-up period covered 4 years (2001-2004). Assessment of hypertension was based on the records of family practitioners and pharmacies. The odds of developing new hypertension were 1.48 times higher in parents of fire victims than in control parents during the follow-up period (odds ratio $=1.48,95 \%$ confidence interval: $1.09,2.02)$. All analyses controlled for age, gender, socioeconomic status, family practice, history of chronic disease, and number of contacts with the family practitioner during follow-up. Since hypertension is an important risk factor for cardiovascular morbidity, it is important to provide interventions that help people fight the negative effects of disaster-related stress.
\end{abstract}




\section{Background}

Disasters are dramatic examples of real-life settings that trigger intense physiologic and emotional reactions $(1,2)$. Acute blood pressure elevations in response to stress have been extensively documented in laboratory settings, and prolonged elevations have been observed with exposure to chronic or repeated stressors $(3,4)$. There are some examples of research dealing with hypertension in catastrophic situations. Most of these studies have described the effects of earthquakes (5-9). An exception is a study documenting increased blood pressure levels among immigrants to Israel who had been affected by the Chernobyl disaster (10). Research in disaster settings is difficult to implement, however, and many such studies suffer from methodological problems. Generally, the major problem is the lack of measurements taken before the event occurred. Other problems concern insufficiently long follow-up periods, lack of control groups, and inappropriate sample sizes.

To our knowledge, there have been only two studies performed in a disaster context where the investigators had access to pre-disaster assessments (11, 12). The findings were inconsistent. The subjects in the first study were participants in a blood pressure telemonitoring trial at four US sites. That study demonstrated significant increases in systolic blood pressure within a time window of 2 months after the terrorist attacks of September 11, 2001, in comparison with the preceding 2 months (11). A second study examined factory workers after a major earthquake in Italy. Here, blood pressure levels remained unchanged, both in the short term and 7 years after the quake (12). However, the participants lived $130 \mathrm{~km}$ (81 miles) from the epicenter. They were uninjured, did not suffer deaths in the family, and did not lose property or employment as a result of the quake.

The current cohort study also had a prospective design but dealt with a different type of disaster exposure. The disaster described here was considered one of the worst mass burn incidents ever to happen in the Netherlands. The fire occurred on January 1, 2001, in an overcrowded pub in Volendam where about 350 young people were celebrating New Year's Eve. It injured more than 200 people and killed 14 (13). After the disaster, the 
victims' parents were forced to deal with a number of stressful experiences. Without doubt, learning that one's child has been injured or killed in a fire is a strong, acute stressor. Over the long term, parents also must cope with the chronic physical disabilities and emotional scars that their children received from the traumatizing event (14). Negative affect, which may manifest itself as depression, anxiety, anger, or hostility, has been related to hypertension in various studies (15-19). Therefore, we hypothesized that parents of affected adolescents would be more at risk of developing hypertension than parents from the same community whose children had not been affected. Parents who had lost a child to death and parents of children who had suffered burns in the fire were expected to be more at risk than parents whose child had survived the fire without physical injuries.

\section{Materials and methods}

\section{Setting}

Volendam is a former fishing town located 20 miles north of Amsterdam and has about 20,000 inhabitants. The population is served by four family practices. In the Netherlands, family practitioners (FPs) have a key position as gatekeepers to specialist care, which is only accessible after referral by a FP. The health care system is organized on an insurance basis. Until 2006, two types of health insurance existed in the Netherlands, public and private insurance. Patients with an annual income below a specific level were insured through public insurance; above this level, patients were privately insured. Insurance type can thus be used as a proxy for the socio-economic status of the patient. Dutch FPs have fixed patient lists and patients are registered with one FP only. In general, complete families are enrolled with the same practice (20). The participating FPs keep electronic registration systems and they code all medical events according to the International Classification of Primary Care (ICPC) (21). Another source of information are the registrations of the local pharmacies. The pharmacy records can be linked to the FP registrations and contain virtually complete information on all drugs dispensed to outpatients (either prescribed by the FPs or, on an extramural basis, by specialists). All prescriptions are coded according to the Anatomical Therapeutic Chemical (ATC) classification system (22). 


\section{Study population}

Firstly, it was necessary to identify the fire victims. According to official estimates, approximately 300-350 people were in the building at the time of the fire. On request, the family practitioners identified 335 victims in their registrations (14 deceased adolescents and 321 survivors, with and without physical injuries). Thirty-five survivors were excluded because they belonged to a practice that was not yet fully computerized, leading to a sample of 300 victims (286 survivors and 14 deceased). The 286 survivors did not differ significantly from nonparticipants $(n=35)$ with respect to burn size, number of days spent in the hospital, gender, age, or insurance status. Participants with burn injuries $(n=162)$ had a mean total burned surface area of 14.9 percent (standard deviation, 17.1) and spent, on average, 34.2 days (standard deviation, 59.3) in the hospital during the first 12 months after the disaster. Secondly, we identified all cohabiting parents of deceased and/or surviving victims with the help of electronic patient registration $(\mathrm{n}=$ 499). Thirdly, we selected all patients $(n=1,756)$ from the three participating family practices who had children within the age range of 14-20 years who had not been trapped in the fire ("community controls").

\section{Subgroups of parents of disaster victims}

The affected parents were further subdivided into three groups according to their exposure to stress). The number of family units per cohort was 884 in controls and 250 in parents of fire victims. In 29 of these 250 units (11.6 percent), more than one child was present during the fire. If at least one child in the family had died as a consequence of the fire, the parent was included in the "bereaved" cohort (14 family units). If all children in the family had survived the fire and at least one child had suffered burns, the parent was assigned to the cohort "parents of children with burns" (140 family units). If all children in the family had survived the fire and none had suffered burns, the parent was included in the cohort named "parents of children without burns" (96 family units).

\section{Inclusion of patients}

Patients who were not enrolled during the full follow-up period were excluded. Figure 5.1 shows the numbers of patients selected for further analysis. 


\section{Baseline data and assessment of medical history}

The characteristics of the cohorts are displayed in tables 5.1 and 5.2. In addition to basic demographic data (gender, insurance type, and age), patients' medical histories were assessed by screening their pharmacy and family practitioner records for the presence of or pharmacologic treatment of conditions often associated with hypertension (i.e., diabetes, cardiovascular disease, asthma/chronic obstructive pulmonary disease, migraine, and hyperthyroidism).

\section{Assessment of hypertension}

A patient was considered hypertensive if he or she was diagnosed with hypertension by the family practitioner (International Classification of Primary Care codes K86 or K87) and/or received at least one prescription for an antihypertensive medication (Anatomical Therapeutic Chemical codes C02, C03, C04, C07, C08, or C09). The codes K86 (uncomplicated hypertension) and K87 (hypertension with involvement target organs) are assigned only when at least three measurements have yielded significantly elevated blood pressure levels (systolic blood pressure $\geq 140 \mathrm{mmHg}$ and/or diastolic blood pressure $\geq 90 \mathrm{mmHg}$ ).

\section{Analyses}

Since the observations in our study were not fully independent (individuals were clustered within couples), all analyses were performed within a multilevel framework considering the patient as the first level and the family as the second level (24). All analyses were based on two-sided tests and were carried out using MLwiN software (available at http:// www.cmm.bristol.ac.uk). In order to answer the study question, we constructed two logistic regression models with "becoming hypertensive during the follow-up period" (yes $=1$, no $=0$ ) as the dependent variable.

The first model was constructed in order to answer the question of whether the risk of becoming hypertensive was higher in parents of fire victims than in controls. The exposure variable thus was "being a parent of a fire victim" (yes $=1$, no $=0)$. As covariates, age (in years), gender $($ male $=0$, female $=1$ ), insurance type (private $=0$, public $=1$ ), history of chronic disease (yes $=1$, no $=0$ ), being a single parent (yes $=1$, no $=0$ ), number of contacts with the 
family practitioner during follow-up (continuous), and the family practice in which the patient was enrolled were included (two dummy variables were used in order to model three practices).

In a second model, we explored whether different types of exposure increased the risk of becoming hypertensive. The three exposure groups (parents of children with burns, parents of children without burns, and bereaved parents) were modeled using three dummy variables, with controls serving as the reference category. The risk of parents of children with burns was compared with the risk of bereaved parents by means of a contrast (effect coding).

Another important question was whether some of the three practices were more likely to detect hypertension in parents of fire victims than in controls because of differential screening behavior. Therefore, we performed a third regression analysis including all centered covariates, one dummy variable for each practice, and interaction terms for the interaction of each practice with the variable "being a parent of a fire victim" (yes $=1$, no $=0$; the intercept was not included in the model). Consequently, these interaction terms were compared with the help of contrasts. 
Figure 5.1: Parents of victims with burns, parents of victims without burns, bereaved parents and controls according to enrolment during follow-up, hypertension at baseline and incident hypertension during follow-up

\begin{tabular}{|c|c|c|c|}
\hline & $\begin{array}{c}\text { parents } \\
\mathrm{n}=499\end{array}$ & & \\
\hline & 7 & $\square$ & \\
\hline $\begin{array}{l}\text { parents of children with burns } \\
\qquad n=273\end{array}$ & $\begin{array}{l}\text { parents of children without burns } \\
\qquad \mathrm{n}=199\end{array}$ & $\begin{array}{l}\text { bereaved parents } \\
\quad n=27\end{array}$ & $\begin{array}{l}\text { controls } \\
n=1756\end{array}$ \\
\hline $\begin{array}{l}\text { enrolled during follow-up } \\
n=269(98.5 \% \text { of } 273)\end{array}$ & $\begin{array}{l}\text { enrolled during follow-up } \\
\mathrm{n}=198(99.5 \% \text { of } 199)\end{array}$ & $\begin{array}{l}\text { enrolled during follow-up } \\
\qquad n=27(100 \% \text { of } 27)\end{array}$ & $\begin{array}{l}\text { enrolled during follow-up } \\
n=1706(97.2 \% \text { of } 1756)\end{array}$ \\
\hline $\begin{array}{c}\text { no hypertension at baseline } \\
n=231(85.9 \% \text { of } 269)\end{array}$ & $\begin{array}{c}\text { no hypertension at baseline } \\
n=164(82.8 \% \text { of } 198)\end{array}$ & $\begin{array}{c}\text { no hypertension at baseline } \\
n=23(85.2 \% \text { of } 27)\end{array}$ & $\begin{array}{c}\text { no hypertension at baseline } \\
n=1462(85.7 \% \text { of } 1706)\end{array}$ \\
\hline $\begin{array}{l}\text { develop hypertension } \\
n=45(19.5 \% \text { of } 231)\end{array}$ & $\begin{array}{l}\text { develop hypertension } \\
n=35(21.3 \% \text { of } 164)\end{array}$ & $\begin{array}{c}\text { develop hypertension } \\
n=8(34.8 \% \text { of } 23)\end{array}$ & $\begin{array}{c}\text { develop hypertension } \\
n=217(14.8 \% \text { of } 1462)\end{array}$ \\
\hline
\end{tabular}

\section{Results}

\section{Baseline characteristics}

Parents of fire victims and controls were comparable regarding gender, insurance type (public or private), history of diseases that may predispose to the development of hypertension, and number of contacts with the family practitioner during the 12 months prior to the disaster (table 5.1). The two groups were not equally distributed among the three practices, however; most parents were registered with practice 3 . In addition, the percentage of persons who were single parents was significantly higher in controls than in parents of fire victims. Correspondingly, the mean family size was significantly lower in controls. Furthermore, parents of fire victims were significantly younger than controls, on average. The three subgroups of parents (parents of victims with burns, parents of victims without burns, and bereaved parents) were comparable with respect to age, gender, insurance type, single parenthood, average family size, number of contacts with the family practitioner during the 12-month pre-disaster period, and the majority of diseases which may predispose to the development of hypertension (table 5.2). They significantly differed with regard to the proportion of persons with a history of asthma or chronic obstructive 
pulmonary disease, with the highest percentage being found in the group of bereaved parents. In addition, the three subgroups of parents were not equally distributed among the three practices.

Table 5.1: Baseline characteristics of 418 parents of fire victims and 1462 controls without evidence of hypertension at baseline

\begin{tabular}{|c|c|c|c|c|c|}
\hline & \multicolumn{2}{|c|}{ Parents $(n=418)$} & \multicolumn{2}{|c|}{$\begin{array}{l}\text { Controls } \\
(\mathrm{n}=1.462) \\
\end{array}$} & \multirow[b]{2}{*}{$\mathrm{p}$ value ${ }^{+}$} \\
\hline & No. & $\%$ & No. & $\%$ & \\
\hline Male & 202 & 48.3 & 694 & 47.5 & 0.757 \\
\hline Public insurance & 252 & 60.3 & 812 & 55.5 & 0.084 \\
\hline \multicolumn{6}{|l|}{ History of... } \\
\hline Hyperlipidemia & 40 & 9.6 & 107 & 7.3 & 0.131 \\
\hline Diabetes & 2 & 0.5 & 20 & 1.4 & 0.195 \\
\hline Cardiovascular diseases & 2 & 0.5 & 13 & 0.9 & 0.405 \\
\hline Migraine & 22 & 5.3 & 56 & 3.8 & 0.195 \\
\hline Asthma/COPD & 31 & 7.4 & 103 & 7.0 & 0.795 \\
\hline Hyperthyroidism & 6 & 1.4 & 23 & 1.6 & 0.840 \\
\hline At least one of the above & 92 & 22.0 & 287 & 19.6 & 0.285 \\
\hline Enrolled at practice 1 & 91 & 21.8 & 452 & 30.9 & $0.000^{* * *}$ \\
\hline Enrolled at practice 2 & 77 & 18.4 & 391 & 26.7 & \\
\hline Enrolled at practice 3 & 250 & 59.8 & 619 & 42.3 & \\
\hline \multirow[t]{2}{*}{ Single parent } & 10 & 2.4 & 109 & 7.5 & $0.000^{* * *}$ \\
\hline & Mean & SD & Mean & SD & \\
\hline Family size & 4.3 & 0.8 & 4.0 & 0.8 & $0.000^{* * *}$ \\
\hline Number of contacts with FP‡ pre-fire & 4.7 & 4.3 & 4.3 & 4.3 & 0.104 \\
\hline Age & 45.9 & 4.4 & 46.4 & 4.8 & $0.033^{*}$ \\
\hline
\end{tabular}

+ Based on two-sided analysis: ${ }^{*} \mathrm{p}<0.05,{ }^{* *} \mathrm{p}<0.01,{ }^{* * *} \mathrm{p}<0.001$ (ANOVA for continuous variables, chi-square tests for discrete variables).

‡ FP family practice. 
Table 5.2: Baseline characteristics of 418 parents without evidence of hypertension at baseline: comparison of parents of victims with burns ( $\mathrm{n}=231)$, parents of victims without burns $(\mathrm{n}=164)$ and bereaved parents $(n=23)$

\begin{tabular}{|c|c|c|c|c|c|c|c|}
\hline & \multicolumn{2}{|c|}{$\begin{array}{c}\text { Parents - } \\
\text { burned } \\
(\mathrm{n}=231)\end{array}$} & \multicolumn{2}{|c|}{$\begin{array}{l}\text { Parents - } \\
\text { unburned } \\
(\mathrm{n}=164)\end{array}$} & \multicolumn{2}{|c|}{$\begin{array}{l}\text { Parents - } \\
\text { bereaved } \\
(\mathrm{n}=23)\end{array}$} & \multirow[b]{2}{*}{$\mathrm{p}$ value $^{\dagger}$} \\
\hline & No. & $\%$ & No. & $\%$ & No. & $\%$ & \\
\hline Male & 110 & 47.6 & 80 & 48.8 & 12 & 52.2 & 0.907 \\
\hline Public insurance & 137 & 59.3 & 98 & 59.8 & 17 & 73.9 & 0.388 \\
\hline \multicolumn{8}{|l|}{ History of... } \\
\hline Hyperlipidemia & 24 & 10.4 & 16 & 9.8 & 0 & 0.0 & 0.270 \\
\hline Diabetes & 2 & 0.9 & 0 & 0.0 & 0 & 0.0 & 0.443 \\
\hline Cardiovascular diseases & 0 & 0.0 & 2 & 1.2 & 0 & 0.0 & 0.211 \\
\hline Migraine & 13 & 5.6 & 9 & 5.5 & 0 & 0.0 & 0.508 \\
\hline Asthma/COPD & 11 & 4.8 & 15 & 9.1 & 5 & 21.7 & $0.007^{* *}$ \\
\hline Hyperthyroidism & 3 & 1.3 & 3 & 1.8 & 0 & 0.0 & 0.761 \\
\hline At least one of the above & 45 & 19.5 & 42 & 25.6 & 5 & 21.7 & 0.350 \\
\hline Enrolled at practice 1 & 68 & 29.4 & 19 & 11.6 & 4 & 17.4 & $0.000^{* * *}$ \\
\hline Enrolled at practice 2 & 40 & 17.3 & 30 & 18.3 & 7 & 30.4 & \\
\hline Enrolled at practice 3 & 123 & 53.2 & 115 & 70.1 & 12 & 52.2 & \\
\hline \multirow[t]{2}{*}{ Single parent $\%$} & 7 & 3.0 & 2 & 1.2 & 1 & 4.3 & 0.418 \\
\hline & Mean & SD & Mean & SD & Mean & SD & \\
\hline Family size & 4.3 & 0.7 & 4.2 & 0.7 & 4.1 & 0.7 & 0.310 \\
\hline \multicolumn{8}{|l|}{ Number of contacts with } \\
\hline $\mathrm{FP} \ddagger$ pre-fire & 4.7 & 4.5 & 4.6 & 4.0 & 4.7 & 5.0 & 0.955 \\
\hline Age & 45.6 & 4.06 & 46.3 & 4.8 & 45.7 & 3.9 & 0.254 \\
\hline
\end{tabular}

+ Based on two-sided analysis: ${ }^{*} \mathrm{p}<0.05,{ }^{* *} \mathrm{p}<0.01,{ }^{* * *} \mathrm{p}<0.001$ (ANOVA for continuous variables, chi-square tests for discrete variables).

‡ FP family practice.

Univariate analysis of patients characteristics in relation to the development of new hypertension

Patients who developed hypertension during the follow-up period more often had a history of diabetes, cardiovascular disease, migraine, and asthma (table 5.3). In addition, more bereaved parents developed hypertension than 
parents of surviving victims. Moreover, persons with incident hypertension had significantly more contacts with their family practitioner during the postfire follow-up period than did patients without incident hypertension, and they were significantly older.

\section{Multivariate analysis}

We examined whether parents of fire victims were more at risk for developing hypertension than controls after adjustment for the covariates age, gender, insurance type, history of chronic disease, number of contacts with the family practitioner during the postfire follow-up period, family practice, and single parenthood. As table 5.4 indicates, the risk of becoming hypertensive during the 4-year follow-up period was 1.48 times higher $(95 \%$ confidence interval $(\mathrm{CI}): 1.09,2.02)$ in parents of fire victims than in controls. We constructed a separate model in order to study differences in risk between the three subgroups of parents and the control group (not shown in table). When compared with controls, bereaved parents had the highest risk of becoming hypertensive (odds ratio $(\mathrm{OR})=2.42,95$ percent CI: $0.90,6.55$ ), followed by parents of victims with burns (OR $=1.43,95$ percent CI: 0.97, 2.11) and parents of victims without burns ( $\mathrm{OR}=1.44$, 95 percent CI: 0.92, 2.26). However, these findings were statistically nonsignificant. We also tested whether the risk of becoming hypertensive was significantly higher in one subgroup than in another. More specifically, the pairs "parents of victims with burns/parents of victims without burns," "parents of victims with burns/bereaved parents," and "parents of victims without burns/bereaved parents" were compared. None of these pairwise comparisons reached statistical significance $(\chi 2=0.00,1 \mathrm{df}$, two-sided $\mathrm{p}=$ 0.964; $\chi 2=1.10,1 \mathrm{df}$, two-sided $\mathrm{p}=0.319 ;$ and $\chi^{2}=1.10,1 \mathrm{df}$, two-sided $\mathrm{p}=$ 0.341 , respectively).

Finally, we examined whether some of the three family practices were more likely to detect hypertension in parents of fire victims than in control parents. The analyses demonstrated that parents of fire victims enrolled with practice 1 were not more likely to be diagnosed with new hypertension than parents of fire victims enrolled with practice $2(\chi 2=2.26,1 \mathrm{df}$, two-sided $\mathrm{p}=$ $0.132)$ or practice $3(\chi 2=1.06,1 \mathrm{df}$, two-sided $\mathrm{p}=0.303)$. Neither were parents of fire victims who were enrolled with practice 2 more likely to be 
diagnosed with new hypertension than parents of fire victims registered with practice $3(\chi 2=0.55,1 \mathrm{df}$, two-sided $\mathrm{p}=0.458$; results not shown in table).

Table 5.3: Patient characteristics according to the presence or absence of incident hypertension

\begin{tabular}{|c|c|c|c|c|c|}
\hline & \multicolumn{4}{|c|}{ Incident hypertension } & \multirow[b]{3}{*}{$p$ value $^{+}$} \\
\hline & \multicolumn{2}{|c|}{ yes $(n=305)$} & \multicolumn{2}{|c|}{ no $(n=1.575)$} & \\
\hline & No. & $\%$ & No. & $\%$ & \\
\hline Male & 135 & 44.3 & 761 & 48.3 & 0.194 \\
\hline Public insurance & 182 & 59.7 & 882 & 56.0 & 0.236 \\
\hline \multicolumn{6}{|l|}{ History of... } \\
\hline Hyperlipidemia & 27 & 8.9 & 120 & 7.6 & 0.463 \\
\hline Diabetes & 8 & 2.6 & 14 & 0.9 & $0.010^{*}$ \\
\hline Cardiovascular diseases & 6 & 2.0 & 9 & 0.6 & $0.012^{*}$ \\
\hline Migraine & 22 & 7.2 & 56 & 3.6 & $0.003^{* *}$ \\
\hline Asthma/COPD & 30 & 9.8 & 104 & 6.6 & $0.045^{*}$ \\
\hline Hyperthyroidism & 5 & 1.6 & 24 & 1.5 & 0.881 \\
\hline At least one of the above & 81 & 26.6 & 298 & 18.9 & $0.002^{* *}$ \\
\hline Enrolled at practice 1 & 84 & 27.5 & 459 & 29.1 & 0.166 \\
\hline Enrolled at practice 2 & 89 & 29.2 & 379 & 24.1 & \\
\hline Enrolled at practice 3 & 132 & 43.3 & 737 & 46.8 & \\
\hline Single parent & 21 & 6.9 & 98 & 6.2 & 0.663 \\
\hline Parents of fire victims & 88 & 28.9 & 330 & 21.0 & 0.002 \\
\hline Parents - victims with burns & 45 & 14.8 & 186 & 11.8 & 0.152 \\
\hline Parents - victims without burns & 35 & 11.5 & 129 & 8.2 & 0.063 \\
\hline \multirow[t]{2}{*}{ Parents - bereaved } & 8 & 2.6 & 15 & 1.0 & $0.015^{*}$ \\
\hline & Mean & SD & Mean & SD & \\
\hline Family size & 4.1 & 0.8 & 4.1 & 0.8 & 0.401 \\
\hline Number of contacts with FP $\ddagger$ during follow- & & & & & \\
\hline up & 31.9 & 17.9 & 19.1 & 15.4 & $0.000^{* * *}$ \\
\hline Age & 47.2 & 5.1 & 46.2 & 4.6 & $0.001^{* *}$ \\
\hline
\end{tabular}

+ Based on two-sided analysis: ${ }^{*} \mathrm{p}<0.05^{* *} \mathrm{p}<0.01{ }^{* * *} \mathrm{p}<0.001$ (ANOVA for continuous variables, chi-square tests for discrete variables).

$\ddagger$ FP family practice. 
A separate model was built in order to study differences in risk between the three subgroups of parents and the control group (not in table). When compared to controls, it appears that bereaved parents have the highest risk of becoming hypertensive (OR 2.42, 95 percent CI 0.90, 6.55), followed by parents of victims with burns (OR 1.43, 95 percent CI 0.97, 2.11) and parents of victims without burns (OR 1.44, 95 percent CI 0.92, 2.26). However, these findings are statistically non-significant. It was also tested whether the risk of becoming hypertensive is significantly higher in one subgroup when compared to one of the other subgroups. More specifically, the pairs 'parents of victims with burns/parents of victims without burns', 'parents of victims with burns/bereaved parents' and 'parents of victims without burns/bereaved' were compared. None of these pairwise comparisons reached statistical significance (chi-square $=0.00, \mathrm{df}=1$, two-sided $\mathrm{p}=0.964$; chisquare=1.10, $\mathrm{df}=1$, two-sided $\mathrm{p}=0.319$; chi-square $=1.10, \mathrm{df}=1$, two-sided $\mathrm{p}=0.341$, correspondingly).

Table 5.4: Multivariate logistic regression with incident hypertension during 4 years of follow-up as dependent variable - comparison of parents $(n=418)$ and controls $(n=1462)$

\begin{tabular}{lcccc}
\hline & OR & \multicolumn{2}{c}{ 95\% CI } & p-value $^{+}$ \\
\hline Age (in years) & 1.07 & 1.03 & 1.10 & $0.000^{* * *}$ \\
Female gender (female=1, male=0) & 1.07 & 0.80 & 1.44 & 0.632 \\
Public insurance (public=1, private=0) & 0.98 & 0.74 & 1.30 & 0.892 \\
History of chronic disease (yes=1, no=0) & 0.86 & 0.62 & 1.19 & 0.360 \\
Number of contacts with FPł during follow-up & 1.04 & 1.03 & 1.05 & $0.000^{* * *}$ \\
Enrolled with practice 1 (yes=1, no=0) & 0.84 & 0.59 & 1.21 & 0.352 \\
Enrolled with practice 3 (yes=1, no=0) & 0.62 & 0.45 & 0.87 & $0.005^{* *}$ \\
Single parent (yes=1, no=0) & 1.06 & 0.62 & 1.82 & 0.839 \\
Parent of a fire victim (parent victim=1, control=0) & 1.48 & 1.09 & 2.02 & $0.012^{*}$ \\
\hline
\end{tabular}

${ }^{+}$Based on two-sided multivariate analysis; ${ }^{*} \mathrm{p}<0.05,{ }^{* *} \mathrm{p}<0.01,{ }^{* * *} \mathrm{p}<0.001$ (Wald chi-square test). $\ddagger$ FP family practice.

$\S$ OR odds ratio, CI confidence interval. 
Finally, it was examined whether some of the three practices are more likely to detect hypertension in parents of fire victims than in controls. The analyses demonstrate that parents of fire victims enrolled with practice 1 are not more likely to be diagnosed with new hypertension when compared to parents of fire victims enrolled with practice 2 (chi-square 2.26, $\mathrm{df}=1$, twosided $\mathrm{p}=0.132$ ) or practice 3 (chi-square 1.06 , $\mathrm{df}=1$, two-sided $\mathrm{p}=0.303$ ). Neither are parents of fire victims who are enrolled with practice 2 more likely to be diagnosed with new hypertension than parents of fire victims registered with practice 3 (chi-square $0.55, \mathrm{df}=1$, two-sided $\mathrm{p}=0.458$; results not in table).

\section{Discussion}

The present study is one of the very few prospective population-based studies of hypertension to have been carried out in a disaster setting. Our results show that being the parent of an adolescent fire victim is independently related to the likelihood of becoming hypertensive. During 4 years of follow-up, the risk of parents' developing hypertension was 1.48 times that of controls (95 percent CI: 1.09, 2.02).

We also examined whether parents of adolescents who had suffered burn injuries during the disaster were more at risk for new hypertension than parents of adolescents who had been present but remained uninjured. The underlying assumption was that having a child who is suffering from burn injuries is especially distressing due to the high burden of care associated with burns (25). Another hypothesis was that parents who had lost a child due to the fire were more at risk of developing hypertension than parents whose child survived the disaster (26). None of the two assumptions was supported by our data, however. In the case of bereaved parents, the sample was very small, and therefore significant differences were hard to detect. In the case of parents of children with burns, the result was more surprising. One explanation could be that both groups were equally distressed. Another explanation could be that there were more stress-reducing interventions available to parents of victims with burns than to parents of victims who survived the catastrophe without burns. Neither can we exclude the 
possibility that community support was lower for these parents, since at first glance they may have seemed more fortunate than parents of burn victims. It should not be forgotten, however, that caring for an adolescent who has survived a life-threatening incident but has witnessed friends or family members die at the site can also be difficult (27).

As with any epidemiological study, there are limitations to our analysis. Firstly, one could criticize the fact that we measured "exposure to disaster" (being the parent of a fire victim) and not disaster-related distress itself, which was assumed to result from exposure. Indeed, a direct assessment of the level of disaster-related stress among patients conducted by means of psychometric questionnaires or interviews could have shed more light on the underlying mechanisms that may link exposure to hypertension. There is no doubt, however, that this group of parents was considerably distressed. Another study of the same parents indicated that they contacted their family practitioners more often for problems related to mental health than did controls (28). This effect was sustained throughout the 3 years after the event (28). Interestingly, as in the present study on hypertension, no differences were found between parents of victims with burns and parents of victims who had survived the fire without physical injuries.

A second limitation concerns the lack of information on obesity, smoking, and alcohol use, all of which are important causes of hypertension. Equally, it is unknown how lifestyle changes (which occur as a consequence of disaster-related stress) or psychosocial interventions that were provided in the aftermath of the disaster influenced the results (29). Thirdly, one could speculate that parents of disaster victims are more likely to be examined for potential health problems. Therefore, the chance of detecting abnormal blood pressure in these parents could have been higher than in controls. Although such detection bias could not be directly assessed in our data, we carried out additional analyses to examine this issue indirectly. A generalized detection bias would be expected to also operate on other medical conditions of which patients were unaware. We therefore checked the incidence of diabetes and hyperlipidemia during the follow-up period in both parents of fire victims and control parents. None of the two conditions provided evidence for a systematic distortion of results. In addition, we 
controlled for the number of contacts with the family practitioner in our analyses in order to minimize the effects of a potential detection bias.

Finally, the Volendam disaster occurred in a close-knit community and probably had a disruptive effect on social networks. It is possible that some of the patients in the community control cohort were relatives or friends of the affected families. Therefore, we cannot exclude the possibility that some of the community controls were also distressed and prone to the development of new hypertension. Should this have been the case, however, it is even more surprising that differences between the two groups were found.

Next to these limitations, the study has several strengths. One is the use of physician-verified diagnoses and prescriptions. This kind of data is preferable because it is not prone to recall bias. Moreover, in the current study, the definition of hypertension was rather strict, since the diagnosis was assigned only when several measurements had yielded significantly elevated blood pressure levels or when the elevation was significant enough to necessitate pharmacologic treatment. This guaranteed that only clinically significant cases of hypertension were captured. Therefore, if anything, the incidence of hypertension was underestimated rather than overestimated in our study.

Another strength of the study is that selection bias can be virtually excluded, since the patients were anonymously monitored. Because of this procedure, loss to follow-up was due only to patients' leaving the medical practice (e.g., dying or moving away) and not to other reasons common in studies based on questionnaires or interviews. Finally, the prospective design and the long follow-up period of the study were exceptional.

In general, the long-term effects described here are in line with the findings of Cwikel et al. (10), who studied immigrants to Israel who had been exposed to the Chernobyl disaster. At the same time, it contradicts the findings of Trevisan et al. (12), who did not find long-term effects in their study of workers exposed to an earthquake. Note that Trevisan et al. studied coronary heart disease risk factors in general and did not specifically 
examine hypertension. Also, one should not forget that a mass burn incident constitutes a different type of exposure than an earthquake or a terrorist attack. Clearly, the parents included here did not experience a threat to their own lives; rather, they were caregivers of potentially traumatized victims. The results presented here are therefore in line with the literature on secondary traumatic stress or "compassion fatigue," which describes adverse effects on persons who are psychologically close to a victim (30).

Based on the finding that parents of adolescent disaster victims are more at risk of developing hypertension, two conclusions can be drawn. On the one hand, the finding emphasizes the impact stressful life situations can have on people's health. It is therefore important to provide interventions that help people fight the negative effects of disaster-related stress, be they short-term or long-term. This is of public health importance, because a substantial proportion of cardiovascular disease is attributable to hypertension. On the other hand, the study demonstrates that disasters or traumatic experiences affect not only those who are directly exposed but also those who are close to the victims. This points to the need to incorporate a family perspective when planning post-disaster interventions.

\section{Acknowledgements}

The Dutch Ministry of Health financially supported this study. We thank all family practitioners and pharmacies in Volendam for the provision of data and Petra ten Veen for the data management. 


\section{References}

1. Norris FH, Friedman MJ, Watson PJ, et al. 60,000 disaster victims speak: part I. An empirical review of the empirical literature, 1981-2001. Psychiatry 2002; 65:207-39.

2. Yzermans CJ, Donker GA, Kerssens JJ, et al. Health problems of victims before and after disaster: a longitudinal study in general practice. Int J Epidemiol 2005; 34:810-19.

3. Kario K, McEwen BS, Pickering TG. Disasters and the heart: a review of the effects of earthquake-induced stress on cardiovascular disease. Hypertens Res 2003; 26:355-67.

4. Ford, DE. Depression, trauma, and cardiovascular health. In: Green BL, Schnurr PP, eds. Trauma and health: physical health consequences of exposure to extreme stress. Washington, DC: American Psychological Association, 2004; 73-97.

5. Armenian HK, Melkonian AK, Hovanesian AP. Long term mortality and morbidity related to degree of damage following the 1998 earthquake in Armenia. Am J Epidemiol 1998; 148:1077-84.

6. Parati G, Antonicelli R, Guazzarotti F, et al. Cardiovascular effects of an earthquake: direct evidence by ambulatory blood pressure monitoring. Hypertension 2001; 38:1093-5.

7. Saito K, Kim JI, Maekawa K, et al. The great Hanshin-Awaji earthquake aggravates blood pressure control in treated hypertensive patients. Am J Hypertens 1997; 10:217-21.

8. Mecocci P, Di Iorio AD, Pezzuto S, et al. Impact of the earthquake of September 26, 1997 in Umbria, Italy on the socioenvironmental and psychophysical conditions of an elderly population. Aging (Milano) 2000; 12:281-6.

9. Bland SH, Farinaro E, Krogh V, et al. Long term relations between earthquake experiences and coronary heart disease risk factors. Am J Epidemiol 2000; 151:1086-90.

10. Cwikel JG, Goldsmith JR, Kordysh E, et al. Blood pressure among immigrants to Israel from areas affected by the Chernobyl disaster. Public Health Rev 1997; 25:317-35.

11. Gerin W, Chaplin W, Schwartz JE, et al. Sustained blood pressure increase after an acute stressor: the effects of the 11 September 2001 attack on the New York City World Trade Center. J Hypertens 2005; 23:279-84.

12. Trevisan M, Jossa F, Farinaro E, et al. Earthquake and coronary heart disease risk factors: a longitudinal study. Am J Epidemiol 1992; 135:632-7.

13. Welling $L$, van Harten SM, Patka $P$, et al. The café fire on New Year's Eve in Volendam, the Netherlands: description of events. Burns 2005; 31:548-54.

14. Barnes, Michael F. Understanding the secondary traumatic stress of parents. In: Figley CR, eds. The systemic costs of caring. Boca Raton, FL: CRC Press, 1998; 75-89.

15. Pickering TG. Mental stress as a causal factor in the development of hypertension and cardiovascular disease. Curr Hypertens Rep 2001; 3:249-54.

16. Jonas BS, Lando JF. Negative affect as a prospective risk factor for hypertension. Psychosom Med 2000; 62:188-96.

17. Jonas BS, Franks P, Ingram DD. Are symptoms of anxiety and depression risk factors for hypertension? Longitudinal evidence from the National Health and Nutrition Examination Survey I Epidemiological Follow-up Study. Arch Fam Med 1997; 6:43-9. 
18. Levenstein S, Smith MW, Kaplan GA. Psychosocial predictors of hypertension in men and women. Arch Intern Med 2001; 161:1341-6.

19. Raikkonen K, Matthews KA, Kuller LH. Trajectory of psychological risk and incident hypertension in middle-aged women. Hypertension 2001; 38:798-802.

20. Centraal Bureau voor de Statistiek. Gemeente op maat-Edam-Volendam. Voorburg, the Netherlands: Centraal Bureau voor de Statistiek, 2004.

21. Boerma WGW, Fleming DM. The role of general practice in primary health care. London, United Kingdom: The Stationery Office, 1998.

22. Lamberts H, Wood M. ICPC: International Classification of Primary Care. Oxford, United Kingdom: Oxford University Press, 1987.

23. WHO Collaborating Centre for Drug Statistics Methodology, Norwegian Institute of Public Health. About the ATC/DDD system. Oslo, Norway: WHO Collaborating Centre for Drug Statistics Methodology, 2006. (http://www.whocc.no/atcddd/).

24. Snijder TB, Bosker R. Multilevel analysis: an introduction to basic and advanced multilevel modeling. Thousand Oaks, CA: Sage Publications, 1999.

25. Van Loey NE, Van Son MJ. Psychopathology and psychological problems in patients with burn scars: epidemiology and management. Am J Clin Dermatol 2003; 4:245-72.

26. O'Connor MF, Allen JJ, Kaszniak AW. Autonomic and emotion regulation in bereavement and depression. J Psychosom Res 2002; 52:183-5.

27. Balk DE, Corr CA. Bereavement during adolescence: a review of research. In: Stroebe MS, ed. Handbook of bereavement research: consequences, coping, and care. Washington, DC: American Psychological Association, 2001; 199-218.

28. Dorn T, Yzermans CJ, Kerssens JJ, et al. Disaster and subsequent health care utilization -a longitudinal study among victims, their family members and controls. Med Care 2006; 44:581-9.

29. Vlahov D, Galea S, Resnick H, et al. Increased use of cigarettes, alcohol, and marijuana among Manhattan, New York, residents after the September 11th terrorist attacks. Am J Epidemiol 2002; 155:988-96.

30. Figley, Charles R. Burnout as systemic traumatic stress: a model for helping traumatized family members. In: Figley CR, eds. The systemic costs of caring. Boca Raton, FL: CRC Press, 1998; 15-28. 
Chapter 5 


\section{Chapter}

\section{Primary health care utilization}

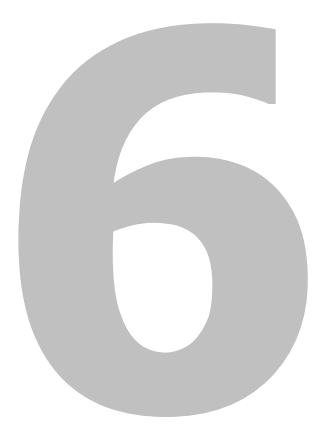

This chapter was published as:

Dorn $T$

Yzermans $C J$

Kerssens JJ

Spreeuwenberg PM

van der Zee J

Disaster and subsequent health care utilization - a longitudinal study among victims, their family members and control subjects

Medical Care, 2006; 44(6):581-9 


\begin{abstract}
Background The impact of disasters on primary health care utilization is largely unknown. Moreover, it is often overlooked how disaster affects those closest to the primary victims, their family members.
\end{abstract}

Objectives To examine the long-term effects of a catastrophic fire on primary health care utilization.

Research Design Prospective, population-based cohort study, covering one year pre- and three years post-fire. Utilization data were extracted from primary care records.

Subjects 286 disaster victims, 802 family members of disaster victims, 3722 community controls, and 10230 patients from a national reference population.

Measures As outcome measures, we study (1) the annual number of contacts in primary care and (2) the annual number of contacts for problems related to mental health. Determinants are injury characteristics of victims and bereavement. All analyses control for age, gender and insurance status.

Results Being an uninjured victim who witnessed the disaster increases the number of contacts by a factor of 1.55 during the first year post-fire $(95 \% \mathrm{CI}$ 1.35-1.78). Uninjured victims contact the family practitioner more often for mental health related problems than adolescent community controls (OR $4.54,95 \%$ CI 1.69-12.20). In adult family members, the loss of a child predicts overall utilization (OR 1.88, 95\% CI 1.35-2.63) and utilization for mental health (OR 8.69, 95\% CI 2.10-35.92) during the first year post-fire.

Conclusion Attention should be paid to the primary care needs of bereaved individuals and those who have witnessed the disaster. 


\section{Introduction}

Disasters are sudden events that have the potential to terrify and cause substantial losses for many people simultaneously (1). Disasters inevitably lead to increased health care utilization due to deaths, injuries or illnesses in the affected community. How long these effects persist depends on the nature of the disaster and, of course, on the nature of the physical injuries (2). Severe injuries requiring immediate trauma care occur mainly at the time of impact, whereas mental health effects may persist on the long-term (3). Reactions to disaster such as depression, anxiety, substance abuse and posttraumatic stress disorder have been studied extensively (4). As recent research into the effect of trauma on health suggests, these reactions may also lead to increased service utilization in victims (5-8).

The present study deals with primary health care utilization prior to and after a fire catastrophe. The fire occurred on January 1st, 2001 in Volendam, the Netherlands. Volendam has about 20,000 inhabitants and is a former fishing town located 20 miles north of Amsterdam. The fire erupted in an overcrowded café-bar where about 350 adolescents were celebrating new year's eve. Due to the fire, 14 adolescents lost their lives and about 240 were hospitalized (9). The current study is based on the follow-up of cohorts identified from electronic medical records in family practice. Since the study uses already existing registrations, baseline information is available as well. This design is exceptional in disaster research, since the effects of disasters usually can only be studied retrospectively due to their sudden and unexpected nature. In fact, there are very few longitudinal studies that compare effects before and after exposure, and even fewer studies that consider health care utilization as an outcome (10). Furthermore, most studies examining the relationship between trauma and health care utilization have relied solely on self-report. Unfortunately, self-reported utilization data can be substantially distorted, with the distortion becoming more pronounced as time increases (11-13). For the planning of services, therefore, automated utilization data captured in existing registrations are most desirable (14). 
It is obvious that service utilization increases in victims who have been directly affected by a disaster. It is less clear, however, how disaster affects the utilization rates of others who are psychologically close to the victim. Traumatic experiences of one member can challenge the entire support system of the victim, causing high levels of distress in those who try to help the traumatized or suffering person. In the literature, the concepts of "secondary exposure" or "compassion stress" are used in order to explain adverse outcomes in family members and other supporters (15). Caring for a survivor can be emotionally draining, particularly when the victim is in need of prolonged medical treatment, as it is the case in burn injuries (16). The research on the health of family members of burn victims, however, is scarce and has produced inconsistent results. Usually, psychological outcomes have been studied, but never health care utilization (17-21). Furthermore, the sudden and unexpected death of a child is one of the most stressful events to happen to any family (22). Bereaved individuals may suffer from lowered immune functions, more somatic complaints, interpersonal difficulties and react with more adverse health behaviors (2325). It is therefore expected that those living with a disaster victim and those who have lost a family member due to the disaster will have higher primary care utilization rates than unexposed controls. To our knowledge, this is the first study investigating these hypotheses. In order to shed light on the community impact of the fire, the utilization of community members is compared to national reference data.

To summarize, the aim of the present study is to examine the long-term effects of exposure to a catastrophic fire on primary health care utilization. For this purpose, the utilization rates of victims with and without burns, their family members, community controls and a national reference population are compared. Two outcome measures are presented: (1) health care utilization in general and, more specifically, (2) utilization related to mental health problems. 


\section{Methods}

This cohort study covers a period starting one-year pre-fire up to three-years post-fire (January 1, 2000 until January 1, 2004). Data are collected at the practices of family practitioners (FPs). In the Netherlands, every citizen is listed with one family practice. Direct access to specialist care is limited by the gate-keeping function of the FP. In one year's time, more than $75 \%$ of the Dutch population will see their FP at least once, and more than $90 \%$ at least once every 3 years (26).

\section{Sampling of cohorts}

Identification of victims

According to official estimates, about 300-350 people were in the building at the time of the fire. Within one month after the fire, all local family practices $(n=4)$ were contacted with the request to identify all patients who had been present during the fire (the deceased and all patients with and without physical injuries). The family practices identified 335 patients in their registrations. One family practice was not yet using electronic registrations, however. This lead to a total of three practices participating. The 335 patients originally identified in family practice were distributed among participating and non-participating practices as follows: 286 of the survivors belonged to the participating practice and 35 to the non-participating practice. The 14 deceased adolescents (and their families) were all registered with the participating practices. Characteristics of survivors enrolled in the nonparticipating practice $(n=35)$ were compared with those of survivors enrolled with the participating practices $(n=286)$. Victims included in the final study sample did not significantly differ from non-participants with respect to burn size, number of days in hospital, gender, age or insurance status. Victims with burn injuries had a mean total burned surface area of $14.9 \%$ $(\mathrm{SD}=17.1)$ and spent, on average, 34.2 days in hospital during the first 12 months after the disaster $(\mathrm{SD}=59.3)$.

\section{Identification of family members of victims}

With the help of the electronic patient registration, we identified all cohabiting family members of deceased and/or surviving victims $(\mathrm{n}=802)$. The disaster victims are distributed among 270 families, with 30 families 
being multiply affected ( 28 families: two survivors, 2 families: one child surviving, one child dead).

\section{Sampling of community controls}

From the three participating FP practices, we selected (1) all adolescents belonging to single or two-parent families, within the age range of 14-20, who had not been present during the fire and (2) their cohabiting family members. This results in a sample of 3722 patients, distributed among 954 family units.

\section{Sampling of national reference}

According to the same criteria as the community controls, we sampled 10230 patients from the LINH (Netherlands Information Network of General Practice) database (27). These patients belong to 15 different communities spread throughout the Netherlands. The sample counts 2541 family units.

All cohorts (victims, family members, community controls and national reference) are mutually exclusive. As an inclusion criterion, all patients had to be enrolled at least 12 months before the disaster in order to guarantee base-line data. None of the disaster victims, 2 of their family members, 49 community controls and 148 patients from the national reference population were excluded as a consequence of this eligibility criterion.

Table 6.1a, $6.1 \mathrm{~b}$ and $6.1 \mathrm{c}$ provide the characteristics of all cohorts. 
Table 6.1a: Patient characteristics at baseline - victims

\begin{tabular}{lrrr}
\hline & $\begin{array}{r}\text { Victims with burns } \\
\mathrm{n}=162\end{array}$ & $\begin{array}{r}\text { Victims without burns } \\
\mathrm{n}=124\end{array}$ \\
\hline Gender & & & \\
Male (\%) & $107(66.0)$ & $66(53.2)$ & $*$ *a \\
Female (\%) & $55(34.0)$ & $58(46.8)$ & \\
Mean age (sd) & $16.9(2.1)$ & $17.8(2.9)$ & $*$ b \\
Insurance & & & \\
Private (\%) & $34(21.0)$ & $22(17.7)$ & n.s \\
Public (\%) & $128(79.0)$ & $102(82.3)$ & \\
Burnsc(\%) & $0(0.0)$ & $9(7.3)$ & \\
Bereaved $\mathbf{d}(\%)$ & $2(1.2)$ & $0(0.0)$ & \\
\hline
\end{tabular}

a Chi-square test.

b ANOVA.

c Person lives with a burned victim.

d Person has lost a family member due to the fire.

* Significant at $\mathrm{p}<0.05,{ }^{* *}$ significant at $\mathrm{p}<0.01,{ }^{* * *}$ significant at $\mathrm{p}<0.001$, n.s. not significant.

Table 6.1b: Patient characteristics at baseline - adolescents

\begin{tabular}{lrrrr}
\hline & $\begin{array}{r}\text { Family of victims } \\
\mathrm{n}=303\end{array}$ & $\begin{array}{r}\text { Community controls } \\
\mathrm{n}=1966\end{array}$ & $\begin{array}{r}\text { National reference } \\
\mathrm{n}=5.616^{\mathrm{e}}\end{array}$ & \\
\hline $\begin{array}{l}\text { Gender } \\
\text { Male (\%) }\end{array}$ & & & & \\
Female (\%) & $166(54.8)$ & $1.068(54.3)$ & $2.994(53.3)$ & n.s. $^{\text {a }}$ \\
Mean age (sd) & $137(45.2)$ & $898(45.7)$ & $2.622(46.7)$ & \\
Insurance & $16.2(5.0)$ & $16.2(4.6)$ & $15.9(4.5)$ & $* *$ b \\
Private (\%) & & & & \\
Public (\%) & $117(38.6)$ & $700(35.6)$ & $2.408(42.9)$ & $* * *$ a \\
Burnsc(\%) & $186(61.4)$ & $1.266(64.4)$ & $3.208(57.1)$ & \\
Bereaved ${ }^{\mathrm{d}(\%)}$ & $169(55.8)$ & - & - & \\
\hline
\end{tabular}

a Chi-square test.

b ANOVA.

c Person lives with a burned victim.

d Person has lost a family member due to the fire.

e Source: National Information Network of GPs (LINH).

* Significant at $\mathrm{p}<0.05,{ }^{* *}$ significant at $\mathrm{p}<0.01,{ }^{* * *}$ significant at $\mathrm{p}<0.001$, n.s. not significant. 
Table 6.1c: Patient characteristics at baseline - adults

\begin{tabular}{|c|c|c|c|c|}
\hline & $\begin{array}{r}\text { Family of victims } \\
n=499\end{array}$ & $\begin{array}{r}\text { Community controls } \\
\mathrm{n}=1.756\end{array}$ & $\begin{array}{r}\begin{array}{r}\text { National reference } \\
\mathrm{n}=4.614\end{array} \\
\end{array}$ & \\
\hline \multicolumn{5}{|l|}{ Gender } \\
\hline Male (\%) & 238 (47.7) & 841 (47.9) & $2.191(47.5)$ & n.s. ${ }^{a}$ \\
\hline Female (\%) & $261(52.3)$ & $261(52.1)$ & $2.423(52.5)$ & \\
\hline Mean age (sd) & $46.2(4.6)$ & $46.7(4.8)$ & $46.5(5.1)$ & *b \\
\hline \multicolumn{5}{|l|}{ Insurance } \\
\hline Private (\%) & 195 (39.1) & $773(44.0)$ & 1.829 (39.6) & $* *_{\mathrm{a}}$ \\
\hline Public (\%) & $304(60.9)$ & $983(56.0)$ & 2.785 (60.4) & \\
\hline Burnsc(\%) & 277 (55.5) & - & - & \\
\hline Bereaved $^{\mathrm{d}}(\%)$ & $27(5.4)$ & - & - & \\
\hline
\end{tabular}

a Chi-square test.

b ANOVA.

c Person lives with a burned victim.

d Person has lost a family member due to the fire.

e Source: National Information Network of GPs (LINH).

* Significant at $\mathrm{p}<0.05,{ }^{*}$ significant at $\mathrm{p}<0.01,{ }^{* * *}$ significant at $\mathrm{p}<0.001$, n.s. not significant.

\section{Outcome measures}

A contact is defined as any professional interchange between a patient and members of the FP practice (doctor or assistant). These contacts can be either direct (face-to-face) or indirect (e.g. telephone calls, repeat prescriptions). All contacts are registered electronically. If a patient has had several entries on the same day, this is counted as one contact in our analyses. We present two outcomes: (1) overall utilization (all contacts, including contacts for mental health), (2) utilization related to mental health (contacts for mental health only).

\section{Overall utilization}

In order to obtain the annual utilization per patient, we calculated a sum score of all contacts within one year's time. If a patient did not seek contact with the FP practice within one year, the sum score for that year was 0 . Patients who were enrolled less than 6 months of a year in question (i.e. due to death or moving away) were excluded from the analysis since the estimate could be imprecise for patients with an insufficiently long 
observation period (community controls: 150 cases; family members: 9 cases). The annual utilization of patients who were enrolled more than 6 months of a year, but less than 12 months, was estimated based on their utilization during the months they were enrolled (community controls: 32 cases; family members: 2 cases; victims without burns: 1 case; national reference: 81 cases). This procedure provides a valid estimate of utilization rates and has been applied earlier by Armstrong and colleagues (28).

\section{Utilization related to mental health}

The FPs classified a patient's health problem according to the International Classification of Primary Care (ICPC). The ICPC is an internationally endorsed classification system which is compatible to the ICD-10 (29). Mental health problems are defined as listed in the $\mathrm{P}$ ('psychological') and $\mathrm{Z}$ ('social') chapter of the ICPC. Data on utilization related to mental health are available for victims and community controls only.

\section{Covariates}

Covariates include variables that could possibly confound the relationship between exposure and utilization such as age, gender and insurance status (30-34). The last variable can be used as an indicator for socio-economic status, since privately insured patients have a higher income than publicly insured patients (only $40 \%$ of the Dutch population have private insurance; approximately $60 \%$ of the population are insured through a compulsory insurance for any citizen with an annual income below a specific level).

\section{Analysis}

Patient characteristics are compared using one-way ANOVA or chi-squaretests (table 6.1a, 6.1b and 6.1c). For both outcome measures, overall utilization and utilization related to mental health problems, the unadjusted mean annual utilization and the percentage of patients with zero utilization are presented in table $6.2 \mathrm{a}, 6.2 \mathrm{~b}$ and $6.2 \mathrm{c}$. The distribution of utilization is heavily right-skewed and resembles a Poisson distribution. The mean and variance of the number of contacts per year are very different. We therefore fitted Poisson regression models that allow for overdispersion. The models in table $6.3 \mathrm{a}$ and $6.3 \mathrm{~b}$ each compare the utilization of two groups. The models in table $6.4 \mathrm{a}$ and table $6.4 \mathrm{~b}$ focus on family members only and try to 
answer the question whether living with a burned child or being bereaved has an impact on utilization. All analyses were carried out with the MLwiN software package. Multi-level modeling was chosen since it accounts for the dependency of observations in our study $(35 ; 36)$.

The models 4 and 6 (table 6.3a) are four-level models (level 1: measurement occasion, level 2: patient, level 3: family, level 4: practice). All other models are three-level models. They are based on three practices only. In this case, practice was not modeled as a level but instead entered as a dummy variable. In order to get stable estimates for model 1 (table 6.4c), we also ignored the family level. For one model, we were not able to get estimates at all (a model equivalent to model 3, table 6.4c, but then for adolescent family members). It is therefore not reported. All models control for the influence of age, gender and insurance status in the fixed part of the model (coefficients not displayed in tables). The four years of the study $(2000,2001,2002,2003)$ are dummy-coded, with 2000 (the year pre-fire) as the reference category.

\section{Results}

\section{Descriptive analysis}

Table $6.2 \mathrm{a}, 6.2 \mathrm{~b}$ and $6.2 \mathrm{c}$ provide descriptive statistics on each cohort's annual utilization and the percentage of patients with zero utilization per year. The year 2000, the year before the fire, provides the baseline for all comparisons. Differences in utilization at baseline can be noted in the different comparison groups. Furthermore, in both victims with and without burns, a strong increase in number of contacts can be seen during the first year after the fire (2001). Victims with burns contact their FP about 4 times more often than before the fire, victims without burns about 1.5 times. In children who belong to the same age group, a slight increase from 2000 to 2001 can be observed. In the adult group, the same is the case in community controls and the national reference group. Adult family members of fire victims contact their FP on average 1 time more often per year than before the disaster. In community controls and the national reference group, the increase is minimal: 0.2 and 0.1 contacts per year. In addition, in adult family members of disaster victims, the rate of patients who have zero utilization 
(those who do not contact the FP practice) drops from 11.2 to $7.2 \%$ during the year 2001. In the other two groups (community and national reference) the percentage roughly remains at the same level. Changes in utilization related to mental health can be observed, too. After the fire, the mean utilization for mental health increases in both victims with and without burns, whereas the mean utilization of community controls (adult and adolescent) remains stable in the course of the 4 years. The percentage of patients with zero utilization for mental health declines in all groups after the fire, with the exception of adult community controls.

Table 6.2a: Unadjusted mean annual utilization (Q1;Q3) for primary care and percentage of patients with zero utilization in victims

\begin{tabular}{lrrr}
\hline & Year & Victims with burns & Victims without burns \\
\hline Mean utilization (overall) & 2000 & $3.2(1 ; 5)$ & $4.6(2 ; 6)$ \\
& 2001 & $13.2(6 ; 18)$ & $7.7(4 ; 10)$ \\
& 2002 & $7.5(3 ; 10)$ & $6.6(4 ; 9)$ \\
& 2003 & $6.9(3 ; 9)$ & $6.2(1 ; 8)$ \\
\% with zero utilization (overall) & 2000 & & \\
& 2001 & 21.6 & 8.9 \\
& 2002 & 2.5 & 1.6 \\
& 2003 & 4.9 & 3.2 \\
Mean utilization (mental) & & 1.9 & \\
& 2000 & & $0.1(0 ; 0)$ \\
& 2001 & $0.4(0 ; 0)$ & $0.5(0 ; 0)$ \\
& 2002 & $0.2(0 ; 0)$ & $0.3(0 ; 0)$ \\
& 2003 & $0.2(0 ; 0)$ & $0.3(0 ; 0)$ \\
& & & \\
& 2000 & 98.8 & 92.7 \\
& 2001 & 79.6 & 66.1 \\
& 2002 & 89.5 & 85.5 \\
& 2003 & 86.4 & 89.4 \\
Number included in analyses & 2000 & & \\
& 2001 & 162 & 124 \\
& 2002 & 162 & 124 \\
& 2003 & 162 & 124 \\
& & 162 & 124 \\
\hline
\end{tabular}

${ }^{a} \mathrm{Q} 1:$ 25th percentile, Q3: 75th percentile. 
Chapter 6

Table 6.2b: Unadjusted mean annual utilization (Q1;Q3) ${ }^{\mathrm{a}}$ for primary care and percentage of patients with zero utilization in adolescents

\begin{tabular}{|c|c|c|c|}
\hline & Family of victims & Community controls & National reference ${ }^{b}$ \\
\hline \multicolumn{4}{|c|}{ Mean utilization (overall) } \\
\hline 2000 & $3.2(1 ; 5)$ & $3.0(1 ; 4)$ & $3.1(0 ; 4)$ \\
\hline 2001 & $3.8(1 ; 6)$ & $3.3(1 ; 5)$ & $3.3(0 ; 5)$ \\
\hline 2002 & $4.5(1 ; 6)$ & $3.9(1 ; 5)$ & $3.4(0 ; 5)$ \\
\hline 2003 & $4.3(1 ; 7)$ & $3.8(1 ; 5)$ & $3.7(0 ; 5)$ \\
\hline \multicolumn{4}{|c|}{$\begin{array}{l}\% \text { with zero utilization } \\
\text { (overall) }\end{array}$} \\
\hline 2000 & 19.5 & 22.4 & 29.0 \\
\hline 2001 & 18.5 & 22.0 & 27.2 \\
\hline 2002 & 12.6 & 16.7 & 27.6 \\
\hline 2003 & 14.3 & 22.0 & 25.5 \\
\hline \multicolumn{4}{|c|}{ Mean utilization (mental) } \\
\hline 2000 & $0.0(0 ; 0)$ & $0.1(0 ; 0)$ & - \\
\hline 2001 & $0.1(0 ; 0)$ & $0.1(0 ; 0)$ & - \\
\hline 2002 & $0.1(0 ; 0)$ & $0.1(0 ; 0)$ & - \\
\hline 2003 & $0.1(0 ; 0)$ & $0.1(0 ; 0)$ & - \\
\hline \multicolumn{4}{|c|}{$\begin{array}{l}\text { \% with zero utilization } \\
\text { (mental) }\end{array}$} \\
\hline 2000 & 97.4 & 96.7 & - \\
\hline 2001 & 91.1 & 94.4 & - \\
\hline 2002 & 96.0 & 94.4 & - \\
\hline 2003 & 94.7 & 94.5 & - \\
\hline \multicolumn{4}{|c|}{ Number included in analyses } \\
\hline 2000 & 303 & 1.966 & 5.616 \\
\hline 2001 & 303 & 1.965 & 5.613 \\
\hline 2002 & 301 & 1.944 & 5.438 \\
\hline 2003 & 300 & 1.908 & 5.277 \\
\hline
\end{tabular}

${ }^{a}$ Q1: 25th percentile, Q3: 75th percentile.

b Source: National Information Network of GPs (LINH). 
Table 6.2c: Unadjusted mean annual utilization (Q1;Q3) ${ }^{\mathrm{a}}$ for primary care and percentage of patients with zero utilization in adults

\begin{tabular}{|c|c|c|c|}
\hline & Family of victims & Community controls & National reference $^{b}$ \\
\hline \multicolumn{4}{|c|}{$\begin{array}{l}\text { Mean utilization } \\
\text { (overall) }\end{array}$} \\
\hline 2000 & $5.3(2 ; 7)$ & $4.8(1 ; 7)$ & $5.9(1 ; 8)$ \\
\hline 2001 & $6.2(2 ; 9)$ & $5.0(1 ; 7)$ & $6.0(1 ; 8)$ \\
\hline 2002 & $6.2(2 ; 9)$ & $5.2(2 ; 7)$ & $6.1(1 ; 8)$ \\
\hline 2003 & $6.7(3 ; 9)$ & $5.7(2 ; 8)$ & $6.5(2 ; 9)$ \\
\hline \multicolumn{4}{|c|}{$\%$ with zero utilization overall } \\
\hline 2000 & 11.2 & 13.7 & 16.5 \\
\hline 2001 & 7.2 & 15.0 & 16.2 \\
\hline 2002 & 10.0 & 14.0 & 15.5 \\
\hline 2003 & 7.1 & 14.8 & 15.3 \\
\hline \multicolumn{4}{|c|}{$\begin{array}{l}\text { Mean utilization } \\
\text { (mental) }\end{array}$} \\
\hline 2000 & $0.2(0 ; 0)$ & $0.2(0 ; 0)$ & - \\
\hline 2001 & $0.6(0 ; 0)$ & $0.2(0 ; 0)$ & - \\
\hline 2002 & $0.3(0 ; 0)$ & $0.2(0 ; 0)$ & - \\
\hline 2003 & $0.3(0 ; 0)$ & $0.2(0 ; 0)$ & - \\
\hline \multicolumn{4}{|c|}{$\%$ with zero utilization (mental) } \\
\hline 2000 & 89.2 & 88.5 & - \\
\hline 2001 & 76.2 & 88.0 & - \\
\hline 2002 & 85.5 & 89.0 & - \\
\hline 2003 & 86.5 & 90.4 & - \\
\hline \multicolumn{4}{|c|}{ Number included in analyses } \\
\hline 2000 & 499 & 1.756 & 4.614 \\
\hline 2001 & 499 & 1.752 & 4.614 \\
\hline 2002 & 498 & 1.735 & 4.543 \\
\hline 2003 & 496 & 1.712 & 4.477 \\
\hline
\end{tabular}

${ }^{a} \mathrm{Q} 1:$ 25th percentile, Q3: 75th percentile.

b Source: National Information Network of GPs (LINH).

\section{Multivariate results}

In a second step, the unadjusted utilization data as presented in table 6.2 are submitted to statistical testing. The results (incidence rate ratios, 95\% confidence intervals, chi-square values, degrees of freedom and p-values for 
contrasts) are displayed in tables $3 \mathrm{a}, 3 \mathrm{~b}, 4 \mathrm{a}$ and $4 \mathrm{~b}$. All models compare each year after the fire with the year before the fire; the interaction terms indicate whether the risk for contacting the family practitioner is higher in patients belonging to one group than in patients belonging to the comparison group during the year in question, holding all other variables in the equation constant.

\section{Overall and Mental Health Utilization}

In the year 2001, the risk for contacting the FP for victims with burns is 2.43 times the risk for victims without burns (95\% CI 1.98-2.99). In 2002, this is 1.61 (95\% CI 1.29-2.01), and in 2003 it is 1.60 (95\% CI 1.26-2.02) (model 1, table 6.3a). When looking at utilization related to mental health (model 1, table 6.3b), it turns out that in both victims with and victims without burns, in each year after the fire, utilization for mental health is higher than before the fire (year 2001: OR 7.68, 95\% CI 3.66-16.09; year 2002: OR 3.71, 95\% CI 1.57-8.76; year 2003: OR 3.82, 95\% CI 1.46-9.99). The interaction terms do not contribute to the model significantly, indicating that victims with and victims without burns do not differ in respect to their utilization for mental health related problems.

Victims without burns and adolescent community controls both show an increase in utilization in the years 2001, 2002 and 2003 (model 2, table 6.3a). In the year 2001, however, the risk for contacting the FP for victims without burns is 1.55 times the risk for adolescent community controls (OR 1.55, 95\% CI 1.35-1.78). In addition, in 2001, victims without burns contact the FP more often for mental health related problems than adolescent community controls (OR 4.54, 95\% CI 1.69-12.20) (model 2, table 6.3b).

Adolescent family members of victims do not differ from adolescent community controls in respect to overall utilization and utilization for mental health during the 3 years after the fire (model 3, table 6.3a). In both groups, however, overall utilization (year 2001: OR 1.09, 95\% CI 1.05-1.15; year 2002: OR 1.28, 95\% CI 1.21-1.34; year 2003: OR 1.25, 95\% CI 1.18-1.31) and utilization for mental health (year 2001: OR 1.58, 95\% CI; year 2002: OR 2.05, 95\% CI 1.44-2.94; year 2003: OR 2.05, 95\% CI 1.45-2.89; model 3, table $6.3 \mathrm{~b})$ are significantly higher than in 2000 . 
Model 4 (table 6.3a) compares adolescent community controls with adolescent patients who do not belong to a community that has been affected by a disaster (national reference). Again, in both groups, we see that during the years following the fire utilization is higher than in 2000. In addition, for adolescent community controls, the risk for contacting the FP increases by a factor of 1.17 (95\% CI 1.10-1.24) in 2002. In 2001 and 2003, the risk is the same for adolescent community controls and adolescents belonging to the national reference population.

Model 5 (table 6.3a) compares adult family members and adult community controls. In adult family members, in 2001, the risk for contacting the FP increases by a factor of 1.13 (95\% CI 1.03-1.24) as compared to adult community controls. Moreover, there are significant differences in risk between the two groups in respect to utilization related to mental health problems (model 4, table 6.3b). During all three years post-fire, adult family members are more likely to contact their FP for mental health problems than adult community controls. The risk ratio is higher during the first year postfire than in the second and third year (year 2001: OR 3.63, 95\% CI 2.31-5.72; year 2002: OR 1.89, 95\% CI 1.16-3.09; year 2003: 1.82, 95\% CI 1.08-3.07).

Model 6 (table 6.3a), finally, compares adult community controls with adult patients who do not belong to a community that has been affected by a disaster (national reference). Two of the three interaction terms are significant, indicating that in 2002 (OR 1.06, 95\% CI 1.00-1.11) and 2003 (OR $1.07,95 \%$ CI 1.01-1.13), the two groups differ in respect to their annual utilization. The risk ratios are very close to 1 , however, indicating that the association is not very strong.

Effects of Living with a Burned Family Member and Bereavement

According to model 1 (table 6.4a) and 3 (table 6.4b), living with a victim with burns does not affect overall utilization of adolescent family members, nor does it affect their utilization for mental health related problems. Model 2 (table 6.4a) indicates however, that, in 2001, the risk for contacting the FP in bereaved adolescent family members is 1.56 times the risk in those who are not bereaved (OR 1.56, 95\% CI 1.03-2.36). In the following years no differences are found between bereaved and non-bereaved adolescent 
family members. As in the adolescent group, it does not seem to matter whether an adult family member lives with a victim who suffers from burns or not: none of the interaction terms contribute significantly to the models (model 1, table 6.4a; model 1, table 6.4c). Bereavement, however, is associated with higher general utilization rates during 2001 (OR 1.88, 95\% CI 1.35-2.63; model 4, table 6.4a). In addition, being bereaved seems to affect the risk for contacting the family practitioner for problems related to mental health: as model 3 (table 6.4c) indicates, in 2001, in the bereaved, the risk for contacting the FP for mental health related problems is 8.69 times the risk of those adult family members who are not bereaved (95\% CI 2.10-35.92). In 2002 , this is 5.51 (95\% CI 1.11-27.35). 
Table 6.3a: Poisson regression analysis with group membership predicting annual primary care utilization, controlling for age, gender and insurance status

\begin{tabular}{|c|c|c|c|c|c|c|c|c|c|}
\hline \multirow{3}{*}{$\begin{array}{l}\text { Utilization } \\
\text { (overall) }\end{array}$} & \multicolumn{3}{|c|}{$\begin{array}{l}\text { Victims with vs. } \\
\text { victims without } \\
\text { burns }^{\text {a }}\end{array}$} & \multicolumn{3}{|c|}{$\begin{array}{l}\text { Victims without } \\
\text { burns vs. adolescent } \\
\text { community controls }\end{array}$} & \multicolumn{3}{|c|}{$\begin{array}{l}\text { Adolescent family } \\
\text { members vs. } \\
\text { adolescent } \\
\text { community } \\
\text { controlsc }\end{array}$} \\
\hline & \multicolumn{3}{|c|}{ Model 1} & \multicolumn{3}{|c|}{ Model 2} & \multicolumn{3}{|c|}{ Model 3} \\
\hline & OR & \multicolumn{2}{|c|}{$95 \% \mathrm{CI}$} & OR & \multicolumn{2}{|c|}{$95 \% \mathrm{CI}$} & OR & \multicolumn{2}{|c|}{$95 \%$ CI } \\
\hline Group & 0.75 & 0.60 & 0.93 & 1.34 & 1.13 & 1.59 & 1.00 & 0.88 & 1.14 \\
\hline $2001 g^{1}$ & 1.70 & 1.46 & 1.97 & 1.10 & 1.05 & 1.15 & 1.09 & 1.05 & 1.15 \\
\hline $2002 \mathrm{~g}$ & 1.45 & 1.24 & 1.71 & 1.27 & 1.21 & 1.33 & 1.28 & 1.21 & 1.34 \\
\hline 2003 g & 1.36 & 1.14 & 1.61 & 1.24 & 1.17 & 1.31 & 1.25 & 1.18 & 1.31 \\
\hline Group ${ }^{*} 2001$ & 2.43 & 1.98 & 2.99 & 1.55 & 1.35 & 1.78 & 1.11 & 0.98 & 1.25 \\
\hline Group $^{* 2002}$ & 1.61 & 1.29 & 2.01 & 1.14 & 0.97 & 1.34 & 1.12 & 0.99 & 1.28 \\
\hline Group*2003 & 1.60 & 1.26 & 2.02 & 1.10 & 0.92 & 1.31 & 1.09 & 0.95 & 1.25 \\
\hline $\begin{array}{l}\text { Contrasts } \\
\text { Group } 2001 /\end{array}$ & $\chi^{2}$ & df & $\mathbf{p}$ & $\chi^{2}$ & df & p & $x^{2}$ & df & $\mathrm{p}$ \\
\hline $\begin{array}{l}\text { Group } \\
\text { Group }^{*} 2002\end{array}$ & 24.22 & 1.00 & 0.00 & 20.72 & 1.00 & 0.00 & 0.05 & 1.00 & 0.82 \\
\hline Group 2003 & 0.01 & 1.00 & 0.92 & 0.29 & 1.00 & 0.59 & 0.24 & 1.00 & 0.62 \\
\hline \multirow{3}{*}{$\begin{array}{l}\text { Utilization } \\
\text { (overall) }\end{array}$} & \multicolumn{3}{|c|}{$\begin{array}{l}\text { Adolescent } \\
\text { community controls } \\
\text { vs. national reference } \\
\text { (adolescents) }^{\mathrm{e}}\end{array}$} & \multicolumn{3}{|c|}{$\begin{array}{l}\text { Adult family } \\
\text { members vs. adult } \\
\text { community controls }\end{array}$} & \multicolumn{3}{|c|}{$\begin{array}{l}\text { Adult community } \\
\text { controls vs. national } \\
\text { reference (adults) }\end{array}$} \\
\hline & \multicolumn{3}{|c|}{ Model 4} & \multicolumn{3}{|c|}{ Model 5} & \multicolumn{3}{|c|}{ Model 6} \\
\hline & OR & \multicolumn{2}{|c|}{$95 \% \mathrm{CI}$} & OR & \multicolumn{2}{|c|}{$95 \% \mathrm{CI}$} & OR & \multicolumn{2}{|c|}{$95 \%$ CI } \\
\hline Group & 0.95 & 0.75 & 1.21 & 1.07 & 0.97 & 1.18 & 0.84 & 0.67 & 1.05 \\
\hline $2001 \mathrm{~g}$ & 1.05 & 1.02 & 1.08 & 1.04 & 0.99 & 1.09 & 1.02 & 0.99 & 1.04 \\
\hline $2002 \mathrm{~g}$ & 1.08 & 1.05 & 1.12 & 1.10 & 1.05 & 1.15 & 1.03 & 1.01 & 1.06 \\
\hline $2003 g$ & 1.18 & 1.14 & 1.22 & 1.20 & 1.14 & 1.26 & 1.11 & 1.08 & 1.14 \\
\hline Group*2001 & 1.05 & 0.99 & 1.11 & 1.13 & 1.03 & 1.24 & 1.02 & 0.97 & 1.08 \\
\hline Group $^{*} 2002$ & 1.17 & 1.10 & 1.24 & 1.06 & 0.97 & 1.17 & 1.06 & 1.00 & 1.11 \\
\hline Group ${ }^{*} 2003$ & 1.05 & 0.99 & 1.12 & 1.05 & 0.95 & 1.16 & 1.07 & 1.01 & 1.13 \\
\hline $\begin{array}{l}\text { Contrasts } \\
\text { Group*2001/ }\end{array}$ & $\chi^{2}$ & df & p & $\chi^{2}$ & df & $\mathrm{p}$ & $x^{2}$ & df & $\mathrm{p}$ \\
\hline $\begin{array}{l}\text { Group }{ }^{*} 2002 \\
\text { Group }^{* 2002 /}\end{array}$ & 17.75 & 1.00 & 0.00 & 1.70 & 1.00 & 0.19 & 1.64 & 1.00 & 0.20 \\
\hline Group 2003 & 16.76 & 1.00 & 0.00 & 0.09 & 1.00 & 0.77 & 0.25 & 1.00 & 0.62 \\
\hline
\end{tabular}

Dummy variable; reference category is victims without burns.

Dummy variable; reference category is adolescent community controls.

Dummy variable; reference category is adolescent community controls.

Dummy variable; reference category is adolescent community con
Dummy variable; reference category is adult community controls.

Dummy variable; reference category is national reference (adolescents).

Dummy variable; reference category is national reference (adults)

Dummy variable; reference category is year 2000 (pre-fire). 


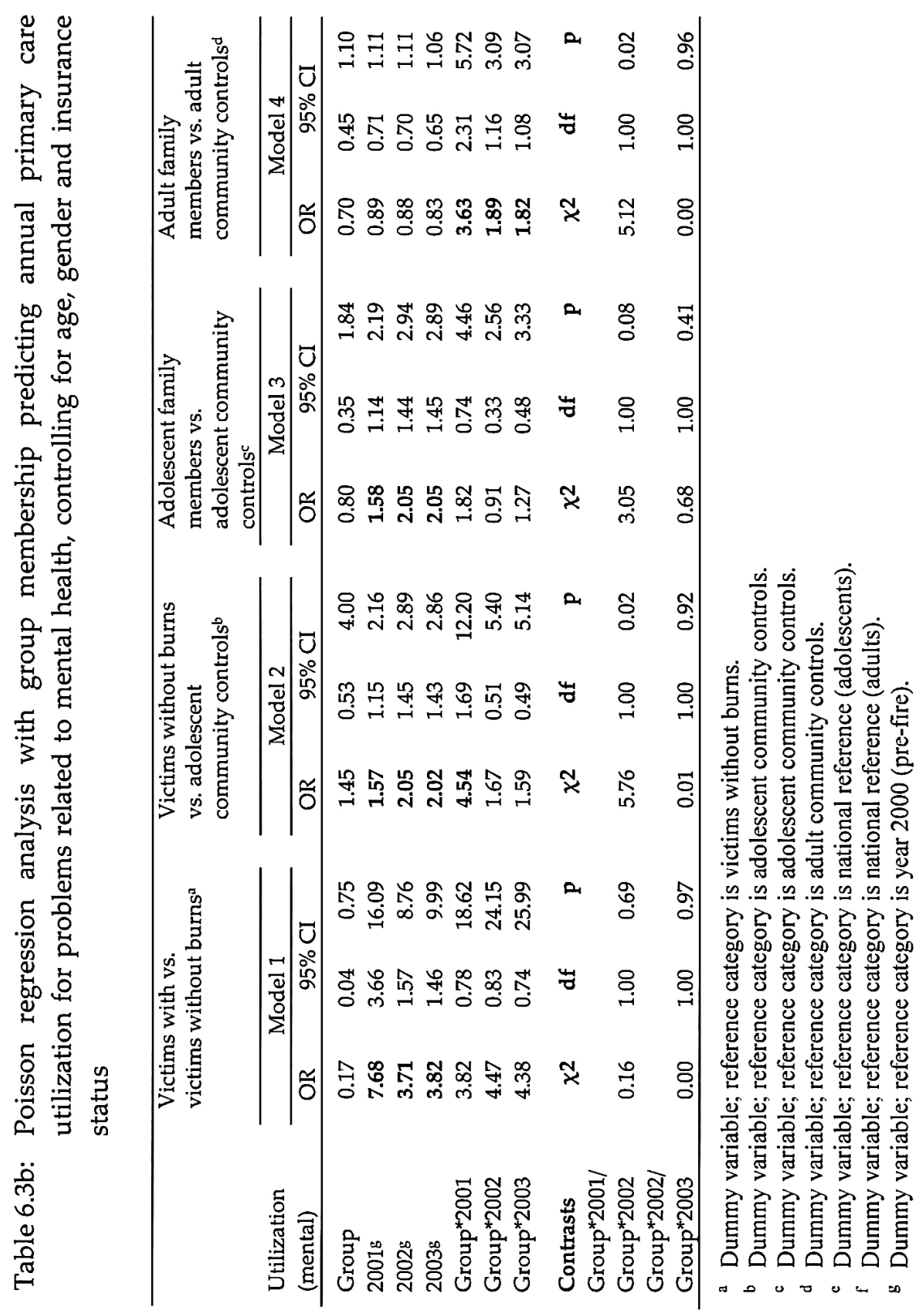


Table 6.4a: Adolescent family members: living with a victim with burns and having lost a family member due to the fire as determinants of annual primary care utilization; Poisson regression analysis controlling for age, gender and insurance status

\begin{tabular}{|c|c|c|c|c|c|c|}
\hline \multirow{4}{*}{$\begin{array}{l}\begin{array}{l}\text { Utilization } \\
\text { (overall) }\end{array} \\
\text { Burns }^{\mathrm{a}}\end{array}$} & \multicolumn{6}{|c|}{ Adolescent family members } \\
\hline & \multicolumn{3}{|c|}{ Model 1} & \multicolumn{3}{|c|}{ Model 2} \\
\hline & \multirow{2}{*}{$\begin{array}{r}\text { OR } \\
0.91\end{array}$} & \multicolumn{2}{|c|}{$95 \% \mathrm{CI}$} & \multirow{2}{*}{$\begin{array}{r}\text { OR } \\
-\end{array}$} & \multicolumn{2}{|c|}{$95 \% \mathrm{CI}$} \\
\hline & & 0.73 & 1.14 & & - & - \\
\hline Bereaved ${ }^{b}$ & - & - & - & 1.14 & 0.69 & 1.87 \\
\hline $2001^{c}$ & 1.32 & 1.14 & 1.54 & 1.18 & 1.05 & 1.32 \\
\hline $2002^{c}$ & 1.40 & 1.18 & 1.65 & 1.45 & 1.29 & 1.64 \\
\hline $2003^{c}$ & 1.33 & 1.12 & 1.59 & 1.38 & 1.22 & 1.56 \\
\hline Burns*2001 & 0.84 & 0.68 & 1.04 & - & - & - \\
\hline Burns*2002 & 1.05 & 0.83 & 1.32 & - & - & - \\
\hline Burns*2003 & 1.03 & 0.81 & 1.32 & - & - & - \\
\hline Bereav*2001 & - & - & - & 1.56 & 1.03 & 2.36 \\
\hline Bereav*2002 & - & - & - & 0.75 & 0.44 & 1.29 \\
\hline Bereav*2003 & - & - & - & 0.68 & 0.38 & 1.21 \\
\hline Contrasts & $x^{2}$ & df & $\mathrm{p}$ & $\chi^{2}$ & df & p \\
\hline Burns*2001/ Burns*2002 & 3.06 & 1.00 & 0.08 & - & - & - \\
\hline Burns*2002/ Burns*2003 & 0.02 & 1.00 & 0.88 & - & - & - \\
\hline Bereav*2001/Bereav*2002 & - & - & - & 7.59 & 1.00 & 0.01 \\
\hline Bereav*2002/Bereav*2003 & - & - & - & 0.14 & 1.00 & 0.71 \\
\hline
\end{tabular}

a Person lives with a victim with burns (yes/no).

b Person has lost a family member due to the fire (yes/no).

c Dummy variable; reference category is year 2000 (pre-fire). 
Table 6.4b: Adult family members: living with a victim with burns and having lost a family member due to the fire as determinants of annual primary care utilization; Poisson regression analysis controlling for age, gender and insurance status

\begin{tabular}{|c|c|c|c|c|c|c|}
\hline \multirow{4}{*}{$\begin{array}{l}\begin{array}{l}\text { Utilization } \\
\text { (overall) }\end{array} \\
\text { Burns }^{\mathrm{a}}\end{array}$} & \multicolumn{6}{|c|}{ Adult family members } \\
\hline & \multicolumn{3}{|c|}{ Model 3} & \multicolumn{3}{|c|}{ Model 4} \\
\hline & \multirow{2}{*}{$\begin{array}{c}\text { OR } \\
1.01\end{array}$} & \multicolumn{2}{|c|}{$95 \% \mathrm{CI}$} & \multirow{2}{*}{$\begin{array}{r}\text { OR } \\
-\end{array}$} & \multicolumn{2}{|c|}{$95 \% \mathrm{CI}$} \\
\hline & & 0.85 & 1.18 & & - & - \\
\hline Bereaved $^{b}$ & - & - & - & 1.08 & 0.76 & 1.53 \\
\hline $2001^{c}$ & 1.24 & 1.10 & 1.40 & 1.12 & 1.03 & 1.22 \\
\hline $2002^{c}$ & 1.25 & 1.10 & 1.42 & 1.15 & 1.05 & 1.26 \\
\hline $2003^{c}$ & 1.32 & 1.16 & 1.51 & 1.26 & 1.15 & 1.38 \\
\hline Burns*2001 & 0.92 & 0.78 & 1.08 & - & - & - \\
\hline Burns*2002 & 0.88 & 0.74 & 1.05 & - & - & - \\
\hline Burns*2003 & 0.92 & 0.77 & 1.10 & - & - & - \\
\hline Bereav*2001 & - & - & - & 1.88 & 1.35 & 2.63 \\
\hline Bereav*2002 & - & - & - & 1.28 & 0.88 & 1.86 \\
\hline Bereav*2003 & - & - & - & 1.09 & 0.74 & 1.61 \\
\hline Contrasts & $x^{2}$ & df & p & $x^{2}$ & df & p \\
\hline Burns*2001/ Burns*2002 & 0.20 & 1.00 & 0.65 & - & - & - \\
\hline Burns*2002/ Burns*2003 & 0.28 & 1.00 & 0.60 & - & - & - \\
\hline Bereav*2001/Bereav*2002 & - & - & - & 5.08 & 1.00 & 0.02 \\
\hline Bereav*2002/Bereav*2003 & - & - & - & 1.03 & 1.00 & 0.31 \\
\hline
\end{tabular}

a Person lives with a victim with burns (yes/no).

b Person has lost a family member due to the fire (yes/no).

c Dummy variable; reference category is year 2000 (pre-fire). 
Table 6.4c: Adolescent and adult family members: living with a victim with burns and having lost a family member due to the fire as determinants of annual primary care utilization for problems related to mental health; Poisson regression analysis controlling for age, gender and insurance status

\begin{tabular}{|c|c|c|c|c|c|c|c|c|c|}
\hline \multirow{4}{*}{$\begin{array}{l}\begin{array}{l}\text { Utilization } \\
(\text { mental })\end{array} \\
\text { Burns }^{\mathrm{a}}\end{array}$} & \multirow{2}{*}{\multicolumn{3}{|c|}{$\begin{array}{c}\begin{array}{c}\text { Adolescent family } \\
\text { members }\end{array} \\
\text { Model } 1 \\
\end{array}$}} & \multicolumn{6}{|c|}{ Adult family members } \\
\hline & & & & \multicolumn{3}{|c|}{ Model 2} & \multicolumn{3}{|c|}{ Model 3} \\
\hline & \multirow{2}{*}{$\begin{array}{r}\text { OR } \\
0.65\end{array}$} & \multicolumn{2}{|c|}{$95 \% \mathrm{CI}$} & \multirow{2}{*}{$\begin{array}{r}\text { OR } \\
1.15\end{array}$} & \multicolumn{2}{|c|}{$95 \% \mathrm{CI}$} & \multirow{2}{*}{$\begin{array}{r}\text { OR } \\
-\end{array}$} & \multicolumn{2}{|c|}{$95 \% \mathrm{CI}$} \\
\hline & & 0.15 & 2.89 & & 0.53 & 2.50 & & - & - \\
\hline Bereaved ${ }^{b}$ & - & - & - & - & - & - & 0.80 & 0.16 & 4.03 \\
\hline $2001^{c}$ & 3.34 & 1.03 & 10.86 & 2.60 & 1.47 & 4.60 & 2.05 & 1.44 & 2.92 \\
\hline $2002^{c}$ & 3.04 & 0.78 & 11.89 & 1.12 & 0.59 & 2.12 & 1.22 & 0.81 & 1.83 \\
\hline $2003^{c}$ & 2.20 & 0.56 & 8.72 & 1.72 & 0.86 & 3.42 & 1.13 & 0.68 & 1.86 \\
\hline Burns*2001 & 0.96 & 0.18 & 5.15 & 1.11 & 0.52 & 2.37 & - & - & - \\
\hline Burns*2002 & 0.67 & 0.10 & 4.62 & 1.39 & 0.60 & 3.21 & - & - & - \\
\hline Burns*2003 & 1.87 & 0.28 & 12.48 & 0.52 & 0.20 & 1.32 & - & - & - \\
\hline Bereav²001 & - & - & - & - & - & - & 8.69 & 2.10 & 35.92 \\
\hline Bereav²002 & - & - & - & - & - & - & 5.51 & 1.11 & 27.35 \\
\hline Bereav²003 & - & - & - & - & - & - & 4.46 & 0.60 & 33.38 \\
\hline Contrasts & $x^{2}$ & df & p & $x^{2}$ & df & $\mathrm{p}$ & $x^{2}$ & df & $\mathrm{p}$ \\
\hline $\begin{array}{l}\text { Burns*2001/ } \\
\text { Burns*2002 }\end{array}$ & 0.30 & 1.00 & 0.58 & 0.67 & 1.00 & 0.41 & - & - & - \\
\hline $\begin{array}{l}\text { Burns*2002/ } \\
\text { Burns*2003 }\end{array}$ & 5.57 & 1.00 & 0.02 & 6.90 & 1.00 & 0.01 & - & - & - \\
\hline $\begin{array}{l}\text { Bereav²001/ } \\
\text { Bereav²002 }\end{array}$ & - & - & - & - & - & - & 1.53 & 1.00 & 0.22 \\
\hline $\begin{array}{l}\text { Bereav*2002/ } \\
\text { Bereav*2003 }\end{array}$ & - & - & - & - & - & - & 0.08 & 1.00 & 0.78 \\
\hline
\end{tabular}

a Person lives with a victim with burns (yes/no).

b Person has lost a family member due to the fire (yes/no).

c Dummy variable; reference category is year 2000 (pre-fire). 


\section{Discussion}

The aim of our study was to quantify the number of contacts in primary health care after a catastrophic fire and to identify determinants of utilization. It was hypothesized that exposure to trauma would lead to increased primary care utilization. Exposure was assumed to be highest in those who had been trapped in the bar, since they experienced life threat and witnessed others being burned or dying. Furthermore, it was hypothesized that the event would also have an impact on the primary care utilization rates of family members of victims since they are part of the victim's support system.

We presented two outcome measures: overall primary care utilization and, more specifically, primary care utilization for mental health related problems. During the three years after the fire, the risk for contacting the family practitioner for victims with burns was higher than for victims without burns. Although utilization for mental health problems increased in both groups when compared to the year before the fire, the two groups did not differ from each other in respect to their utilization for mental health problems. In our study, those victims who had been present during the fire and who had not been injured had significantly more contacts with their family practitioner than adolescents from the same community who had not been trapped in the café. This was true for the first year post-disaster. In addition, during the first year after the fire, victims without burns were 4.54 times more likely to contact the family practitioner for mental health problems than adolescent community controls. To conclude, the presence of physical injuries alone does not determine increased primary care utilization after a disaster.

We also compared the utilization rates of adolescent community controls to a national reference population. This comparison revealed that in all years, in both groups, utilization had increased when compared to the year before the fire. The two groups did not differ from each other, however, except from a small difference in the second year after the fire. Another study on the same disaster indicates that adolescents in Volendam reported more substance abuse, and more emotional and behavioral problems in the 
aftermath of the fire than controls outside the community (37). Effects substantially decreased after 12 months after the disaster (38). Adolescents are generally healthy and rarely seek help with their family practitioner for behavioral or emotional problems (39). This might explain why no effect is found in our study.

In order to shed light on the impact the fire had on the family level, the parents and siblings of disaster victims were studied. It was assumed that due to traumatic experiences involving the entire support system of the victim, increased utilization would be shifted across several individuals. In our study, this seems to apply to the bereaved. In parents, the effect is limited to the first two year after the fire, and it levels off in the third year. In siblings, bereavement seems to impact utilization during the first year after the fire only. Generally spoken, the effect it is larger in size for parents of victims than for siblings of victims. In parents, the association is even stronger for mental health related problems.

Furthermore, it was expected that the impact on utilization would be higher in family members of adolescents with burns when compared to family members of adolescents without burns since we assumed a higher burden of care and more distress in these families. This hypothesis was not supported by the current data, neither for primary care utilization in general, nor for mental health utilization in the primary care context in particular. Possibly, it is insufficient to simply distinguish those families who live with a burn victim from those who do not without shedding light on the consequences of burns from a psychological perspective.

Finally, an increase of utilization was also observed in families from the same community who did not live with a disaster victim. A similar time trend was observed in patients belonging to communities who had not been exposed to disaster. The observed increase in community controls can thus not be ascribed to the effects of living in a community that has been affected by a fire catastrophe.

The presence of baseline data, the presence of two control groups (national reference and community controls), and the long follow-up period make this 
study unique in the field of disaster research, and, equally, in the field of utilization studies (10;40). In studies based on interviews or questionnaires, non-response can be a problem. Here, this source of bias is ruled out since it is based on already existing registrations of family practitioners. Study groups are therefore more comprehensive than in other types of studies and loss to follow-up is minimized.

The use of existing registrations of family practitioners also has its limitations. It was determined which patients had been exposed to the fire, but the subjective experience of individuals was not measured. Individuals may vary considerably in how they experience the fire and its consequences, and their subjective experience may be an important moderator in the care seeking process. In addition, other types of research are needed in order to clarify the psychological mechanisms that link trauma and health.

The data for this study were collected in a health care system that builds on the gate-keeping role of family practitioners. Our results thus generalize to other highly regulated primary care systems (i.e. health maintenance organizations, or other European countries with "gate-keeping" systems). Since approximately $90 \%$ of Dutch patients' health problems are addressed in family practice (41), our data supply a comprehensive account of health care utilization. On the other hand, the study does not account for treatment that was provided outside the primary care setting. Victims with burns, in particular, have been treated in specialist care, leading to an underestimation of effects in this group.

Finally, it should not be assumed that each type of trauma or disaster will lead to similar changes in utilization. Persons can experience trauma on an individual level (such as life-threatening injuries or sexual assault) or the experience can be shared by a group as it is the case in disasters. Although disasters share important generic characteristics (e.g. sudden onset, lifethreat, exposure to death and dying), they also vary along a number of specific dimensions (e.g. type of injuries inflicted, degree of loss of property). Victims may belong to the same community as it is the case here, or they may stem from different areas as in transportation accidents. Findings from this study probably apply best to (1) man-made disasters that (2) occur in a 
community context and (3) have a one-time impact (no ongoing threat over a long period of time). To conclude, more systematic investigations of the full range of disasters are needed in order to determine the general impact of disaster and trauma on health care utilization.

\section{Acknowledgements}

This study was financially supported by the Dutch Ministry of Health. We thank all Volendam family practitioners for supplying the data. We also thank Petra ten Veen for the data management and Harald Abrahamse for preparing the LINH data set. 


\section{References}

1. Norris FH. Psychosocial consequences of disaster. PTSD Research Quarterly. 2002;13:1-8.

2. Noji E.K. The nature of disaster: general characteristics and public health effects. In: Noji E.K., ed. The public health consequences of disaster. New York: Oxford University Press; 1997; 3-20.

3. Yzermans CJ, Donker GA, Kerssens JJ, Dirkzwager AJ, Soeteman RJ, Ten Veen PM. Health problems of victims before and after disaster: a longitudinal study in general practice. Int J Epidemiol. 2005; 34:810-819.

4. Norris FH, Friedman MJ, Watson PJ, Byrne CM, Diaz E, Kaniasty K. 60,000 disaster victims speak: Part I. An empirical review of the empirical literature, 1981-2001. Psychiatry. 2002; 65:207-39.

5. Schnurr PP, Green BL. Understanding relationships among trauma, posttraumatic stress disorder, and health outcomes. In: Schnurr PP, ed. Trauma and health: Physical health consequences of exposure to extreme stress. Washington DC: American Psychological Association; 2004; 247-75.

6. Walker EA, Newman E, Koss MP. Costs and health care utilization associated with traumatic experiences. In: Schnurr PP, ed. Trauma and health: Physical health consequences of exposure to extreme stress. Washington DC: American Psychological Association; 2004; 43-69.

7. Williams R, Zyzanski SJ, Wright AL. Life events and daily hassles and uplifts as predictors of hospitalization and outpatient visitation. Social Science and Medicine. 1992; 34:763-68.

8. Donker GA, Yzermans CJ, Spreeuwenberg P, van der Zee J. Symptom attribution after a plane crash: comparison between self-reported symptoms and GP records. Br J Gen Pract. 2002; 52:917-22.

9. van Vugt AB. [Disaster medicine: lessons from Enschede and Volendam]. Ned Tijdschr Geneeskd. 2001; 145:2309-12.

10. Norris FH, Friedman MJ, Watson PJ. 60,000 disaster victims speak: Part II. Summary and implications of the disaster mental health research. Psychiatry. 2002; 65:240-260.

11. Ritter PL, Stewart AL, Kaymaz H, Sobel DS, Block DA, Lorig KR. Self-reports of health care utilization compared to provider records. J Clin Epidemiol. 2001; 54:136-41.

12. Stange KC, Zyzanski SJ, Smith TF, Kelly R, Langa DM, Flocke SA et al. How valid are medical records and patient questionnaires for physician profiling and health services research? A comparison with direct observation of patients visits. Med Care. 1998; 36:85167.

13. Roberts RO, Bergstralh EJ, Schmidt L, Jacobsen SJ. Comparison of self-reported and medical record health care utilization measures. J Clin Epidemiol. 1996; 49:989-95. 
14. Walker EA, Newman E, Koss MP. Costs and health care utilization associated with traumatic experiences. In: Green BL, Schnurr PP, eds. Trauma and health: Physical health consequences of exposure to extreme stress. Washington, DC, US: American Psychological Association; 2004; 43-69.

15. Figley CR. Burnout in families: The systemic costs of caring. Boca Raton, FL, US: CRC Press; 1998.

16. Van Loey NE, Van Son MJ. Psychopathology and psychological problems in patients with burn scars: epidemiology and management. Am J Clin Dermatol. 2003; 4:245-72.

17. Mancuso MG, Bishop S, Blakeney P, Robert R, Gaa J. Impact on the family: psychosocial adjustment of siblings of children who survive serious burns. J Burn Care Rehabil. 2003; 24:110-118.

18. Shelby J, Sullivan J, Groussman M, Gray R, Saffle J. Severe burn injury: effects on psychologic and immunologic function in noninjured close relatives. J Burn Care Rehabil. 1992; 13:58-63.

19. Meyer WJ, Blakeney P, Moore P, Murphy L, Robson M, Herndon D. Parental well-being and behavioral adjustment of pediatric survivors of burns. J Burn Care Rehabil. 1994; 15:62-68.

20. Rizzone LP, Stoddard FJ, Murphy JM, Kruger LJ. Posttraumatic stress disorder in mothers of children and adolescents with burns. J Burn Care Rehabil. 1994; 15:158-63.

21. Watkins PN, Cook EL, May SR, Still JM, Jr., Luterman A, Purvis RJ. Postburn psychologic adaptation of family members of patients with burns. J Burn Care Rehabil. 1996; 17:78-92.

22. Barnes MF. Understanding the secondary traumatic stress of parents. In: Figley CR, ed. Burnout in families: The systemic costs of caring. Innovations in psychology. 1998; 75-89.

23. Rubin SS, Malkinson R. Parental response to child loss across the life cycle: Clinical and research perspectives. In: Stroebe MS, ed. Handbook of bereavement research: Consequences, coping, and care. Washington, DC: American Psychological Association. 2001; 219-40.

24. Hall M, Irwin M. Physiological indices of functioning in bereavement. In: Stroebe MS, ed. Handbook of bereavement research: Consequences, coping, and care. Washington, DC: American Psychological Association; 2001; 473-92.

25. Spratt ML, Denney DR. Immune variables, depression, and plasma cortisol over time in suddenly bereaved parents. J Neuropsychiatry Clin Neurosci. 1991; 3:299-306.

26. Okkes IM, Groen A, Oskam SK, Lamberts H. Advantages of long observation in episodeoriented electronic patient records in family practice. Methods Inf Med. 2001; 40:229-35.

27. Landelijk Informatienetwerk Huisartsenzorg. Feiten en cijfers over huisartsenzorg in Nederland [LINH web-site]. Verheij, R. A. Jabaaij L. Abrahamse H. Van den Hoogen H. Braspenning J. and Van Althuis T. http://www.linh.nl. Accessed 06-24-2005.

28. Armstrong MA, Midanik LT, Klatsky AL. Alcohol consumption and utilization of health services in a health maintenance organization. Med Care. 1998; 36:1599-605.

29. Hofmans-Okkes IM, Lamberts H. The International Classification of Primary Care (ICPC): new applications in research and computer-based patient records in family practice. Fam Pract. 1996; 13:294-302. 
30. Kersnik J, Svab I, Vegnuti M. Frequent attenders in general practice: quality of life, patient satisfaction, use of medical services and GP characteristics. Scand J Prim Health Care. 2001; 19:174-77.

31. Neal RD, Wickenden G, Cottrell D, Mason J, Rugiano J, Clarkson P et al. The use of primary, secondary, community and social care by families who frequently consult their general practitioner. Health Soc Care Community. 2001; 9:375-82.

32. Heywood PL, Blackie GC, Cameron IH, Dowell AC. An assessment of the attributes of frequent attenders to general practice. Fam Pract. 1998; 15:198-204.

33. Scaife B, Gill P, Heywood P, Neal R. Socio-economic characteristics of adult frequent attenders in general practice: secondary analysis of data. Fam Pract. 2000; 17:298-304.

34. Bergh $\mathrm{H}$, Marklund B. Characteristics of frequent attenders in different age and sex groups in primary health care. Scand J Prim Health Care. 2003; 21:171-77.

35. Goldstein H. Multilevel models in education and social research. Oxford: Oxford University Press; 1987

36. Snijder TB, Bosker R. Multilevel analysis: an introduction to basic and advanced multilevel modeling. Thousand Oaks, CA: Sage; 1999.

37. Reijneveld SA, Crone MR, Verhulst FC, Verloove-Vanhorick SP. The effect of a severe disaster on the mental health of adolescents: a controlled study. Lancet. 2003; 362:691-96.

38. Reijneveld SA, Crone MR, Schuller AA, Verhulst FC, Verloove-Vanhorick SP. The changing impact of a severe disaster on the mental health and substance misuse of adolescents: follow-up of a controlled study. Psychol Med. 2005; 35:367-76.

39. Zwaanswijk M, Verhaak PF, van der EJ, Bensing JM, Verhulst FC. Consultation for and identification of child and adolescent psychological problems in Dutch general practice. Fam Pract. 2005; 22:498-506.

40. Eisenberg JM. Physician utilization: the state of research about physicians' practice patterns. Med Care. 2002; 40:1016-35.

41. van der Lei J, Duisterhout JS, Westerhof HP, van der DE, Cromme PV, Boon WM et al. The introduction of computer-based patient records in The Netherlands. Ann Intern Med. 1993; 119:1036-41. 


\section{Chapter}

\section{Benzodiazepine use}

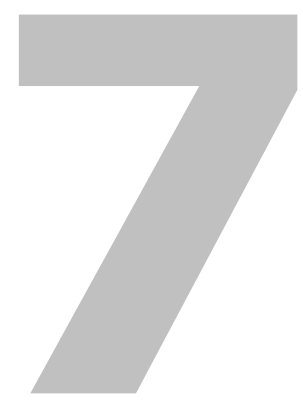

This chapter has been accepted for publication and will be published as:

Prospective cohort study into post-disaster benzodiazepine use demonstrated only short-term increase

Dorn T

Yzermans $C J$

van der Zee J

Journal of Clinical Epidemiology, 2007 


\begin{abstract}
Objectives Benzodiazepines are typically prescribed for anxiety and insomnia, two complaints often reported after disasters. Benzodiazepines can cause mental or physical dependence, especially when taken for a long time. This study aims at evaluating benzodiazepine use in a disaster-stricken community with the help of computer-based records.
\end{abstract}

Study Design and Setting This prospective cohort study covers a period of four years. For every patient, pre-disaster baseline data are available. Multilevel regression is applied in order to study differences in benzodiazepine use in 496 patients whose children were involved in the Volendam café bar fire on January 1st, 2001, compared to 1,709 community controls and 4,530 patients from an unaffected cohort.

Results In community controls and patients from the unaffected cohort, benzodiazepine use remained stable throughout the period under review. In the first year post-fire, the parents of disaster victims were 1.58 times more likely to use benzodiazepines than community controls (95\% CI 1.13-2.23). With regard to long-term use, differences between community controls and parents were statistically non-significant.

Conclusions In the studied community, benzodiazepines were predominantly prescribed as a short-term intervention. Clinical guidelines that advocate a conservative prescription policy were well adhered to. 


\section{Background}

The data in computer-based patient records are increasingly used to evaluate the provision of care $(1 ; 2)$. In pharmacoepidemiological research, the source of data, whether pharmacy, physician or billing records, will affect the quality and content of data (3). Although pharmacy records provide detailed and well-structured information on the drugs themselves, data on the consumers are often very limited. The latter is not the case when patients purchase prescription drugs at only one designated pharmacy, as is the case in the Netherlands (4). In addition, at times the pharmacies are electronically linked to the registration systems of family practitioners - a favorable situation in drug research (5).

The study contained in this chapter provides an example of how longitudinal data captured in computerized registries can be used in order to evaluate the provision of care. It aims at quantifying benzodiazepine use in a disaster-stricken community and is centered around the question whether clinical guidelines for prescribing have been adhered to.

Benzodiazepines are effective anti-anxiety and sleep-inducing medications (6). Since anxiety and insomnia are problems which are often presented to health care practitioners after disasters (7-10), it is possible that in times of crisis a proportion of patients is exposed to benzodiazepines for the first time (11). Although benzodiazepines have several favorable aspects, they are also known to cause physical and psychological dependence when taken for prolonged periods of time $(12 ; 13)$. Clinical guidelines therefore recommend benzodiazepines only for short term relief $(14 ; 15)$.

The disaster described here is considered to be one of the worst mass burn incidents to occur in the Netherlands in recent years (16-18). The fire broke out in an overcrowded bar where about 350 adolescents were celebrating New Year's Eve. Fourteen young people lost their lives and a large number suffered burn injuries. The youngest victim was 13 years old, with the others all aged under 25 . 
This chapter concentrates on the parents of these victims. The parents of fire victims were exposed to high levels of post-disaster stress (19-22). Previous research has demonstrated that these adults were more at risk for developing hypertension after the fire than controls from the same community whose children had not been directly affected (23). Moreover, the parents of the affected children contacted their family practitioners more often for mental health issues when compared to community controls (24).

It is therefore hypothesized that the parents of fire victims are more likely to receive prescriptions for benzodiazepines. We also investigate whether those who lost a child and those whose children suffered burns are more likely to use benzodiazepines than parents of children who survived the fire without suffering burns $(25 ; 26)$. Finally, we expect affected mothers to use benzodiazepines more often than affected fathers (27-29).

\section{Method}

\section{Setting}

The Dutch health care system is organized on an insurance basis. When the study was carried out, two types of health insurance existed, public and private insurance. Patients with an annual income below a specific level were insured through public insurance; above this level, patients were privately insured. Insurance type can thus be used as an indicator for the socio-economic status of the patient. In the Netherlands, family practitioners (FPs) act as gatekeepers to specialist services. Dutch family practitioners have fixed patient lists and patients are enrolled with one FP only, which is ideal for population-based research. Usually, complete families are registered with the same practice (30).

Volendam, a former fishing town located 20 miles north of Amsterdam with about 20,000 inhabitants, is served by four family practices. In Volendam, the FP registrations can be linked to the registrations of the local pharmacies due to shared patient identification numbers. These pharmacy records contain virtually complete information on all drugs dispensed to outpatients (either prescribed by the family doctors or, on an extramural basis, by 
specialists). If a prescribed drug is not picked up by a patient (less than $1 \%$ of all prescriptions), the prescription is removed from the record. It is thus assumed that the number of prescribed drugs very closely approximates the number of dispensed drugs. The terms "prescribed" and "dispensed" are therefore used interchangeably in this article.

\section{Data collection}

Three population-based cohorts were tracked throughout one year before and three years after the fire: (1) parents of the fire victims, (2) community controls, and (3) patients from 14 unaffected Dutch communities. The last sample consisted of a cohort of patients who are monitored within the Netherlands Information Network of General Practice (LINH), a representative network of computerized family practitioners (31). For this cohort, only family practice-based registrations of benzodiazepine prescriptions were available. These registrations are less comprehensive than pharmacy registrations for three reasons. First, they do not contain prescriptions issued by specialists (as is the case in pharmacy records). Second, repeat prescriptions are not fully captured in these records. Third, since they are not used for billing (as pharmacy records), they are generally more prone to underregistration. As a consequence, estimates based on family doctors' records are generally lower than estimates based on pharmacy records (32).

Nevertheless, the LINH-data were used here because they were available at the patient level and therefore allow for in-depth statistical comparisons of patients who belong to the Volendam community (parents of fire victims and community controls) with patients who do not belong to this community (LINH). Although the LINH-data provide an underestimation of true rates, there is no reason to assume that these data were systematically distorted by other factors. On the one hand, the LINH-data allow for an assessment of time trends in benzodiazepine use in a population outside Volendam. On the other hand, they are not suitable for the assessment of absolute differences between groups. In order to compensate for this, we also report estimates of the percentage of benzodiazepine users in the same age group on the national level. These figures were provided by the Dutch Foundation for Pharmaceutical Statistics (Stichting Farmaceutische 
Kerngetallen, SFK). Since these data were not available at the patient level, the number of patients with more than 90 daily defined doses (DDDs) per year or three or more months of use cannot be provided in this case. Nevertheless, the figures give a general idea of the level of benzodiazepine use in Volendam in relation to the national level (table 7.1).

\section{Sampling of cohorts}

Parents of fire victims and community controls

As a first step, it was necessary to identify the fire victims. According to official estimates, about 300-350 people were in the building at the time of the fire. The four family practices were able to identify a total of 335 in their registrations (14 deceased adolescents and 321 survivors, with and without physical injuries). 35 of the surviving victims were excluded from the study since they belonged to a practice that was not yet fully computerized. None of the deceased adolescents belonged to this practice. The characteristics of victims enrolled in the non-participating practice $(n=35)$ were compared with those of victims enrolled with the participating practices $(n=286)$. Victims included in the final study sample did not significantly differ from non-participants with respect to burn size, number of days in hospital, gender, age or insurance status. Victims with burn injuries had a mean total burned surface area of $14.9 \%(\mathrm{SD}=17.1)$ and spent, on average, 34.2 days in hospital during the first 12 months after the disaster $(\mathrm{SD}=59.3)$. As a second step, we identified all parents of deceased and/or surviving victims with the help of the electronic patient registration $(n=499)$. 27 of these parents lost a child and 277 live with a child who is suffering from burn injuries. As a third step, from the three participating family practices, we included all patients with children aged 14-20, who had not been trapped in the fire $(n=1,756)$. These patients are referred to as 'community controls'.

Sampling of an unaffected control group outside Volendam (LINH-cohort)

According to the same procedure as the community controls, we sampled a cohort of 4,851 patients from the LINH-database (Netherlands Information Network of General Practice). These patients belong to 14 different communities spread throughout the Netherlands. 


\section{Inclusion criterion}

Patients were included in the analyses when they were enrolled during the full 4-year period. This results in a final sample of 496 parents, 1,709 community controls and 4,530 patients from the LINH-database.

\section{Assessment of benzodiazepine use}

Information on the benzodiazepine use of parents of fire victims and community controls was extracted from the electronic pharmacy records; information on the use of the LINH-cohort was based on the electronic registrations of family practitioners. Both registers code prescriptions according to the Anatomical Therapeutic Chemical (ATC) classification system (33). In the current study, a patient was considered a benzodiazepine user if he or she had received at least one prescription for a benzodiazepine (ATC-codes N05BA, N05CD and N05CF). The proportion of benzodiazepine users was calculated on a yearly basis. Likewise, long-term benzodiazepine use was defined on an annual basis.

It was considered present if:

(1) the amount of benzodiazepine prescriptions was more than 90 DDDs. Given that the DDD is the assumed average maintenance dose per day for a drug used for its main indication in adults, this amount would be sufficient for more than 90 days.

(2) prescriptions for benzodiazepines covered a period of 3 months or more (at least one benzodiazepine prescription per month in at least three consecutive months).

These definitions for long-term use were derived from clinical guidelines for benzodiazepine use $(6 ; 14 ; 34)$.

\section{Analysis}

Patient characteristics were compared by t-tests (continuous variables) or chi-square-tests (categorical variables). Logistic regression analysis was used to model the number of patients using benzodiazepines/using more than 90 DDDs/using benzodiazepines during three or more consecutive months. The independent variables were group membership, year, age, gender, insurance status $(27 ; 35 ; 36)$. All regressions were carried out within a multi-level framework since it accounts for the dependency of observations in our study 
$(35 ; 37 ; 38)$. We specified the following levels: level 1: measurement occasion, level 2: patient, level 3: family, level 4: practice. In analyses involving only three practices (the comparison of parents of fire victims and community controls), level 4 was eliminated and practice was introduced into the model as an additional independent variable. The variable year was dummy-coded in order to model the repeated measurements. The omitted category was the year 2000 which functions as a baseline. Next to the main effects, interaction terms were introduced, indicating whether the risk for using benzodiazepines/using more than 90 DDDs/using benzodiazepines during three or more consecutive months was higher in these patients than in patients belonging to the reference group during the year in question, holding all other variables in the equation constant. Coefficients are presented as odds ratios (OR) with 95\% confidence intervals. For the analyses, we used the MLWiN (version 1.1) and SPSS (version 11.5) software packages.

\section{Results}

Table 7.1 presents patient characteristics at baseline. Parents of victims $(n=496)$ and community controls $(n=1,709)$ did not differ in respect of the proportion of women or patients with private health insurance, neither did community controls nor the LINH-cohort. Although small in size, the age difference between the parents and community controls and community controls and the LINH-cohort was statistically significant $(\mathrm{p}=.013$ and $\mathrm{p}=.027)$. 27 parents had lost a child due to the fire (5.4\%) and 275 parents had a child who suffered from burn injuries as a consequence of the fire (55.4\%). 
Table 7.1: Background characteristics of parents of victims, community controls and non-community controls (LINH)

\begin{tabular}{|c|c|c|c|c|c|}
\hline & $\begin{array}{r}\begin{array}{r}\text { Parents of } \\
\text { victims }\end{array} \\
n=496\end{array}$ & $\begin{array}{r}\text { Community } \\
\text { controls } \\
n=1,709 \\
\end{array}$ & $\begin{array}{r}\text { LINH } \\
\mathrm{n}=4,530\end{array}$ & $\begin{array}{r}\text { Comparison } \\
\text { parents vs. } \\
\text { community } \\
\text { controls } \\
\end{array}$ & $\begin{array}{r}\text { Comparison } \\
\text { community } \\
\text { controls vs. } \\
\text { LINH } \\
\end{array}$ \\
\hline \multicolumn{6}{|l|}{ Gender } \\
\hline Men (\%) & $237(47.8)$ & 819 (47.9) & $2,153(47.5)$ & n.s. ${ }^{*}$ & n.s. $\#$ \\
\hline Women (\%) & $259(52.2)$ & $890(52.1)$ & 2,377 (52.5) & & \\
\hline Mean age (std) & $46.1(4.6)$ & $46.7(4.8)$ & $46.4(5.1)$ & * & * \\
\hline \multicolumn{6}{|l|}{ Insurance } \\
\hline Public (\%) & $302(60.9)$ & 963 (56.3) & $2,526(55.8)$ & n.s. ${ }^{*}$ & n.s. ${ }^{\prime}$ \\
\hline Private (\%) & $194(39.1)$ & $746(43.7)$ & $2,004(44.2)$ & & \\
\hline $\begin{array}{l}\text { Lost a child due } \\
\text { to the fire }(\%)\end{array}$ & $27(5.4)$ & - & - & - & - \\
\hline $\begin{array}{l}\text { Child has burn } \\
\text { injuries (\%) }\end{array}$ & $275(55.4)$ & - & - & - & - \\
\hline
\end{tabular}

${ }^{*} \mathrm{p}<.05$; \#not significant.

Table 7.2 presents, on an annual basis, the proportion of users, the proportion of patients who use more than 90 DDDs and the proportion of patients who use benzodiazepines in at least three consecutive months. The proportions in patients belonging to the LINH-cohort were much lower than in parents or community controls, which can be ascribed to the different types of registration systems (LINH: GP-based registrations, community controls and parents: pharmacy-based registrations). At baseline, during the year preceding the fire, parents and community controls did not differ from each other (table 7.2). In the parent group, during the first year after the fire, there was a stronger increase of the number of users, the number of patients with more than 90 DDDs and the number of patients with more than 3 months of use when compared to the community controls. In the other two years post-fire (2002 and 2003), the proportions in the parent group were lower than in 2001, but still higher than in 2000. In the LINH- and SFKcohorts, the proportions were slightly increasing throughout the years. 
Table 7.2: Number of users, number of patients with $>90$ DDDs, patients with 3 or more months of use; comparison of parents $(\mathrm{P})$, community controls (C), non-community controls (LINH) and national estimates (SFK), one year pre-fire and three years postfire

\begin{tabular}{lrrrr}
\hline Outcome measure & $\begin{array}{r}2000 \\
\text { (pre-fire) }\end{array}$ & $\begin{array}{r}2001 \\
\text { (post-fire) }\end{array}$ & $\begin{array}{r}2002 \\
\text { (post-fire) }\end{array}$ & $\begin{array}{r}2003 \\
\text { (post-fire) }\end{array}$ \\
\hline Users (\%) & & & & \\
P & $101(20.4)$ & $153(30.8)$ & $113(22.8)$ & $120(24.2)$ \\
C & $328(19.2)$ & $360(21.1)$ & $334(19.5)$ & $347(20.3)$ \\
LINH & $503(11.1)$ & $504(11.1)$ & $478(10.6)$ & $501(11.1)$ \\
SFK & $455,925(19.6)$ & $454,569(20.0)$ & $453,148(20.3)$ & $446,651(20.4)$ \\
> 90 DDDs (\%) & & & & \\
P & $33(6.7)$ & $50(10.1)$ & $43(8.7)$ & $44(8.9)$ \\
C & $109(6.4)$ & $114(6.7)$ & $118(6.9)$ & $126(7.4)$ \\
LINH & $88(1.9)$ & $93(2.1)$ & $92(2.0)$ & $101(2.2)$ \\
>=3 months (\%) & & & & \\
P & $29(5.8)$ & $43(8.7)$ & $33(6.7)$ & $40(8.1)$ \\
C & $98(5.7)$ & $99(5.8)$ & $100(5.9)$ & $103(6.0)$ \\
LINH & $87(1.9)$ & $99(2.2)$ & $99(2.2)$ & $112(2.5)$ \\
\hline
\end{tabular}

a Adjusted for age and gender $(n=2,324,265)$.

\section{Comparison of parents, community controls and the LINH-cohort}

In a next step, these figures were submitted to statistical testing (table 7.3). The models 1 to 3 compare parents and community controls, the models 4 to 6 deal with the comparison of community controls and the LINH-cohort. According to model 1 (table 7.3), in the first year post-fire, the risk for using benzodiazepines for parents was 1.58 times the risk for community controls (95\% CI 1.13-2.23). In 2002 and 2003, differences between the two groups were not statistically significant. The two indicators for long-term use (more than 90 DDDs per year or three or more months of use), were non-significant for every year post-fire, indicating that community controls and parents did not differ in any of the years with respect to long-term use. 
Table 7.3: Logistic regression analysis with group membership predicting being a user, using more than 90 DDDs, using benzodiazepines during 3 or more months; comparison of parents $(\mathrm{P})$ and community controls (C) and non-community controls (LINH), one year pre-fire and three years post-fire

\begin{tabular}{|c|c|c|c|c|c|c|}
\hline \multirow{3}{*}{ User $^{1}$} & \multicolumn{3}{|c|}{$\mathrm{P}_{\mathrm{vs} \mathrm{C}^{4}}$} & \multicolumn{3}{|c|}{ C vs. LINH ${ }^{5}$} \\
\hline & \multicolumn{3}{|c|}{ Model 1} & \multicolumn{3}{|c|}{ Model 4} \\
\hline & OR & \multicolumn{2}{|c|}{$95 \% \mathrm{CI}$} & OR & \multicolumn{2}{|c|}{$95 \% \mathrm{CI}$} \\
\hline Group & 1.10 & 0.85 & 1.42 & 1.91 & 1.64 & 2.22 \\
\hline $2001^{6}$ & 1.13 & 0.95 & 1.34 & 1.00 & 0.88 & 1.14 \\
\hline $2002^{6}$ & 1.02 & 0.86 & 1.22 & 0.94 & 0.83 & 1.08 \\
\hline $2003^{6}$ & 1.08 & 0.91 & 1.28 & 1.00 & 0.87 & 1.14 \\
\hline Group*2001 & 1.58 & 1.13 & 2.23 & 1.12 & 0.91 & 1.39 \\
\hline Group*2002 & 1.13 & 0.80 & 1.61 & 1.08 & 0.87 & 1.35 \\
\hline Group*2003 & 1.17 & 0.83 & 1.66 & 1.08 & 0.87 & 1.34 \\
\hline \multirow[t]{2}{*}{$>90$ DDDs $^{2}$} & \multicolumn{3}{|c|}{ Model 2} & \multicolumn{3}{|c|}{ Model 5} \\
\hline & OR & \multicolumn{2}{|c|}{$95 \% \mathrm{CI}$} & OR & \multicolumn{2}{|c|}{$95 \% \mathrm{CI}$} \\
\hline Group & 1.08 & 0.72 & 1.63 & 3.39 & 2.55 & 4.51 \\
\hline $2001^{6}$ & 1.05 & 0.80 & 1.38 & 1.06 & 0.79 & 1.42 \\
\hline $2002^{6}$ & 1.09 & 0.83 & 1.43 & 1.05 & 0.78 & 1.40 \\
\hline $2003^{6}$ & 1.17 & 0.90 & 1.53 & 1.15 & 0.87 & 1.53 \\
\hline Group*2001 & 1.51 & 0.89 & 2.59 & 0.99 & 0.67 & 1.48 \\
\hline Group*2002 & 1.23 & 0.71 & 2.12 & 1.04 & 0.70 & 1.55 \\
\hline Group*2003 & 1.17 & 0.68 & 2.02 & 1.02 & 0.69 & 1.50 \\
\hline \multirow[t]{2}{*}{$>=3$ months ${ }^{3}$} & \multicolumn{3}{|c|}{ Model 3} & \multicolumn{3}{|c|}{ Model 6} \\
\hline & OR & \multicolumn{2}{|c|}{$95 \% \mathrm{CI}$} & OR & \multicolumn{2}{|c|}{$95 \% \mathrm{CI}$} \\
\hline Group & 1.01 & 0.76 & 1.35 & 3.06 & 2.29 & 4.09 \\
\hline $2001^{6}$ & 1.02 & 0.77 & 1.36 & 1.14 & 0.86 & 1.52 \\
\hline $2002^{6}$ & 1.06 & 0.79 & 1.40 & 1.14 & 0.86 & 1.52 \\
\hline $2003^{6}$ & 1.53 & 0.87 & 2.69 & 1.30 & 0.98 & 1.71 \\
\hline Group*2001 & 1.13 & 0.63 & 2.03 & 0.89 & 0.59 & 1.33 \\
\hline Group*2002 & 1.35 & 0.76 & 2.39 & 0.90 & 0.60 & 1.34 \\
\hline Group*2003 & 1.01 & 0.76 & 1.35 & 0.81 & 0.55 & 1.21 \\
\hline
\end{tabular}

${ }^{1}$ Coefficients adjusted for gender, age, insurance status; dependent variable is coded as user (1), non-user (0).

2 Coefficients adjusted for gender, age, insurance status; dependent variable is coded as receiving more than 90 DDDs (1), 0-90 DDDs (0).

3 Coefficients adjusted for gender, age, insurance status; dependent variable is coded as receiving a prescription in at least three or more consecutive months (1), not receiving a prescription/receiving a prescription in less than three consecutive months (0).

${ }_{4}$ Dummy variable; reference category is community controls.

5 Dummy variable; reference category is LINH-cohort.

${ }^{6}$ Dummy variable; reference category is year 2000 (pre-fire). 
A second set of regression analyses dealt with the comparison of community controls and the LINH-cohort (models 4 to 6, table 7.3). This analysis provided insight into the development over the course of time. The main effect of 'group' was significant for every outcome measure (being a user: OR 1.91, 95\% CI 1.64-2.22; using more than 90 DDDs: OR 3.39, 95\% CI 2.554.51; using three or more months: OR 3.06, 95\% CI 2.29-4.09), indicating that community controls and the LINH-cohort generally differed with respect to these measures. Since none of the interaction terms reached statistical significance, we can conclude that this effect was independent of the year under study. Community controls thus followed the same development over time as patients from the LINH-cohort for any of the three outcome measures.

\section{Determinants specific to parents of victims}

In a separate analysis, we studied determinants specific to parents of victims (table 7.4). We aimed at answering the question (1) whether parents of survivors with burns differ from parents of survivors without burns, (2) whether bereaved parents differ from non-bereaved parents and (3) whether affected mothers are more likely to use benzodiazepines than affected fathers. Since the number of patients who were using benzodiazepines for more than three months or using more than 90 DDDs was low, and significant effects were hard to detect under these circumstances, the analysis was only carried out for the outcome 'being a user'. As model 1 (table 7.4) indicates, parents of survivors with burns were more likely to use benzodiazepines than parents of survivors without burns (OR 2.16, 95\% CI 1.32-3.52), the likelihood was not significantly associated with the year of the study, however (no significant interaction terms). According to model 2 (table 7.4), bereaved parents were more likely to use benzodiazepines during the first (OR 3.99, 95\% CI 1.13-14.12) and second year post-disaster (OR 3.78, 95\% CI 1.09-13.09), but not during the third year post-disaster. It must be noted that the estimates were unstable due to the small cell sizes, which is reflected in the large confidence intervals. Finally, mothers of survivors were generally more likely to use benzodiazepines than fathers (OR 2.03, 95\% CI 1.41-2.94), but this was independent of the year of study and thus not related to the fire (interaction terms not significant). 
Table 7.4: Logistic regression analysis with being the parent of a child with burns, being a bereaved parent, being a mother, predicting being a user; one year pre-fire and three years post-fire

\begin{tabular}{|c|c|c|c|}
\hline \multirow[b]{3}{*}{ Bereav $^{4}$} & \multicolumn{3}{|c|}{ Model 1} \\
\hline & \multirow{2}{*}{$\begin{array}{l}\mathrm{OR}^{1} \\
5.17\end{array}$} & \multicolumn{2}{|c|}{$95 \% \mathrm{CI}$} \\
\hline & & 3.34 & 7.98 \\
\hline Burn $^{3}$ & 2.16 & 1.32 & 3.52 \\
\hline $2001^{6}$ & 1.82 & 1.33 & 2.49 \\
\hline $2002^{6}$ & 1.19 & 0.86 & 1.64 \\
\hline $2003^{6}$ & 1.31 & 0.95 & 1.80 \\
\hline Burn*2001 & 1.27 & 0.67 & 2.41 \\
\hline Burn*2002 & 0.82 & 0.43 & 1.59 \\
\hline \multirow[t]{3}{*}{ Burn*2003 } & 0.52 & 0.27 & 0.99 \\
\hline & \multicolumn{3}{|c|}{ Model 2} \\
\hline & $\mathrm{OR}^{1}$ & & \\
\hline Burn $^{3}$ & 1.86 & 1.47 & 2.36 \\
\hline Bereav $^{4}$ & 1.89 & 0.74 & 4.80 \\
\hline $2001^{6}$ & 1.80 & 1.33 & 2.45 \\
\hline $2002^{6}$ & 1.14 & 0.83 & 1.56 \\
\hline $2003^{6}$ & 1.24 & 0.91 & 1.70 \\
\hline Bereav²001 & 3.99 & 1.13 & 14.12 \\
\hline Bereav²002 & 3.78 & 1.09 & 13.09 \\
\hline \multirow[t]{3}{*}{ Bereav*2003 } & 3.44 & 0.99 & 11.90 \\
\hline & \multicolumn{3}{|c|}{ Model 3} \\
\hline & $\mathrm{OR}^{2}$ & & \\
\hline Gender 6 & 2.03 & 1.41 & 2.94 \\
\hline $2001^{5}$ & 1.53 & 1.21 & 1.92 \\
\hline $2002^{5}$ & 1.06 & 0.82 & 1.36 \\
\hline $2003^{5}$ & 1.15 & 0.89 & 1.47 \\
\hline Gender*2001 & 0.96 & 0.60 & 1.52 \\
\hline Gender*2002 & 1.34 & 0.80 & 2.25 \\
\hline Gender*2003 & 1.22 & 0.74 & 2.02 \\
\hline
\end{tabular}

1 Coefficients adjusted for gender, age, insurance status; dependent variable is coded as user (1), non-user (0).

2 Coefficients adjusted for age, insurance status; dependent variable is coded as user (1), nonuser (0).

3 Dummy variable; reference category is parents of survivor without burns.

4 Dummy variable; reference category is non-bereaved parents of survivors.

${ }^{5}$ Dummy variable; reference category is year 2000 (pre-fire).

6 Dummy variable; reference category is male. 


\section{Discussion}

Our analyses demonstrate that during the first year after the fire, the parents of fire victims were 1.58 times more likely to use benzodiazepines when compared to community controls. In the following years, the proportion of users was still higher in parents than in community controls, but these differences did not reach statistical significance. In respect of long-term use, no significant differences between parents and community controls were found. Our results thus show that benzodiazepines were predominantly prescribed as a short-term intervention. We therefore conclude that clinical guidelines which advocate a conservative prescription policy were generally well adhered to.

Since it could not be ruled out that the fire had effects on community controls as well, we also examined the benzodiazepine use of a cohort of patients outside Volendam. The a-priori differences between the two groups were large, which very likely was due to the different kinds of registration systems used to collect the data. Community controls and patients from the LINH-cohort follow the same trend over time. This indicates that the benzodiazepine use of community controls was not influenced by the disaster in significant ways. In addition, our findings indicate that both before and after the fire, the percentage of benzodiazepine users in the unaffected families in Volendam was comparable to the percentage found elsewhere in the Netherlands.

Finally, we studied determinants which are specific to parents of fire victims. More precisely, we expected parents of burn victims, mothers and bereaved parents to be more likely to use benzodiazepines. Our results showed that parents of victims with burns did not significantly differ from parents of physically uninjured victims in respect to benzodiazepine use. Already before the fire, the share of benzodiazepine users was higher among parents of burn victims. The same applied for women. The last finding is consistent with other studies on benzodiazepine use which generally indicate that women are more likely to use benzodiazepines then men $(27 ; 28 ; 35 ; 36)$. Furthermore, as expected, our study demonstrated that parents who had lost a child due to the fire were more likely to use benzodiazepines 
during the first and the second year after the fire when compared to parents of surviving victims.

In this context, some limitations of our study should be noted. First, the number of bereaved parents in our study was small $(n=27)$ and the power of the analyses was therefore low. This is reflected in relatively large confidence intervals. The same was the case when indicators of long-term use were examined. With small sample sizes, significant effects are hard to detect. Second, the fact that having a child with burn injuries did not significantly predict benzodiazepine use in our study, could be due to the circumstance that parents of seriously burned victims had been seen in specialized burn centers, especially during the first months after the fire. It cannot be ruled out that some of the parents had received benzodiazepines there. Since these clinics are located outside of Volendam (17;39), we were not able to capture benzodiazepine use in these cases. It should be noted that, although not statistically significant, our results pointed into the expected direction.

Generally, our findings probably provided a slight underestimation of benzodiazepine users since the pharmacy records used here supplied information on benzodiazepine prescriptions issued on an extramural basis. Inpatient benzodiazepine use thus could not be monitored here. The underestimation should be very small, however, since in the Netherlands more than $95 \%$ of benzodiazepines are prescribed in family practice (27). Another issue concerns the calculation of the rate of long-term benzodiazepine users. In the first year of the study, this rate may have been underestimated. More specifically, some patients may have met the definition of long-term use if their use in the months before the chosen time window was known. Since this underestimation applies to all examined groups, it will not affect the conclusions of the study.

Finally, it should be noted that drug prescribing does not necessarily equal drug intake. Although the term benzodiazepine use was applied in this article, the present study primarily provided evidence on prescriber behavior and not on the actual use of benzodiazepines. 
In spite of these limitations, the study has several strengths. First of all, its design was robust, with the presence of base-line data, the use of two control groups (LINH-cohort and community controls) and the long follow-up period. Furthermore, non-response bias and recall bias, which can be a problem in survey data, could be ruled out since the study was based on existing electronic registrations (40-42). Finally, as we were able to link the pharmacy records to information stemming from the patients' family- doctor records, additional information on the consumers of the drugs was available and a population-based approach was possible - a circumstance which is rather the exception than the rule in drug epidemiology research (43).

On the one hand, this chapter shows that health care providers indeed prescribed benzodiazepines more often to patients who suffered from disaster-related distress. On the other hand, they seemed to prescribe in a way that minimized the risk of abuse and dependence. Possibly, this was the result of the continuous efforts to promote a rational use of benzodiazepines in the past (44).

\section{Acknowledgements}

This study was financially supported by the Dutch Ministry of Health. We thank Arnoul van Mierlo for the provision of the pharmacy data, Petra ten Veen for the data management and Harald Abrahamse for preparing the LINH data set. 


\section{References}

1. de Lusignan $S$, van Weel C. The use of routinely collected computer data for research in primary care: opportunities and challenges. Fam Pract 2006; 23(2):253-63.

2. Knottnerus JA. Role of the electronic patient record in the development of general practice in The Netherlands. Methods Inf Med 1999; 38(4-5):350-54.

3. van Bemmel JH, Musen MA. Handbook of Medical Informatics. Houten: Bohn Stafleu Van Loghum, 1997.

4. van Mil JW. Pharmaceutical care in community pharmacy: practice and research in the Netherlands. Ann Pharmacother 2005; 39(10):1720-25.

5. Porteous T, Bond C, Robertson R, Hannaford P, Reiter E. Electronic transfer of prescription-related information: comparing views of patients, general practitioners, and pharmacists. Br J Gen Pract 2003; 53(488):204-09.

6. Salzman C. The APA Task Force report on benzodiazepine dependence, toxicity, and abuse. Am J Psychiatry 1991; 148(2):151-52.

7. Bromet E, Dew MA. Review of psychiatric epidemiological research on disasters. Epidemiological Reviews 1995; 17(1):113-19.

8. Norris FH, Friedman MJ, Watson PJ. 60,000 disaster victims speak: Part II. Summary and implications of the disaster mental health research. Psychiatry 2002; 65(3):240-60.

9. Norris FH, Friedman MJ, Watson PJ, Byrne CM, Diaz E, Kaniasty K. 60,000 disaster victims speak: Part I. An empirical review of the empirical literature, 1981-2001. Psychiatry 2002; 65(3):207-39.

10. Yzermans CJ, Donker GA, Kerssens JJ, Dirkzwager AJ, Soeteman RJ, Ten Veen PM. Health problems of victims before and after disaster: a longitudinal study in general practice. Int J Epidemiol 2005; 34:810-19.

11. Herz M. Benzodiazepine prescribing in a community in crisis. Fam Pract 1993; 10(3):31719.

12. Isacson D, Carsjo K, Bergman U, Blackburn JL. Long-term use of benzodiazepines in a Swedish community: an eight-year follow-up. J Clin Epidemiol 1992; 45(4):429-36.

13. van Hulten R, Isacson D, Bakker A, Leufkens HG. Comparing patterns of long-term benzodiazepine use between a Dutch and a Swedish community. Pharmacoepidemiol Drug Saf 2003; 12(1):49-53.

14. Ashton H. Guidelines for the rational use of benzodiazepines. When and what to use. Drugs 1994; 48(1):25-40.

15. Gorgels WJ, Oude Voshaar RC, Mol AJ, Breteler MH, van de Lisdonk EH, Zitman FG. (Long-term use of benzodiazepines). Ned Tijdschr Geneeskd 2001; 145(28):1342-46.

16. van Harten SM, Welling L, Perez RS, Patka P, Kreis RW. Management of multiple burn casualties from the Volendam disaster in the emergency departments of general hospitals. Eur J Emerg Med 2005; 12(6):270-74.

17. Welling L, van Harten SM, Patka P, Bierens JJ, Boers M, Luitse JS et al. The café fire on New Year's Eve in Volendam, the Netherlands: description of events. Burns 2005; 31(5):548-54. 
18. van Vugt AB. (Disaster medicine: lessons from Enschede and Volendam). Ned Tijdschr Geneeskd 2001; 145(48):2309-12.

19. Barnes MF. Understanding the secondary traumatic stress of parents. In: Figley CR. The systemic costs of caring. Boca Raton, FL, US: CRC Press, 1998; 75-89.

20. Landolt MA, Vollrath M, Ribi K, Gnehm HE, Sennhauser FH. Incidence and associations of parental and child posttraumatic stress symptoms in pediatric patients. J Child Psychol Psychiatry 2003; 44(8):1199-1207.

21. Shelby J, Sullivan J, Groussman M, Gray R, Saffle J. Severe burn injury: effects on psychologic and immunologic function in noninjured close relatives. J Burn Care Rehabil 1992; 13(1):58-63.

22. Watkins PN, Cook EL, May SR, Still JM, Jr., Luterman A, Purvis RJ. Postburn psychologic adaptation of family members of patients with burns. J Burn Care Rehabil 1996; 17(1):7892.

23. Dorn T, Yzermans CJ, Guijt H, van der Zee J. Disaster-related stress as a prospective risk factor for hypertension in parents of adolescent disaster victims. American Journal of Epidemiology 2007; 165(4):410-7.

24. Dorn T, Yzermans CJ, Kerssens JJ, Spreeuwenberg PM, van der Zee J. Disaster and subsequent healthcare utilization: a longitudinal study among victims, their family members, and control subjects. Med Care 2006; 44(6):581-89.

25. Applebaum DR, Burns GL. Unexpected childhood death: Posttraumatic stress disorder in surviving siblings and parents. Journal of Clinical Child Psychology 1991; 20(2):114-20.

26. Stroebe W, Schut H. Risk factors in bereavement outcome: A methodological and empirical review. In: Stroebe MS, editor. Handbook of bereavement research: Consequences, coping, and care. Washington, DC: American Psychological Association, 2001; 349-71.

27. van der Waals FW, Mohrs J, Foets M. Sex differences among recipients of benzodiazepines in Dutch general practice. BMJ 1993; 307(6900):363-66.

28. Paulose-Ram R, Jonas BS, Orwig D, Safran MA. Prescription psychotropic medication use among the U.S. adult population: results from the third National Health and Nutrition Examination Survey, 1988-1994. J Clin Epidemiol 2004; 57(3):309-17.

29. Ohayon MM, Caulet M, Priest RG, Guilleminault C. Psychotropic medication consumption patterns in the UK general population. J Clin Epidemiol 1998; 51(3):273-83.

30. Boerma WGW, Fleming DM. The role of general practice in primary health care. London: World Health Organization, 1998.

31. Landelijk Informatienetwerk Huisartsenzorg. Feiten en cijfers over huisartsenzorg in Nederland (LINH web-site). Verheij R., editor. http://www.linh.nl. Accessed 3-4-2006.

32. Florentinus SR. New drugs in general practice - Prescribing patterns and external influences. Dissertation, University of Utrecht, the Netherlands, 2006.

33. WHO Collaborating Centre for Drug Statistics Methodology. Anatomical Therapeutic Chemical (ATC) Classification System. http://www.whocc.no/atcddd/. Accessed 1-1-2006.

34. Health Council of the Netherlands: Committee on Medical Technology Assessment. Towards the effective use of benzodiazepines. The Hague: Health Council of the Netherlands, 1998. 
35. Groenewegen PP, Leufkens HG, Spreeuwenberg P, Worm W. Neighbourhood characteristics and use of benzodiazepines in The Netherlands. Soc Sci Med 1999; 48(12):1701-11.

36. Gene-Badia J, Blay-Pueyo C, Soler-Vila M. Risk factors in the use of benzodiazepines. Fam Pract 1988; 5(4):283-88.

37. Snijder TB, Bosker R. Multilevel analysis: an introduction to basic and advanced multilevel modeling. Thousand Oaks, CA: Sage, 1999.

38. Cardol M, Groenewegen PP, de Bakker DH, Spreeuwenberg P, van Dijk L, van den BW. Shared help seeking behaviour within families: a retrospective cohort study. BMJ 2005; 330(7496):882.

39. Pirson J, Degrave E. Aeromedical transfer to Belgium of severely burned patients during the initial days following the Volendam fire. Mil Med 2003; 168(5):360-63.

40. Beiderbeck AB, Sturkenboom MC, Coebergh JW, Leufkens HG, Stricker BH. Misclassification of exposure is high when interview data on drug use are used as a proxy measure of chronic drug use during follow-up. J Clin Epidemiol 2004; 57(9):973-77.

41. Klungel OH, de Boer A, Paes AH, Herings RM, Seidell JC, Bakker A. Influence of question structure on the recall of self-reported drug use. J Clin Epidemiol 2000; 53(3):273-77.

42. Korthuis PT, Asch S, Mancewicz M, Shapiro MF, Mathews WC, Cunningham WE et al. Measuring medication: do interviews agree with medical record and pharmacy data? Med Care 2002; 40(12):1270-82.

43. Schneeweiss S, Avorn J. A review of uses of health care utilization databases for epidemiological research on therapeutics. J Clin Epidemiol 2005; 58(4):323-37.

44. Rosenbaum JF. Attitudes toward benzodiazepines over the years. J Clin Psychiatry 2005; 66 Suppl 2:4-8. 
Chapter 7

152 
Chapter

Discussion

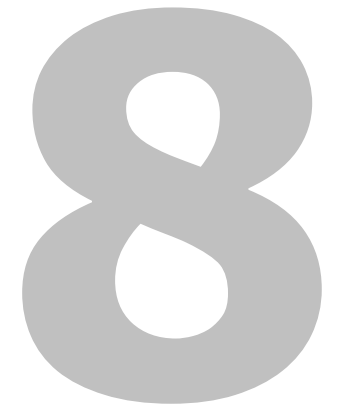


The aim of this final chapter is to provide an overview of findings described in the individual chapters and to address their implications for patient care, public policy and further research. 


\section{Overview of the main findings}

In essence, three research questions were posed. These were:

1. How does the Volendam fire influence the health of the population under study?

2. What is the influence of the Volendam fire on primary health care utilization and the utilization of medicines?

3. Is there a relationship between the degree of disaster exposure and the observed health effects?

The answers to these research questions will be briefly reviewed in the next section. For this purpose, a distinction between short and long-term effects is made, with short-term effects referring to effects seen during the first year after the fire and long-term effects referring to effects which persist beyond the first year.

Research question 1: How does the Volendam fire influence the health of the population under study?

The first research question dealt with the health problems of the affected population in Volendam. These health problems have been examined in three different chapters in both primary (chapter 3) and secondary victims (chapters 4 and 5)

\section{Primary victims}

$\checkmark$ Primary victims with burns suffered from long-term physical health problems, especially in the respiratory, dermatological and musculoskeletal tracts.

$\checkmark \quad$ No evidence was provided for adverse long-term physical health effects in primary victims without burns.

$\checkmark$ Mental health problems were found to be long-standing in primary victims with burns. In primary victims without burns, the increase in mental health problems was significantly larger during the first year after the fire when compared to community controls, but not in the following years. 
$\checkmark$ Community controls also exhibited post-fire increases in mental health problems, but the increases were significantly smaller than in victims without burns.

\section{Secondary victims}

$\checkmark$ The number of patients presenting with mental health problems significantly increased in parents of burn victims in the short-term and in the long-term (second year after the fire). In parents of victims without burns and in community controls, no significant increases were observed. The child's burned surface area and female gender were risk factors for mental health problems in parents of burn victims. Insurance type or the number of children who were affected by the fire were not significantly associated with mental health problems in parents of burn victims, however.

$\checkmark$ Significant post-fire increases in cardiovascular health problems were observed in all study groups, but the increases were largest in parents of victims with burns, followed by parents of victims without burns and community controls. Differences between parents of burn victims and community controls were significant, in contrast to those between parents of victims without burns and community controls.

$\checkmark$ In parents of primary victims with burns, no effects were found for gastrointestinal, respiratory, musculoskeletal or dermatological health problems.

$\checkmark$ In parents of children with burns, cardiovascular health problems during follow-up were significantly associated with female gender and public health insurance, but not with the number of children affected by the fire or the total burn surface area of the child.

In order to shed more light on the development of hypertension after the fire, a cohort study was performed based on parents of primary victims without prior evidence of hypertension (chapter 5). The analyses demonstrated that

$\checkmark$ parents of fire victims were significantly more likely to develop hypertension during the 4-year follow-up period when compared to parents of children who had not been involved in the disaster (community controls) 
$\checkmark$ the percentage of new cases of hypertension was highest in bereaved parents, followed by parents of victims with burns and parents of victims without burns who were at comparable levels. The differences between the groups were statistically non-significant, however.

Research question 2: What is the influence of the Volendam fire on primary health care utilization and the utilization of medicines?

Two aspects of utilization were assessed in the context of this thesis, viz., the number of contacts in primary care and the use of benzodiazepines (chapter 6).

\section{Primary health care utilization}

$\checkmark$ With regard to utilization in general, long term effects of the fire were seen only in primary victims with burns. Short-term effects, by contrast, were observed in primary victims without burns and in parents of primary victims. In siblings of primary victims and tertiary victims (community controls), no effects were found.

$\checkmark$ With respect to utilization for mental health problems, long-term effects were visible in primary victims with burns and in parents of primary victims. In primary victims without burns, only short-term effects were seen. In siblings of primary victims, no effects were observed.

$\checkmark \quad$ In addition to this, the influence of bereavement and living with a primary victim with burns were examined.

$\checkmark$ With regard to utilization in general, a short-term effect was observed in bereaved family members, both in siblings and parents of the deceased. Besides this, mental health care utilization was significantly elevated during the first and second year post-fire in bereaved parents when compared to non-bereaved parents. No effect was found in bereaved siblings.

$\checkmark$ Utilization in general and utilization for mental health problems was comparable in family members of children with burns and family members of children without burns, both in the short and in the long term. 


\section{Benzodiazepine use}

$\checkmark$ With respect to benzodiazepine use, only short-term effects were observed and they were seen only in parents of primary victims, but not in community controls (tertiary victims).

$\checkmark$ In addition, with regard to problematic patterns of use (defined as use in 3 or more consecutive months or more than 90 daily defined doses per year), no differences between the groups were found.

$\checkmark$ When compared to non-bereaved parents of primary victims, bereaved parents were more likely to use benzodiazepines during the first and second, but not during the third year after the fire. No difference was found between parents of primary victims with burns and parents of primary victims without burns, however.

$\checkmark$ Mothers of primary victims, finally, were more often users of benzodiazepines than fathers, but the increase in use was the same in mothers and fathers.

Research question 3: Is there a relationship between the degree of disaster exposure and the observed health effects?

A final question was whether a relationship existed between the varying degrees of disaster exposure and the observed health effects. In the younger age group, exposure was assumed to be highest in primary victims with burns, followed by primary victims without burns and community controls. In the adult group, the severity of adversity was hypothesized to be highest in parents of victims who suffered burns, followed by parents of victims who had been present during the fire but survived without burns. Bereavement was considered a risk factor for adverse outcomes, while community controls were thought to have the least exposure to the disaster.

\section{Primary victims}

$\checkmark$ A relationship is clearly visible in primary disaster victims, with burn victims being in poorer physical health than victims without burns. Also the mental health effects seen in victims with burns are stronger than in victims without burns. In line with expectations, the effects are weakest in community controls. This pattern is also observed when health care utilization is considered as an outcome. 


\section{Secondary disaster victims}

$\checkmark$ Bereavement was studied as a risk factor in the studies on primary health care utilization, benzodiazepine use and hypertension. All three studies showed conclusively that bereaved parents were at increased risk for adverse health outcomes when compared to non-bereaved parents. For the outcomes primary health care utilization and benzodiazepine use, the association was statistically significant; for hypertension the association pointed in the expected direction, but was non-significant.

$\checkmark$ Neither the study on primary health care utilization, nor the study on benzodiazepines, nor the study on hypertension reported significant differences between the parents of victims with burns and parents of victims without burns. An exception is the study on health problems which delineated significant differences between the different parent groups with regard to mental and cardiovascular health problems.

There are two types of explanations for these inconsistencies. One is methodological, the other theoretical. To start with the methodological explanation, when considering the study on hypertension, it should be noted that on a descriptive level, the incidence of new hypertension was highest in bereaved parents but this difference did not reach statistical significance. This could be due to the small number of bereaved parents included in the study $(n=23)$. Only if effects are large enough is statistical significance reached. This was apparently the case in the study on primary health care utilization and benzodiazepine use where bereavement was found to be a significant predictor.

In addition, the way outcomes were assessed was different in each study. In the first case, cardiovascular health problems as defined by the ICPCchapter 'cardiovascular' were considered. This chapter includes a broad array of cardiovascular problems, ranging from minor complaints (e.g. awareness of heartbeat, tightness in chest) to the more severe endpoints of cardiovascular disease (e.g. stroke, myocardial infarction). Hypertension is the most prevalent health problem within this chapter. Apparently, only when the outcome definition is based on the broader ICPC-chapter, is a difference between parents of victims with and without burns seen, and not 
when solely hypertension is considered. In contrast to the first study, the assessment of hypertension was not only based on the registrations of family practitioners, but was derived from a combination of ICPC-codes for hypertension and the prescription of antihypertensive medications. Also, the second study was carried out for subjects without prior evidence of hypertension, whereas the first study included all patients. A final difference between the two studies is the fact that the hypertension study controlled for a number of confounders which are known to elevate the risk for hypertension. Leaving these differences in methodology aside, other explanations can be given for the failure to identify differences between parents of victims with burns and parents of victims without burns in the hypertension study. Our study was based on the implicit assumption that life stress would be higher in parents of victims with burns than in parents of victims without burns. Stress was not assessed directly, however. It is possible that stress management was more successful in parents of burn victims because more resources were directed at these parents when compared to parents of non-burn victims.

\section{Methodological considerations}

\section{Generalizability of findings}

One central issue in any type of research is the question whether results can be generalized to other settings and populations. In our case, there are three important points to consider. The first point concerns the question whether the findings of this study are representative for the other populations within and outside Volendam. The second point is whether our findings can be generalized to other health care settings. A final point concerns the generalizability of findings to other disasters.

\section{Generalizability to other populations in and outside Volendam}

Conclusions regarding the first aspect are positive since approximately $86 \%$ of the adolescents present in the building when the fire broke out could be included in the study. As noted in chapter 2 of this thesis, the included victims did not significantly differ from victims who could not be included because they were registered with the non-participating practice in regard to 
gender, insurance type, burn size or number of days spent in hospital during the first year after the disaster. They can thus be considered as representative of the population of victims in general. The parents and siblings of these victims were traced with the help of the information included in the electronic patient file, namely through a unique household number which is assigned to patients registered at the same address. Community controls, in turn, were included provided that they belonged to families with children of the same age as the disaster victims. This resulted in a sample of control parents from the same community with an age-gender structure comparable to the one found in parents of disaster victims. Although differences existed with respect to insurance type, the confounding influence of insurance type was corrected by statistical means. The cohort of community controls was thus not selected to represent the Volendam community in general, but to provide a comparison group for the parents of the disaster victims. Findings concerning the community controls can thus be best generalized to unaffected parents of teenage children in Volendam. Findings concerning the parents of disaster victims, respectively, can be generalized to the population of parents of Volendam disaster victims.

A subgroup of these parents comprised parents of children with burns. As already noted, the literature on parents of children with burns was often based on clinic samples, and fathers are heavily underrepresented in the research literature (chapter 4). This is no surprise since clinic based samples tend to suffer from selection bias, often excluding parents who cope relatively well despite the burn incident, as well as males who are generally less inclined to participate in surveys. Our study, by contrast, did not suffer from this sort of bias since individual consent of parents for extracting the information captured in the electronic patient files was not necessary. A strength of the findings presented in this thesis is thus that the results can be better generalized to the population of parents of adolescents with burns than was the case in previous literature. 


\section{Generalizability regarding other health care settings}

Another important aspect concerns the question: to which kind of health care systems can this study be generalized? The research was carried out in a gate-keeping health care system which assigns a key role to family practitioners. In the Netherlands, the bulk of health problems is addressed in the primary care setting, and access to specialists is generally only possible after referral by the family practitioner. The study on health care utilization as presented in chapter 6 of this thesis in particular, but also the other studies can thus best be generalized to other highly regulated health care systems. Such systems can be either found in other European countries such as the UK, but they are also operational in the US where a fixed patient population is enrolled with one health maintenance organization.

\section{Generalizability regarding other disasters}

A last point concerns the question: to which kinds of disasters can the findings presented in this thesis be generalized? First, the age-structure of both victims and parents in our study was specific, since in Volendam, the victims of the disaster were almost all teenagers and, consequently, their parents were of middle age. In other disasters, the age of the victims might be more heterogeneous than in the current study. Second, as outlined in the introductory section, the Volendam fire can be classified as a man-made disaster with a one-time impact and no ongoing threat. Although the number of casualties was high, the loss of property was minimal and the local infrastructure was not affected. It occurred in a wealthy country which was able to provide various types of support to victims. Altogether, these efforts may have alleviated the long-term consequences of the disaster.

\section{Strengths of the study}

This study has several strengths which can be grouped into three categories. These are (1) the breadth of health outcomes examined, (2) the fact that the family was taken into account as a unit of analysis and (3) the way the data were collected. 
The types of health outcomes examined in the context of this thesis are not very typical for disaster research. While the research on the psychosocial consequences of disasters is vast, less is known on how disaster-related stress influences physical health (1). Equally, the literature on parents of burn victims is marked by a lack of studies which consider physical health outcomes (chapter 4).

Second, this study incorporated a systemic point of view by taking into account the family as a unit, rather than just the individuals who survived the fire. This view is particularly important given that traumatic experiences and stressful life events frequently involve the entire support system of the victim.

Third, the way data were collected in this study is relatively new to disaster research. The monitoring of post-disaster health effects, based on the electronic registries of family practitioners and pharmacies, has several advantages over survey data. In short, these are the possibilities permitted:

$\checkmark$ to collect data in a way that does not interfere with the lives of disaster victims and is therefore less burdensome to them

$\checkmark \quad$ to reduce selection bias and recall bias

$\checkmark$ to determine the size of the population at risk, that is the denominator needed when calculating rates

$\checkmark$ to take account of information on pre-disaster health.

The last point is especially important, since only few studies on disasters exist which are able to provide pre-disaster assessments. When pre-disaster health is taken into account, the confounding of study results due to predisaster health differences between exposed and non-exposed individuals is diminished. To give an example, our study showed that the pre-disaster overall utilization in primary care was higher in victims without burns than in victims with burns (chapter 6). In addition, the pre-disaster prevalence of musculoskeletal, respiratory and dermatological health problems was higher in victims without burns than in victims with burns (chapter 3). If these predisaster differences had not been taken into account, the effects in the group of victims without burns would have been overestimated and erroneously attributed to the fact that these youngsters had been involved in the disaster. 


\section{Limitations of the study}

In spite of these advantages, there are also some limitations and difficulties with the chosen approach. First, the assessment of exposure in the current study was not very fine-grained. Information on exposure was obtained with the help of local family practitioners who were well integrated in the Volendam community. The practitioners indicated in the electronic medical record whether an individual had been in the building or not. This enabled the identification of 335 victims. Assuming that, according to official figures, 300 to 350 people were in the café at the time of the fire, the practitioners' list of involved individuals was near-complete. It was thus a favorable situation that Volendam is a close-knit community where only 4 family practices exist (three of which contributed data). Although a basic assessment of exposure according to the absence or presence of individuals in the café was possible, it is imaginable that other exposed groups exist which have not been covered by this assessment, i.e. the many residents who were in neighboring café-bars at the time of the fire or rushed to the scene after learning about what had occurred. Many witnessed grotesque sights and became involved at the scene as helpers. In our study, this group of people was 'diluted' by the greater group of community members who were not actually present at the scene that very night. To conclude, the assessment of exposure was rather basic and limited information was available concerning the actual degree of involvement in the disaster.

Other limitations of the current study are intrinsic to the type of data available in electronic registrations. The assessment of mental health problems based on codes as provided in the International Classification for Primary Care (ICPC) is rather basic when compared to diagnostic interviews or other screening instruments. For example, the ICPC does not allow for the coding of Posttraumatic Stress Disorder which is one of the most commonly studied disorders after disasters (2). An advantage of using a classification such as the ICPC is that it results in well-structured data which greatly facilitates the data analysis. On the other hand, the coding leads to a reduction of the 'medical reality' and it can remain unclear what the explanation for a certain problem is. To give an example, if a doctor records the code L03 for 'low back pain', it is unclear to the researcher if the pain is due to a physical injury, associated with incorrect posture, or is the 
symptom of a rheumatic condition. The family practitioner who has seen the patient during a consultation probably knows the origin of the problem or at least has a hypothesis, but the researcher only has the ICPC-code at his disposal. An understanding of the etiology of health problems is essential in disaster research, however, since part of the physical morbidity in survivors can be due to somatization or a change in symptom perception (3-5). A limitation of our study is therefore that it is difficult to develop an understanding of such processes based on the ICPC.

Another methodological aspect which should be discussed is the problem of inter-doctor variation. It is obvious that the choice of ICPC-code is not always unequivocal. The family practitioners who participated in this study were using the ICPC already before the fire and they received additional training during the initial stage of the research project in order to reduce potential differences in coding. Besides this, at the analytical level, we addressed the problem of inter-doctor variation in two ways. On the one hand, health problems were summarized into greater groups. On the other hand, the statistical analysis controlled for the influence of the family practice (either by introducing the practice as a level in the multi-level analysis, or by modeling the influence of the different practices as dummy variables). Inter-doctor variation therefore should not have had a major influence on the data presented in this thesis.

A final limitation is the fact that the family practitioners were not 'blind' for the exposure of their patients. The doctors themselves identified the victims of the fire in their registrations for the purpose of this research and they were alerted to the possibility that certain health problems were more likely in specific groups than in others. These expectations may have guided the diagnostic process to a degree which is unknown and almost impossible to assess. 


\section{Implications for public policy and patient care}

Having presented the above overview and discussion of results, the implications of this thesis for patient care and public policy will be addressed. Three aspects are particularly important in this context. These concern the timing of interventions, the need to tailor family practitioner care to the altered medical and psychosocial needs of patients, and the care for those who are 'hidden victims' of the disaster.

With regard to the timing of interventions, there is one major message for public policy: the first year after a disaster is the peak time for effects. This is in line with the conclusion drawn from recent reviews of disaster studies (6). If victims and family practitioners need support after a disaster on a considerable scale, it is then. Since family practitioners play a key role in the Dutch health care system, it is important to provide appropriate support to these professionals in the aftermath of a disaster. After disasters, typically, an altered spectrum of morbidity is seen in primary care. In Volendam, an increased number of patients was in need of psychosocial support after the fire. In addition, a large number of youngsters suffered burns. These patients were not treated only in specialist settings, but also by their family doctors. The family doctors therefore had to refresh their knowledge on the treatment of these injuries. To conclude, due to the altered health needs of patients after disasters, family practitioners were confronted with a situation which deviates from their routine practice. This creates specific educational needs which can be met by additional training. Examples are training on the screening for and treatment of posttraumatic stress disorder (PTSD) and other mental disorders, management strategies for somatization in disaster victims or the treatment of injury-related health problems. A major implication of this thesis is therefore to provide additional support to family doctors in the aftermath of disasters, in particular during the first year after the event.

Another implication of this thesis is to target interventions not only at those who were physically harmed in a disaster, but also at the 'hidden victims'. In Volendam, these 'hidden victims' were the primary victims without burns, and the parents of primary victims. To the public at large, it is 
obvious that the Volendam youngsters who suffered severe burns as a consequence of the fire are the major victims of the disaster. Those who survived the fire without suffering burns, at first sight, seemed so much more fortunate than those who had to endure a significant and irreversible loss of health at a young age. On the other hand, these survivors also had to fear for their lives and were forced to witness their friends and peers being severely burned or dying at the scene. The current findings show that, certainly during the first year after the fire, those young people were in need of psychosocial support as well.

It is important to take into account that this study was conducted in a primary care setting and the estimation of mental health problems is based on those who were consulting their family practitioner for these problems. This may have led to an underestimation of the 'real' prevalence of mental health problems. Nevertheless, our findings are in line with other studies carried out in Volendam which were based on self-report (7-10). None of these studies documented long-term behavioral and emotional problems in Volendam youngsters (as measured by the Youth Self-Report). Post-fire increases seen for excessive alcohol use, by contrast, were significantly larger for Volendam youngsters when compared to controls (8), and excessive alcohol use was more prevalent in youngsters who indicated that they had been affected by the fire (9). Based on these study results, family doctors and health policy makers should be alerted to the possibility that some of these 'hidden' victims may engage in health risk behaviors which can damage their health in the long run.

The second group of possible 'hidden victims' comprises the parents of primary victims. Besides mental health effects, our study revealed long-term physical health effects in this group. Given that there was a larger increase in cardiovascular problems in parents of burn victims when compared to parents of survivors without burns throughout the years, it is an obvious conclusion to further monitor these patients in general practice in order to prevent more serious outcomes (11). In addition to pharmacological treatment, behavioral interventions should be considered as well. A relationship between psychosocial stress and poor health practices (e.g. lack of exercise, smoking, increased alcohol intake, poor diet) has been 
documented in numerous studies (12). These behaviors, in turn, have the potential to damage cardiovascular health (13). In this study, we did not directly assess whether disaster-related stress led to a deterioration of health behaviors in parents of primary victims, but based on other publications it is realistic to assume such a link (14).

It has often been argued that in the Dutch health care system, family practitioners are in a prime position to question and educate their patients about health-promoting behaviors (15). The family doctor can therefore play an important role by addressing the relationships between stress, poor health practices and cardiovascular disease during consultations.

The fact that parents of primary victims are at increased risk for cardiovascular health problems also calls attention to the need to incorporate a systemic approach in the care for families who are affected by disasters or other life events (16). To give an example, in families who were forced to deal with the acute serious illness of one member, an increase in the number of both minor and serious complaints was noted in the year following the illness. Those families with adequate coping resources were found to present fewer complaints, however $(17 ; 18)$. This example shows that, beyond the medical treatment of complaints in individual members of the family, there are other ways of intervening. Interventions could - for instance - focus on the strengthening of coping resources in affected families. In psychology and social work, numerous intervention models have been developed which embrace the extended system within which a person is embedded (for an overview see (19)). After disasters, but also in during periods of stability, this knowledge should be used when designing interventions for affected families.

\section{Recommendations for future research}

With regard to disaster research, this thesis shows how information captured in existing electronic registrations of health care practitioners can be used for research purposes. Although it is difficult to give general recommendations, it is clear that electronic registration systems are an important source of epidemiological information that can provide both pre- 
disaster information as well as long-term observations. Nevertheless, the current approach can be further improved by taking into account the following points:

1. Complement record-based data with survey data

2. Use a comprehensive theoretical framework

3. Pay attention to the influence of community characteristics

4. Include more focus on factors related to recovery.

\section{Complement record-based data with survey data}

A useful strategy which can enrich record-based research is to complement the data extracted from electronic registrations with data stemming from cross-sectional surveys. While the medical files contain information on primary health care utilization and health problems, surveys can shed light on psychosocial constructs which may act as mediators in the exposuredisease link. An example of this type of approach is the research on the health consequences of the Enschede disaster in the Netherlands which generated a wealth of studies (e.g. $(20 ; 21)$ ). The Enschede disaster was caused by an explosion in a firework storage depot on May 13, 2000. As in Volendam, an information and advice center (IAC) was set up immediately after the explosion. In Enschede, all disaster victims were invited to register with the IAC (22). Based on this registration, local family practitioners were asked to mark the medical files of those patients who were victims of the explosion. Later, the IAC list was also used to sample participants for the surveys. Thanks to the IAC list, the medical records of victims could be linked to the survey data as well.

In Volendam, it was more difficult to link the information contained in the medical records to data from surveys. A list comparable to the IAC-list in Enschede was not available to the Volendam research team. It soon became clear that there were too many practical hurdles, because informed consent would have to be obtained from every single individual. A lesson learned from these two research projects, therefore, is to obtain consent for record linkage from victims (and appropriate control subjects) as early as possible after a disaster. The more time elapses between the disaster and the attempt to obtain consent from victims, the more obstacles arise. There are two reasons for this. First, when the acute phase is over and a community starts 
to recover, it can become difficult to obtain the support from other 'players' in the field whose help is needed for accomplishing the task. Second, victims can become less motivated to consent because they have been repeatedly approached by researchers. The recommendation therefore is to put efforts into a valid registration of victims immediately and to obtain their consent for record linkage at the same moment. Because the information captured in medical files must be handled carefully, adequate measures have to be taken to guarantee the privacy of patients.

\section{Use a comprehensive theoretical framework}

A famous quotation ascribed to Kurt Lewin is "nothing is as practical as a good theory" and this definitely applies to disaster research, too (23). Disaster research is a multidisciplinary field. On the one hand, disasters can be looked at in terms of medical needs and the effectiveness of somatic or psychosocial care. On the other hand, in the eyes of social scientists, disasters are quasi-experiments which permit the study of human reactions to extreme stress in larger groups of people. Irrespective of the scientific perspective used, knowing which factors lead to poor outcomes can facilitate the detection of vulnerable individuals and can help to implement interventions that reduce risk.

Above, it was proposed that record-based research should be complemented with data obtained in surveys. The question therefore is: what kind of complementary data is worthwhile? Ideally, this data collection is guided by sound theoretical models. Currently, there are two models which are comprehensive enough to be of value for disaster research. These models are not competing, but address different aspects. The first is the model on the physical health effects of traumatic stress as elaborated by Schnurr and colleagues; the second the conservation of resource model (COR) as formulated by Hobfol (24-27). Whereas the first model attempts to explain adverse physical health outcomes in trauma survivors, the value of the second model is that it allows for a detailed assessment of the type and degree of losses experienced by disaster victims. 
The Schnurr model is suitable because it attempts to integrate a variety of factors which may lead to changes in health following exposure to extreme stress. The model assumes that a distress reaction following traumatic exposure is essential for subsequent changes in health or well-being. Although Schnurr sees PTSD as the primary pathway by which trauma leads to poor health, she also acknowledges that significant distress reactions other than PTSD could mediate the relationship between trauma exposure and physical health (27). As components of the model, she proposes psychological, biological, behavioral and attentional mechanisms. To our knowledge, no standard measures exist to assess all factors simultaneously and researchers may use a variety of instruments for the assessment of the single components. Although the assessment of the different components is left up to the individual researcher, the Schnurr model is of heuristic value to disaster researchers due to its breadth.

The situation is different for the Conservation of Resource model (COR) where standard measures of resource loss exist. The COR-E (28), for example, measures the degree of loss in different resource categories (i.e. social, personal, material). There is one major advantage to such an assessment. If exposure (in terms of resource losses and gains) is assessed the same way across various disaster settings, different disasters can be compared. In the past, comparative studies of disaster-affected communities were rarely undertaken, although such studies can provide valuable information on which type of experiences are the most stressful and most likely to lead to adverse health outcomes. Comparative studies can also shed light on how different communities deal with disasters, and on the community characteristics which might help alleviate the impact of disasters. A third recommendation therefore is to pay more attention to the characteristics of communities.

\section{Pay attention to the influence of community characteristics}

The idea that communities have distinct characteristics which can either foster or protract post-disaster recovery dates back to Barton who called these variables 'properties of collectives'(29). It is a general assumption in sociology that the lives of individuals are affected not only by their personal characteristics but also by characteristics of the social group to which they 
belong. Also in the field of epidemiology, attention has been called to group or macro-level variables, since both group-level and individual-level variables interact in shaping health and disease (30). These group-level variables are constant for all individuals in the community in question. Examples are the size of a community (rural/urban), the percentage of unemployed individuals or single people or the degree of interconnectedness of people in the community. Consequently, in order to understand individual outcomes, it may be useful to analyze not only the characteristics of individuals but also those of the social groups to which they belong. Since group-level variables are constant for one community, comparisons between different communities have to be made in order to shed light on the influence of 'collective' characteristics.

\section{Include more focus on factors related to recovery}

As a final point, the recommendation is made to increase the focus on factors which are related to recovery. Two aspects are important to consider in this context (1) the evaluation of interventions, (2) the assessment of the role of social support.

This thesis described the impact of the Volendam fire on the health of disaster victims. The fire took place in a wealthy country. Victims received financial compensation. Family practitioners were supported during the initial stage after the disaster. A volunteer-based support project was set up, self-help groups for parents of victims were provided and an information and advice center as well as a local medical treatment center were erected (31). In addition, Volendam youngsters were screened by means of psychometric questionnaires in order to assess their mental health needs $(9 ; 10)$. In conclusion, numerous interventions had taken place with the aim to aid people in recovering from the disaster. Although the experiences with some of the projects were documented, they are all evaluations of process, but rarely oriented towards the measurement of effects. Although interventions beyond the primary care setting play an important role in the care seeking process and very probably affect the morbidity seen at family practices, it remains largely unclear what these interventions meant for the health and well-being of individuals. Clearly, when studying health 
outcomes, a process view is necessary, focusing on how the interplay between resources and demand changes over time.

A last important aspect is social support. Volendam is a community which is characterized by a strong interconnectedness of individuals and an emphasis on self-reliance. Unfortunately it was beyond the scope of this study to address research questions concerning the influence of these characteristics. The nesting of individuals in social networks has often been considered a general resistance resource (32-34). But there is also the possibility that when people rely on or offer social support, they can make themselves vulnerable to 'stress contagion'. Especially in disasters, where a group of people is affected simultaneously and potential supporters and supportees experience the same crisis, resources can be depleted quickly. To conclude, more research is needed on the role of social support in disaster settings.

\section{Conclusion}

This thesis has drawn attention to the health problems of both primary and secondary disaster victims. It has also contributed to the literature on parental caregivers of burn patients. It has demonstrated how pharmacy data can be used for the evaluation of the provision of pharmaceutical care, and has provided a picture of how health care utilization can change after a disaster in a primary care setting. Hopefully, this thesis has not only contributed to the scientific disaster literature, but has also provided valuable insights to policy makers and others involved in the care for disaster victims. 


\section{References}

1. McFarlane AC. The effects of stressful life events and disasters: research and theoretical issues. Aust N Z J Psychiatry 1985; 19(4):409-421.

2. Norris FH. Psychosocial consequences of disaster. PTSD Research Quarterly 2002; 13(2):18.

3. Engel CC. Somatization and multiple idiopathic physical symptoms: Relationship to traumatic events and posttraumatic stress disorder. In: Schnurr PP, Green BL, editors. Trauma and health - physical health consequences of exposure to extreme stress. Washington, DC: American Psychological Association, 2003; 191-216.

4. Havenaar J, Rumyantzeva G, Kasyanenko A, Kaasjager K, Westermann A, van den Brink $\mathrm{W}$ et al. Health effects of the Chernobyl disaster: illness or illness behavior? A comparative general health survey in two former Soviet regions. Environ Health Perspect 1997; 105 Suppl 6:1533-1537.

5. Yzermans J, Gersons BPR. The chaotic aftermath of an airplane crash in Amsterdam: A second disaster. In: Havenaar JM, Cwikel JG, Bromet EJ, editors. Toxic turmoil: Psychological and societal consequences of ecological disasters. New York, NY, US: Kluwer Academic / Plenum Publishers, 2002; 85-99.

6. Gezondheidsraad. Gevolgen van rampen voor de gezondheid op middellange en lange termijn. [The medium and long-term health impact of disaster] Den Haag: Gezondheidsraad, 2006.

7. Reijneveld SA, Crone MR, Verhulst FC, Verloove-Vanhorick SP. The effect of a severe disaster on the mental health of adolescents: a controlled study. Lancet 2003; 362(9385):691696.

8. Reijneveld SA, Crone MR, Schuller AA, Verhulst FC, Verloove-Vanhorick SP. The changing impact of a severe disaster on the mental health and substance misuse of adolescents: follow-up of a controlled study. Psychol Med 2005; 35:367-376.

9. GGD Zaanstreek-Waterland. Psychosociaal welbevinden van jongeren na de cafébrand. [Psychosocial wellbeing of young people after the café fire] Signaleringsonderzoek middelbare scholieren Volendam. Zaandam: GGD Zaanstreek-Waterland, 2003.

10. GGD Zaanstreek-Waterland. Het psychosociaal welbevinden van jongeren 4,5 jaar na de cafébrand. [Psychosocial wellbeing of young people 4, 5 years after the café fire] Zaandam: GGD Zaanstreek-Waterland, 2006.

11. Harms LM, Schellevis FG, van Eijk JT, Donker AJ, Bouter LM. Cardiovascular morbidity and mortality among hypertensive patients in general practice: the evaluation of long-term systematic management. J Clin Epidemiol 1997; 50(7):779-786.

12. Ng DM, Jeffery RW. Relationships between perceived stress and health behaviors in a sample of working adults. Health Psychol 2003; 22(6):638-642.

13. Rozanski A, Blumenthal JA, Kaplan J. Impact of psychological factors on the pathogenesis of cardiovascular disease and implications for therapy. Circulation 1999; 99(16):2192-2217. 
14. Vlahov D, Galea S, Resnick H, Ahern J, Boscarino JA, Bucuvalas M et al. Increased use of cigarettes, alcohol, and marijuana among Manhattan, New York, residents after the September 11th terrorist attacks. Am J Epidemiol 2002; 155(11):988-996.

15. van Eijk JT. The role of Dutch general practitioners in clinical health promotion. Patient Educ Couns 1995; 25(3):269-276.

16. Figley CR. Burnout as systemic traumatic stress: A model for helping traumatized family members. In: Figley CR. The systemic costs of caring. Boca Raton, FL, US: CRC Press, 1998; 15-28.

17. van Eijk JT. Serious illness and family dynamics. 1. Changes in consulting patterns of the unafflicted family members. Fam Pract 1985; 2(2):61-69.

18. van Eijk JT. Serious illness and family dynamics. 2. Changes in consulting patterns of the afflicted family members. Fam Pract 1985; 2(2):70-75.

19. Vernberg EM. Children's responses to disaster: Family and systems approaches. In: Gist R, Lubin B, editors. Response to disaster: Psychosocial, community, and ecological approaches. Philadelphia: Brunner/Mazel, 1999; 193-210.

20. Yzermans CJ, Donker GA, Kerssens JJ, Dirkzwager AJ, Soeteman RJ, Ten Veen PM. Health problems of victims before and after disaster: a longitudinal study in general practice. Int J Epidemiol 2005; 34:810-819.

21. Dirkzwager AJ, Grievink L, van der Velden PG, Yzermans CJ. Risk factors for psychological and physical health problems after a man-made disaster. Prospective study. Br J Psychiatry 2006; 189:144-149.

22. Roorda J, van Stiphout WA, Huijsman-Rubingh RR. Post-disaster health effects: strategies for investigation and data collection. Experiences from the Enschede firework disaster. J Epidemiol Community Health 2004; 58(12):982-987.

23. Lewin K. Field theory in social science: Selected theoretical papers. New York: Harper \& Row, 1951.

24. Hobfoll SE. Conservation of resources: a new attempt at conceptualizing stress. Am Psychol 1989; 44:513-524.

25. Schnurr PP, Green BL. Trauma and health: Physical health consequences of exposure to extreme stress. Washington, DC, US: American Psychological Association UR, 2004.

26. Hobfoll SE. The ecology of stress. New York: Hemisphere, 1988.

27. Schnurr PP, Green BL. Understanding relationships among trauma, posttraumatic stress disorder, and health outcomes. In: Green BL, Schnurr PP, editors. Trauma and health: Physical health consequences of exposure to extreme stress. Washington, DC, US: American Psychological Association, 2004; 247-275.

28. Hobfoll SE, Lilly RS. Resource conservation as a strategy for community psychology. J Community Psychol 1993; 21(2):128-148.

29. Barton AH. Communities in disaster: A sociological analysis of collective stress situations. Garden City, NY: Doubleday, 1969.

30. Diez-Roux AV. Bringing context back into epidemiology: Variables and fallacies in multilevel analysis. Am J Public Health 1998; 88(2):216-222.

31. Klein Beernink M. Support in Volendam. Houten: Bohn Stafleu van Loghum, 2006. 
32. Haines VA, Hurlbert JS, Beggs JJ. Exploring the determinants of support provision: Provider characteristics, personal networks, community contexts, and support following life events. J Health Soc Behav 1996; 37:252-264.

33. Norris FH, Kaniasty K. Received and perceived social support in times of stress: A test of the social support deterioration deterrence model. J Pers Soc Psychol 1996; 71(3):498-511.

34. Solomon SD. Mobilizing social support networks in times of disaster. In: Figley CR, editor. Trauma and its wake. Vol II: Traumatic stress, theory, research and intervention. New York: Brunner Mazel, 1986; 232-263. 
Summary 


\section{Summary}

This thesis deals with the health effects of a major fire disaster which occurred in a café-bar in Volendam, the Netherlands, on January 1st, 2001. It consists of five studies reported in individual chapters, all based on data extracted from the electronic registrations of local family practices and pharmacies. The study design was a combination of prospective and retrospective cohort designs (pre-fire health assessments were derived from past records and assessment of outcomes continued into the future). The registration period covered one year pre-disaster and, depending on the specific study, three to four years post-disaster.

For the purpose of this study, a distinction was made between several cohorts, that is primary and secondary victims of the fire, and other Volendam residents who had not been directly affected by the catastrophe. Those youngsters who were in the burning building were considered the primary victims; family members of these youngsters were considered the secondary victims. Other unaffected Volendam residents, finally, served as community controls.

The major aim of this thesis was to measure the influence of the Volendam fire on the health of these groups. As outcome measures, mental and physical health problems as presented in primary care were examined, as well as the number of contacts in family practice and the use of psychotropic medications.

Chapter 1 provides an introduction to the topic of this thesis. It starts with a description of the incident, followed by a literature review of related studies. The fire in Volendam has been considered as one of the major burn incidents in the Netherlands that happened in the recent years. The victims of the fire were almost all local teenagers who had gathered in the café-bar for a New Year's Eve celebration. The fire was caused when, shortly after midnight, a reveler accidentally set the ceiling decoration on fire, holding up a bunch of sparklers. At this moment, the café bar was occupied by 350 revelers and seriously overcrowded. Moreover, emergency exits were either blocked or difficult to find. Fourteen youths died due to the fire, and the number of 
victims who suffered burns was especially high. The fire took place in a close-knit community, meaning that there were multiple family and social ties between the disaster victims and the rest of the community.

In chapter 1, it is also attempted to situate the fire in the context of the literature on disasters. From this literature, it is known that disasters have various health consequences. Besides the direct effects of disasters (e.g. injuries and deaths), mental health problems have been well documented in survivors of disasters, ranging from depression, substance abuse, posttraumatic stress symptoms, somatization and anxiety. However, in contrast to mental health research, indirect physical health effects (which reach beyond the presence of physical injuries) are understudied after disasters. Most of the evidence on deteriorating physical health stems from research on trauma survivors (e.g. veterans, victims of physical or sexual abuse). Other fields of study which are important in the context of this study concern the research on the systemic effects of trauma (e.g. vicarious or secondary traumatization). Equally, for this field of research, it is concluded that physical health outcomes are underrepresented.

Chapter $\mathbf{2}$ is concerned with the method and the design of the study. The study was carried out in Dutch family practice. This setting has two features which facilitate research on the health of a defined population. First, in the Netherlands, family practitioners act as gatekeepers to specialist services. Therefore, the majority of health problems are dealt with in the primary care setting. Second, Dutch family practices keep fixed patient lists, meaning that a patient is registered with one family practice only. This way, the population under study can be tracked for extended periods of time.

In the current study, all participating family practitioners used a uniform classification system for health problems, the International Classification for Primary Care (ICPC). In addition, data on medication use was extracted from electronic pharmacy records and linked to the family practitioners' registrations. Both pharmacy and family practice registrations were operational before the disaster occurred. As a consequence, an assessment of pre-disaster health, health care and medication use was possible. 
Chapter 3 deals with the health problems of primary victims. As a comparison group, unaffected adolescents from the same community were included. All cohorts were followed during four years post-disaster. In primary victims, a rise of mental health problems was expected. In primary victims with burns, in addition, an increase of injury-related physical problems was foreseen. Next to this, an increase of physical health problems was assumed to occur in survivors without burns. This expectation was based on previous studies on survivors of psychological trauma which demonstrated a poorer health status in trauma-exposed individuals when compared to non-exposed individuals.

The results showed that, in the post-disaster period, mental health problems had increased in all study groups. The increases observed in victims with burns were significantly larger than in victims without burns during the first, second and third year following the fire. In victims without burns, when compared to community controls, the increase in mental health problems was significantly larger during the first year after the fire.

The study reported in chapter three also demonstrated significant postdisaster increases with regard to physical health problems. After the fire, victims with burns contacted their family practitioner more often for musculoskeletal (third and fourth year post-disaster), dermatological (second year post-disaster) and respiratory health problems (first, second and third year post-disaster). Victims without burns showed significant increases only for musculoskeletal (first year post-disaster) and dermatological health problems (second year post-disaster). These increases were significantly larger than in community controls. Contrary to expectations, the study provided no strong evidence for adverse long-term health effects in survivors without burns.

In chapter 4, the health problems of secondary disaster victims, that is, the parents of the primary victims, were investigated. The hypothesis was that caring for a burn survivor could have an adverse affect on the health of these parents because of the chronic strain imposed on these families. Data were available for one year pre-fire to four years post-fire. 
The analysis revealed that the health of parents of burn victims differed from the health of other parents in two main areas, namely cardiovascular and mental health. When compared to the year pre-disaster, the number of patients presenting with mental health problems significantly increased in parents of burn victims during the first and the second year post-disaster, but not during the third and fourth year. In parents of victims without burns and in community controls, no significant increases regarding mental health problems were observed.

Next to increases in mental health problems, significant post-fire increases in cardiovascular problems were seen in all study groups. The increases were the largest in parents of victims with burns, followed by parents of victims without burns and community controls. During every year after the disaster, the increases observed in parents of victims with burns were significantly larger than those seen in controls. No significant differences were observed between parents of victims without burns and community controls.

A second analysis focused exclusively on parents of children with burns. The results showed that mothers of burn survivors showed larger postdisaster increases in mental health problems when compared to their partners. Moreover, post-disaster mental health problems were more likely to occur in parents of children with serious burns (as measured by the total burn surface area of the child). Two other predictors, public health insurance and having more than one affected child who was involved in the fire were not significantly related to post-disaster mental health problems, however.

In addition, in parents of children with burns, post-disaster cardiovascular health problems were more common in those with public health insurance, which is an indicator for a lower socioeconomic status. Moreover, mothers of burned children were more at risk for cardiovascular problems after the disaster when compared to their male partners. In contrast, neither the seriousness of the burn injury of the child (as measured by the total burned surface area), nor the number of affected children in the family was related to the risk of having a cardiovascular health problem in the post-disaster period. 
The study described in chapter $\mathbf{5}$ of this thesis dealt with the incidence of hypertension in secondary disaster victims. This study was undertaken since a large body of literature stresses the influences of psychosocial factors and negative affect on blood pressure levels. Moreover, the study described in chapter 4 demonstrated that cardiovascular health problems were more prevalent in parents of primary victims. Based on this, it was hypothesized that parents of fire victims were more at risk for developing hypertension than other parents in Volendam. In this study, only patients without prior evidence of hypertension were included. The follow-up period covered four years. A patient was considered hypertensive if he had been diagnosed by the FP with hypertension and/or if he had received a prescription for antihypertensive medication. The results demonstrated that (after adjusting for the influence of gender, age, insurance type, history of predisposing diseases, membership in a certain family practice, number of contacts during follow-up and being a single parent), parents of fire victims were more likely to develop hypertension during the follow-up period when compared to parents of children who had not been directly involved in the disaster.

In addition, differences in risk between subgroups of parents (parents who had lost a child due to the fire, parents of victims with burns and parents of victims without burns and controls) were examined. The statistical analysis did not yield statistically significant differences between the controls and these subgroups of parents. Neither were difference between the subgroups significant (parents of children with burns, without burns and parents who had lost a child due to the fire).

Chapter 6 of this thesis deals with primary health care utilization. Two outcome measures where considered; (1) the annual number of contacts in family practice in general, and (2) the number of contacts for mental health related problems in particular. The observation period comprised one year before and three years after the incident. The analysis included the primary victims, their family members, community controls and a national reference group.

The study demonstrated a significant post-disaster increase of contacts with the family practitioner (FP) in primary victims with burns, both in the short term (first year post-disaster) and in the longer term (second and third year 
post-disaster). Primary victims without burns and parents of primary victims only demonstrated a short term increase in annual contacts with the FP. In siblings of primary victims and community controls, the development of utilization rates was similar to the development seen in the national reference group.

With respect to utilization for mental health problems, short-term effects were observed in primary victims without burns. In primary victims with burns, the effects were more persistent (visible during every year after the disaster). In siblings of primary victims, no effects were detected. Parents of primary victims demonstrated significant post-disaster increases in utilization for mental health problems in every year post-disaster. Bereavement due to the disaster was a risk factor for a short term increase in utilization in parents and siblings of primary victims. Moreover, parents who had lost a child due to the fire had more contacts with the FP for mental health problems than non-bereaved parents of primary victims during the first and second year post-disaster. No differences in utilization were found when family members of primary victims with and without burns were compared; neither for the number of contacts in general, nor for mental health related contacts.

The aim of the study described in chapter 7 was to quantify benzodiazepine use in Volendam before and after the fire. The study was undertaken because anxiety and sleeping problems (the main indication for benzodiazepine treatment) are common in disaster-affected populations. Although benzodiazepines are effective in controlling anxiety and sleeping problems, their use is recommended for short term relief only because they can lead to psychological and physical dependence when taken for longer periods of time. The aim of the study therefore was to determine the proportion of problematic users of benzodiazepines. The observation period of the study was four years, covering one year before the disaster and three years after. Data on prescriptions were extracted from pharmacy records, data on the consumers of the drugs were available from the records of family practitioners. As study groups, the parents of primary victims, community controls, and a cohort of patients from communities outside Volendam were included. The outcome measures were the proportion of 
users in a given group, the proportion of patients who used benzodiazepines for 3 or more consecutive months and the proportion of those who used more than 90 Daily Defined Doses (DDDs; the assumed average dose per day used for its main indication in adults).

The results of the study showed that, at baseline, the proportion of users and the proportion of patients using more than 90 DDDs or those using for three or more consecutive months was comparable in parents and community controls. In addition, this proportion was similar to national estimates. During the first year after the fire, parents of fire victims were more likely to use benzodiazepines when compared to community controls. No significant differences between these two groups were found for the second and third year post-fire. In community controls and patients from unaffected communities outside Volendam, the number of benzodiazepine users remained stable in the course of the years. With regard to problematic use, differences between community controls and parents of fire victims were statistically non-significant.

In a separate analysis, determinants specific to parents of victims were studied. The analysis demonstrated that parents of victims with burns were in general more likely to use benzodiazepines, but this effect was independent of the year of the study and thus not related to the fire. Parents who had a lost a child due to the fire, however, were more likely to use benzodiazepines during the first and second, but not during the third year post-fire. Mothers of fire victims, finally, were more often users of benzodiazepines than fathers, but the increase in benzodiazepine use seen in parents of fire victims after the disaster was the same in mothers and fathers.

In Chapter 8, the findings of the above studies are summarized and discussed. This chapter shows that this study has several strengths. These are the broad range of health outcomes examined, the fact that the family was taken into account as a unit of analysis, and the way the data were collected. With regard to the first point, it is important to note that the types of health outcomes examined in this thesis are not very typical for disaster research. While the research on the psychosocial consequences of disasters is vast, less is known on how disaster-related stress influences physical health. 
Second, this study incorporated a systemic point of view by taking into account the family as a unit, rather than just the individuals who survived the fire. This view is particularly important given that traumatic experiences and stressful life events frequently involve the entire support system of the victim.

Third, the way data were collected in this study is relatively new to disaster research. Record-based research has some major advantages when compared to survey data. In short, these are the possibility to collect data in a way that does not interfere with the lives of the affected individuals and the major opportunity to take account of information on pre-disaster health. In addition, in contrast to surveys, selection bias and recall bias is absent in record-based research. Chapter 8 also discussed the limitations of this approach. To give an example, the assessment of mental health problems based on codes as provided in the International Classification for Primary Care (ICPC) is limited when compared to diagnostic interviews or other screening instruments. Another limitation is the fact that the family practitioners were not 'blind' for the exposure of their patients because they were alerted to the possibility that certain health problems were more likely in specific groups than in others.

Chapter 8 also addressed the implications of this thesis for public policy and patient care. In this context, three aspects were considered important. These concern the timing of interventions, the need to tailor family practitioner care to the altered medical and psychosocial needs of patients, and the care for those who are 'hidden victims' of the disaster. With regard to the timing of interventions, the major message was that the first year after the disaster is the peak time for effects. This is in line with the conclusions drawn from recent systematic reviews of disaster research. Another implication of this thesis was to target interventions not only at those who were physically harmed in a disaster, but also at other survivors who have been exposed to potentially traumatizing stressors. Moreover, based on the finding that parents of disaster victims were at increased risk for cardiovascular problems after the fire, it was argued that there is a need to incorporate a systemic approach in the care for families who are affected by disasters or other life events. 
Samenvatting 


\section{Samenvatting}

In de nieuwjaarsnacht van 2001 brak er brand uit in café Het Hemeltje aan de haven in Volendam. De korte, maar hevige brand resulteerde in een groot aantal slachtoffers met ernstige brandwonden. Door de brand vonden veertien jonge mensen de dood.

De studies in dit proefschrift richten zich op de gevolgen van de brand voor de gezondheid van de getroffen jongeren en hun gezinsleden. Doel van het onderzoek is het in kaart brengen van de gezondheidsproblemen en van het zorg- en medicijngebruik in de Volendamse gemeenschap.

Dit proefschrift bestaat uit vijf studies die in aparte hoofdstukken worden behandeld. Alle studies zijn gebaseerd op data uit de elektronische registraties van plaatselijke huisartsenpraktijken en apotheken. Doordat deze gegevens ook beschikbaar zijn voor de periode voorafgaand aan de brand heeft het onderzoeksdesign een retrospectief element. Tegelijk heeft het design ook kenmerken van een prospectief cohort onderzoek, omdat de onderzochte groepen in de tijd zijn gevolgd. De onderzoeksperiode omvat één jaar voor de ramp en drie tot vier jaar erna; de opzet is dus longitudinaal.

Voor dit onderzoek is een onderscheid gemaakt tussen verschillende groepen, namelijk primaire en secundaire slachtoffers van de brand en andere inwoners van Volendam die niet rechtstreeks getroffen zijn door de ramp. Jongeren die zich in het brandende gebouw bevonden worden als primaire slachtoffers beschouwd. Gezinsleden van deze primaire slachtoffers worden als secundaire slachtoffers gezien. Andere inwoners van Volendam die niet getroffen zijn door de ramp vormen een referentiegroep.

Hoofdstuk 1 is een inleiding op het onderwerp van deze dissertatie en begint met een beschrijving van het incident, gevolgd door een literatuurstudie van vergelijkbare studies. De brand in Volendam wordt beschouwd als een van de grootste brandincidenten in Nederland in de afgelopen jaren. De brand vond plaats in een hechte gemeenschap, hetgeen betekent dat iedereen wel een slachtoffer kende of in de familie had. Bijna alle slachtoffers 
waren Volendamse tieners die in het café waren gekomen om nieuwjaar te vieren. De brand ontstond doordat een feestvierder, net na twaalven, per ongeluk de plafondversiering in brand stak toen hij sterretjes ophield. Op dat moment waren er 350 personen in het café en daarmee was de zaak overvol. Bovendien waren de nooduitgangen ofwel geblokkeerd of moeilijk te vinden.

Naast een beschrijving van de ramp wordt in hoofdstuk 1 geprobeerd de brand te plaatsen in de context van literatuur over rampen. Uit deze literatuur is bekend dat rampen verschillende gevolgen hebben voor de gezondheid. Naast de directe consequenties van rampen, zoals verwondingen en overlijden, worden veelal psychische problemen genoemd bij de overlevenden, zoals depressiviteit, drugmisbruik, posttraumatische stresssymptomen en angstaanvallen. Indirecte consequenties voor de lichamelijke gezondheid die verder gaan dan lichamelijk letsel zijn echter minder vaak onderzocht. Bewijs van verslechtering van lichamelijke gezondheid is merendeels afkomstig van onderzoek onder overlevenden van een trauma, zoals oorlogsveteranen en slachtoffers van seksueel misbruik. Andere onderzoeksgebieden die in de context van dit proefschrift belangrijk zijn, betreffen onderzoek naar de gezinseffecten van trauma. Ook voor dit onderzoeksgebied werd geconcludeerd dat cijfers over de lichamelijke gezondheidstoestand ondervertegenwoordigd zijn.

Hoofdstuk 2 houdt zich bezig met de methode van het onderzoek. Er werd gebruik gemaakt van gegevens uit twee bronnen: de elektronische registraties van huisartsen en van apotheken. Ieder registratie kent zijn eigen classificatiesysteem. Huisartsen coderen de gezondheidsproblemen van hun patiënten met behulp van de International Classification of Primary Care (ICPC). In de apotheek worden alle geneesmiddelen geclassificeerd volgens het ATC-systeem (Anatomical Therapeutic Chemical Classification).

Naast een beschrijving van het onderzoek noemt hoofdstuk 2 de voordelen van onderzoek dat gebaseerd is op gegevens uit de huisartspraktijk. Samengevat zijn dit de mogelijkheid om (1) informatie over de gezondheidstoestand voorafgaand aan het gebeurtenis te verzamelen, (2) een steekproef 
van personen te trekken die representatief is voor de getroffen bevolking en (3) longitudinale gegevens te genereren.

Hoofdstuk 3 beschrijft de gezondheidsproblemen van de primaire slachtoffers (met en zonder brandwonden) en een referentiegroep bestaande uit Volendamse leeftijdgenoten die niet rechtstreeks getroffen waren door de ramp. Alle cohorten werden gedurende vier jaar na de ramp gevolgd. Er werd verwacht dat er een toename zou zijn van psychische gezondheidsproblemen bij de primaire slachtoffers. Bovendien werd bij primaire slachtoffers met brandwonden een toename van lichamelijke problemen verwacht die met de bij de brand opgelopen verwondingen te maken hadden. In aanvulling hierop werd een toename van lichamelijke problemen bij overlevenden zonder brandwonden verwacht, aangezien voorgaande onderzoeken onder overlevenden van psychologische trauma's aantoonden dat deze groep een slechtere gezondheidstoestand had dan degenen die daaraan niet hadden blootgestaan.

De in hoofdstuk 3 beschreven studie toont aan dat in de periode na de ramp alle onderzoeksgroepen meer problemen kregen met de psychische gezondheid. De toename, waargenomen bij de slachtoffers met brandwonden, was significant groter dan bij slachtoffers zonder brandwonden, gedurende het eerste, tweede en derde jaar na de brand. Bij slachtoffers zonder brandwonden was, vergeleken met de referentiegroep, de toename in problemen met de psychische gezondheid significant hoger gedurende het eerste jaar na de brand.

De studie liet ook zien dat er een significant hogere toename was van lichamelijke klachten na de ramp. Slachtoffers met brandwonden hadden na de brand significant meer contact met hun huisarts voor gezondheidsproblemen op het gebied van het bewegingsapparaat (derde en vierde jaar na de ramp), de huid (tweede jaar na de ramp) en de luchtwegen (eerste, tweede en derde jaar na de ramp). Slachtoffers zonder brandwonden hadden alleen significant meer contact met hun huisarts voor problemen van het bewegingsapparaat (eerste jaar na de ramp) en de huid (tweede jaar na de ramp). Deze toename was significant hoger dan bij de referentiegroep. In tegenstelling tot hetgeen werd verwacht, gaf het onderzoek geen duidelijk 
bewijs voor nadelige gezondheidseffecten op de lange termijn bij slachtoffers zonder brandwonden.

In hoofdstuk 4 worden de gezondheidsproblemen van secundaire slachtoffers van de ramp, d.w.z. de ouders van de primaire slachtoffers, onderzocht. De hypothese was dat het zorgen voor een kind met brandwonden een nadelig effect zou hebben op de gezondheid van de ouders, omdat het gezin voortdurend onder spanning staat. Er waren gegevens beschikbaar over één jaar voor de brand tot vier jaar na de brand.

De analyse liet zien dat de gezondheid van de ouders van brandwondenslachtoffers op twee hoofdgebieden van die van andere ouders afweek, namelijk op het gebied van hart en bloedvaten en van de psychische gezondheid. Vergeleken met het jaar voorafgaande aan de ramp, was het aantal patiënten met problemen op het gebied van de psychische gezondheid significant hoger geworden bij ouders van brandwondenslachtoffers gedurende het eerste en tweede jaar na de ramp, maar niet gedurende het derde en vierde jaar. Bij ouders van slachtoffers zonder brandwonden en bij de referentiegroep is geen significante toename aangetroffen in problemen met de psychische gezondheid.

Naast een toename van psychische problemen werd na de brand bij alle onderzoeksgroepen een significante toename in problemen met hart en bloedvaten waargenomen. Deze toename was het hoogst bij ouders van slachtoffers met brandwonden, gevolgd door ouders van slachtoffers zonder brandwonden en de referentiegroep. In de jaren na de ramp was de toename bij ouders van slachtoffers met brandwonden significant hoger dan die bij de referentiegroep. Tussen ouders van slachtoffers zonder brandwonden en de referentiegroep werd geen significant verschil waargenomen.

Verder bleek dat moeders van kinderen met brandwonden na de ramp een sterkere toename van psychische problemen vertoonden dan hun partners. Bovendien was het waarschijnlijker dat problemen met de psychische gezondheid na de ramp optraden bij ouders van kinderen met ernstige brandwonden (gemeten naar de totale verbrande oppervlakte bij het kind). Twee andere voorspellers - ziektekostenverzekering en of er sprake was van 
meer dan één kind dat bij de brand betrokken was geweest - hadden echter geen significant verband met psychische problemen na de ramp. Ouders van kinderen met brandwonden hadden over het algemeen meer last van harten vaatproblemen na de ramp als zij onder het ziekenfonds vielen, hetgeen een indicator is voor een lagere sociaal-economische status. Bovendien hadden moeders van verbrande kinderen meer kans op hart- en vaatproblemen na de ramp dan hun mannelijke partners. Daar staat tegenover dat noch de aard van de verwondingen van het kind (gemeten naar de totale verbrande oppervlakte), noch het aantal kinderen binnen het gezin dat door de brand is getroffen, een relatie vertoonde met de kans op problemen met hart en bloedvaten in de periode na de ramp.

In hoofdstuk 5 is onderzocht of ouders van bij de brand aanwezige jongeren na de brand vaker hypertensie ontwikkelden dan ouders van niet getroffen kinderen. De hypothese was dat deze ouders door de brand onder grote druk zijn komen te staan en dat dit een negatieve uitwerking op de bloeddruk van deze groep zou kunnen hebben. In dit onderzoek werden alleen ouders betrokken die voor de brand geen last hadden gehad van een hoge bloeddruk. De resultaten lieten zien dat ouders van slachtoffers van de brand gedurende de follow-up periode meer kans liepen een hoge bloeddruk te krijgen dan ouders van kinderen die niet rechtstreeks bij de ramp waren betrokken geweest (na controle voor de effecten van geslacht, leeftijd, type verzekering, bestaande co-morbiditeit, de huisartsenpraktijk waarbij men is aangesloten, het aantal contacten gedurende de follow-up en al of niet éénouder zijn).

Bovendien werden risicoverschillen onderzocht tussen de verschillende groepen ouders (ouders die een kind hadden verloren door de brand, ouders van kinderen met brandwonden en ouders van slachtoffers zonder brandwonden en de referentiegroep). De statistische analyse resulteerde niet in statistisch significante verschillen tussen de referentiegroep en deze groepen ouders. Ook werden er geen significante verschillen tussen de groepen onderling gevonden (ouders van kinderen met brandwonden, zonder brandwonden en ouders die een kind hadden verloren door de brand). 
In de studie in hoofdstuk 6 werden twee afhankelijke variabelen onderzocht: (1) het aantal contacten in de huisartsenpraktijk per jaar in het algemeen en (2) het aantal contacten voor problemen die met de psychische gezondheid te maken hadden (een subgroep van de eerste groep). In deze studie was, naast de primaire en secundaire slachtoffers en de Volendamse referentiegroep, ook een landelijke referentiegroep beschikbaar. De observatieperiode liep van één jaar voor tot drie jaar na de brand.

Uit de studie bleek dat na de ramp het aantal contacten met de huisarts bij primaire slachtoffers met brandwonden significant was toegenomen, zowel op de korte termijn (eerste jaar na de ramp), als op de lange termijn (tweede en derde jaar na de ramp). Primaire slachtoffers zonder brandwonden en ouders van primaire slachtoffers bleken alleen op de korte termijn vaker contact met de huisarts te hebben gehad. Bij broers en zussen van primaire slachtoffers en de Volendamse referentiegroep was de ontwikkeling vergelijkbaar met die van de landelijke referentiegroep.

Voor wat betreft het zorggebruik voor psychische gezondheidsproblemen, werden er bij primaire slachtoffers zonder brandwonden alleen korte termijneffecten gezien. Bij primaire slachtoffers met brandwonden waren de effecten van langere duur (ieder jaar na de ramp zichtbaar). Bij broers en zussen van primaire slachtoffers zijn geen significante effecten geconstateerd. Ouders van primaire slachtoffers vertoonden na de ramp een significante toename in gebruik voor psychische gezondheidsproblemen, voor alle jaren na de ramp. Het overlijden van een kind ten gevolge van de brand was een risicofactor voor een toename van het aantal contacten voor psychische gezondheidsproblemen op korte termijn, bij ouders en broers en zussen van deze slachtoffers.

Hoofdstuk 7 gaat in op het gebruik van benzodiazepines (slaap- en kalmeringsmiddelen). Omdat rampen en stressvolle gebeurtenissen de kans op slaapproblemen en angsten verhogen, werd verwacht dat na de ramp ook het gebruik van benzodiazepines in Volendam was toegenomen. Hoewel benzodiazepines effectief zijn bij de behandeling van angsten en slaapproblemen, wordt het gebruik alleen aanbevolen voor een korte periode, omdat de middelen psychologische en lichamelijke afhankelijkheid 
kunnen veroorzaken wanneer ze lang worden gebruikt. Doel van het onderzoek was derhalve het aantal problematische gebruikers van benzodiazepines na de ramp vast te stellen. In deze studie zijn (op jaarbasis) twee indicatoren voor problematisch gebruik onderzocht: (1) het gebruik tijdens 3 aaneengesloten maanden of langer en (2) het gebruik van meer dan 90 standaard dagdoseringen. Omdat benzodiazepines met name aan volwassenen worden voorgeschreven, zijn in hoofdstuk 7 alleen de ouders van de primaire slachtoffers onderzocht. Deze ouders worden vergeleken met een Volendamse referentiegroep én een landelijke referentiegroep.

De uitkomsten van het onderzoek toonden aan dat het benzodiazepinegebruik van ouders van bij de brand aanwezige jongeren en de Volendamse referentiegroep voor de brand vergelijkbaar was met het landelijk gebruik. Aan ouders van slachtoffers van de brand werden in het eerste jaar na de brand echter vaker benzodiazepines verstrekt dan aan de Volendamse leeftijdgenoten. Voor het tweede en derde jaar na de brand werden geen significante verschillen gevonden tussen deze twee groepen. Bij de landelijke referentiegroep en de Volendamse referentiegroep was het percentage gebruikers stabiel in de loop van de tijd. Op het gebied van problematisch gebruik konden tussen de groepen geen significante verschillen aangetoond worden.

Daarnaast zijn de ouders van bij de brand aanwezige jongeren in een aparte analyse onderzocht. Deze analyse toonde aan dat ouders van slachtoffers met brandwonden over het algemeen vaker benzodiazepines gebruikten, maar hierbij speelde het jaar van het onderzoek geen rol en dus was er geen verband met de brand. Echter, ouders die een kind hadden verloren door de brand, gebruikten vaker benzodiazepines tijdens het eerste en tweede jaar na de brand, maar niet gedurende het derde jaar. Tussen vaders en moeders van de slachtoffers bestond geen statistisch significant verschil; in beide groepen was de toename van het aantal gebruikers na de brand even groot.

In hoofdstuk 8 worden de resultaten van bovenstaande studies samengevat en besproken. Dit hoofdstuk laat zien dat dit onderzoek een aantal sterke punten heeft. Ten eerste wordt in dit onderzoek niet alleen de nadruk op de psychische problematiek gelegd, maar zijn ook lichamelijke gezondheids- 
problemen onderzocht. Ten tweede werd niet alleen de problematiek van primaire slachtoffers bestudeerd, maar ook die van secundaire slachtoffers. Dit is van groot belang omdat traumatische ervaringen van één gezinslid ook andere gezinsleden kunnen beïnvloeden. Gezinsleden gaan gedurende langere tijd intensief met het slachtoffer om. Vaak staan zij onder grote druk die voortkomt uit het helpen of hulp willen bieden aan de dierbare. Dit maakt ze kwetsbaar voor het ontstaan van psychische en lichamelijke gezondheidsproblemen. Voor dit laatste aspect was er tot nu toe maar nog weinig aandacht in de literatuur.

Ten derde is de manier waarop in dit onderzoek gegevens zijn verzameld, betrekkelijk nieuw voor rampenonderzoek. Onderzoek dat gebaseerd is op bestaande registraties van zorgverleners heeft veel voordelen. Doordat deze gegevens regelmatig en systematisch worden verzameld (onafhankelijk van de ramp), zijn ze vaak ook beschikbaar over de periode voorafgaand aan de ramp. Daardoor kunnen veranderingen in gezondheid of zorgbehoefte geanalyseerd worden en is een soort 'voormeting' beschikbaar. Een ander voordeel is dat individuele getroffenen hierdoor niet nog eens extra belast hoeven te worden. Bovendien kunnen bij onderzoek in de huisartspraktijk vaak grote, voor de bevolking representatieve steekproeven getrokken worden. Verder is er bij onderzoek dat gebruik maakt van registraties geen sprake van geheugenvertekening, zoals het bij enquêtes wel het geval kan zijn. Natuurlijk heeft deze onderzoeksmethode ook beperkingen. Huisartsen kennen hun patiënten en weten wie getroffen is door de ramp en wie niet. Ook weten zij dat er de mogelijkheid bestaat dat bepaalde gezondheidsproblemen bij specifieke groepen eerder zouden kunnen optreden dan bij anderen. Daarnaast wordt er voor onderzoek in de huisartspraktijk met behulp van de International Classification of Primary Care gewerkt. Dit heeft een groot voordeel: alle gezondheidsproblemen worden op een uniforme manier geregistreerd. Een nadeel is echter dat de 'medische realiteit' gereduceerd wordt en (op basis van de ICPC-code alleen) de oorzaak van een gezondheidsprobleem soms niet te achterhalen is. Een laatste nadeel van het gebruik van ICPC-codes is dat het benoemen van psychische problemen na een ramp kan worden belemmerd, omdat het classificatiesysteem niet gedetailleerd genoeg is. Hiervoor zijn diagnostische interviews of vragenlijsten beter geschikt. 
In hoofdstuk 8 worden ook de implicaties van de resultaten van de studies voor het nazorgbeleid na rampen en voor de patiëntenzorg besproken. Drie aspecten worden in deze context als belangrijk beschouwd. Het eerste aspect betreft de 'timing' van interventies: een belangrijk boodschap van dit proefschrift is dat de meeste effecten tijdens het eerste jaar na de ramp optreden. Ten tweede moeten 'verborgen slachtoffers' niet over het hoofd worden gezien. De nazorg moet niet alleen worden gericht op diegenen die lichamelijk letsel oplopen bij een ramp, maar ook op andere overlevenden en betrokkenen die door de ramp (op korte én op lange termijn) zijn blootgesteld aan stress en spanning. Ten derde hebben huisartsen na een ramp extra ondersteuning nodig omdat zij na een ramp vaak niet alleen geconfronteerd zijn met een hoge werkdruk, maar ook met de sterk veranderde medische en psychosociale behoeften van hun patiënten. 
Samenvatting 
Literature 


\section{Literature}

American Psychiatric Association. Diagnostic and statistical manual of mental disorders ( $^{\text {th }}$ ed.). Washington, DC. American Psychiatric Association, 2000.

Applebaum DR, Burns GL. Unexpected childhood death: Posttraumatic stress disorder in surviving siblings and parents. Journal of Clinical Child Psychology 1991; 20(2):114-20.

Armenian HK, Melkonian AK, Hovanesian AP. Long term mortality and morbidity related to degree of damage following the 1998 earthquake in Armenia. Am J Epidemiol 1998; 148:1077-84.

Armstrong MA, Midanik LT, Klatsky AL. Alcohol consumption and utilization of health services in a health maintenance organization. Med Care. 1998; 36:1599-605.

Ashton H. Guidelines for the rational use of benzodiazepines. When and what to use. Drugs 1994; 48(1):25-40.

Balk DE, Corr CA. Bereavement during adolescence: a review of research. In: Stroebe MS, ed. Handbook of bereavement research: consequences, coping, and care. Washington, DC: American Psychological Association, 2001; 199-218.

Barlow JH, Ellard DR. The psychosocial well-being of children with chronic disease, their parents and siblings: an overview of the research evidence base. Child Care Health Dev 2006; 32(1):19-31.

Barnes, Michael F. Understanding the secondary traumatic stress of parents. In: Figley CR, eds. The systemic costs of caring. Boca Raton, FL: CRC Press, 1998; 75-89.

Barton AH. Communities in disaster: A sociological analysis of collective stress situations. Garden City, NY: Doubleday, 1969.

Beiderbeck AB, Sturkenboom MC, Coebergh JW, Leufkens HG, Stricker BH. Misclassification of exposure is high when interview data on drug use are used as a proxy measure of chronic drug use during follow-up. J Clin Epidemiol 2004; 57(9):973-77.

Bergh H, Marklund B. Characteristics of frequent attenders in different age and sex groups in primary health care. Scand J Prim Health Care. 2003; 21:171-77.

Black PH, Garbutt LD. Stress, inflammation and cardiovascular disease. J Psychosom Res 2002; 52(1):1-23.

Blakeney P, Moore P, Broemeling L, Hunt R, Herndon DN, Robson M. Parental stress as a cause and effect of pediatric burn injury. J Burn Care Rehabil 1993; 14(1):73-79.

Bland SH, Farinaro E, Krogh V, et al. Long term relations between earthquake experiences and coronary heart disease risk factors. Am J Epidemiol 2000; 151:1086-90.

Boerma WG, van der Zee J, Fleming DM. Service profiles of general practitioners in Europe. European GP Task Profile Study. Br J Gen Pract 1997; 47(421):481-486.

Boerma WGW, Fleming DM. The role of general practice in primary health care. London: World Health Organization, 1998.

Bolton D, O'Ryan D, Udwin O, Boyle S, Yule W. The long-term psychological effects of a disaster experienced in adolescence: II: General psychopathology. J Child Psychol Psychiatry 2000; 41(4):513-523.

Boscarino JA. Posttraumatic stress disorder and physical illness: results from clinical and epidemiological studies. Ann N Y Acad Sci 2004; 1032:141-153. 
Brandsjo K, Hedelin A, Lundin T, Lundalv J. KAMEDO Report No. 75: Fire Catastrophe in Gothenburg 29-30 October 1998. Prehospital Disaster Med 2005; 20(4):258-261.

Brehaut JC, Kohen DE, Raina P, Walter SD, Russell DJ, Swinton M et al. The health of primary caregivers of children with cerebral palsy: how does it compare with that of other Canadian caregivers? Pediatrics 2004; 114(2):e182-e191.

Broberg AG, Dyregrov A, Lilled L. The Goteborg discotheque fire: posttraumatic stress, and school adjustment as reported by the primary victims 18 months later. J Child Psychol Psychiatry 2005; 46(12):1279-1286.

Bromet E, Dew MA. Review of psychiatric epidemiological research on disasters. Epidemiological Reviews 1995; 17(1):113-19.

Brosschot JF, Gerin W, Thayer JF. The perseverative cognition hypothesis: a review of worry, prolonged stress-related physiological activation, and health. J Psychosom Res 2006; 60(2):113-124.

Cachet A, Daemen HHFM, Ringeling AB, Schaap L. Het derde klaphek voorbij. Een analyse van de Volendamse bestuurscultuur. Rotterdam: Centre for Local Democracy, Erasmus Universiteit Rotterdam, 2001.

Cameron L, Leventhal EA, Leventhal H. Seeking medical care in response to symptoms and life stress. Psychosom Med 1995; 57(1):37-47.

Cannon WB, Mendenhall WL. Factors affecting the coagulation time of blood: IV. The hastening of coagulation in pain and emotional excitement. American Journal of Physiology 1914; 34:251-261.

Cannon WB. The wisdom of the body. New York: Norton, 1932.

Cardol M, Groenewegen PP, de Bakker DH, Spreeuwenberg P, van Dijk L, van den BW. Shared help seeking behaviour within families: a retrospective cohort study. BMJ 2005; 330(7496):882.

Cartwright M, Wardle J, Steggles N, Simon AE, Croker H, Jarvis MJ. Stress and dietary practices in adolescents. Health Psychol 2003; 22(4):362-369.

Cassuto J, Tarnow P. The discotheque fire in Gothenburg 1998. A tragedy among teenagers. Burns 2003; 29(5):405-416.

Centraal Bureau voor de Statistiek. Gemeente op maat-Edam-Volendam. Voorburg, the Netherlands: Centraal Bureau voor de Statistiek, 2004.

Cohen RE, Ahearn FL. Handbook for mental health care of disaster victims. Baltimore: John Hopkins University, 1980.

Commissie Onderzoek Cafébrand (Commissie Alders). Cafébrand Nieuwjaarsnacht Eindrapport. 2001. [New Year's Eve café fire. Final Report]

Cwikel JG, Goldsmith JR, Kordysh E, et al. Blood pressure among immigrants to Israel from areas affected by the Chernobyl disaster. Public Health Rev 1997; 25:317-35.

Dacey MJ. Tragedy and response- the Rhode Island nightclub fire. N Engl J Med 2003; 349(21):1990-1992.

de Lusignan S, van Weel C. The use of routinely collected computer data for research in primary care: opportunities and challenges. Fam Pract 2006; 23(2):253-63.

Diez-Roux AV. Bringing context back into epidemiology: Variables and fallacies in multilevel analysis. Am J Public Health 1998; 88(2):216-222. 
Dirkzwager AJ, Grievink L, van der Velden PG, Yzermans CJ. Risk factors for psychological and physical health problems after a man-made disaster. Prospective study. Br J Psychiatry 2006; 189:144-149.

Dirkzwager AJ, Kerssens JJ, Yzermans CJ. Health problems in children and adolescents before and after a man-made disaster. J Am Acad Child Adolesc Psychiatry 2006; 45(1):94-103.

Dohrenwend BP, Dohrenwend BS, Warheit GJ, Bartlett GS, Goldsteen RL, Goldsteen K et al. Stress in the community: a report to the President's Commission on the Accident at Three Mile Island. Ann N Y Acad Sci 1981; 365:159-174.

Doka KJ. What makes a tragedy public? In: Lattanzi-Licht M, Doka KJ, editors. Living with grief: Coping with public tragedy. New York: Brunner-Routledge, 2003; 3-13.

Donker GA, Yzermans CJ, Spreeuwenberg P, van der Zee J. Symptom attribution after a plane crash: comparison between self-reported symptoms and GP records. Br J Gen Pract. 2002; 52:917-22.

Dorn T, Yzermans CJ, Kerssens JJ, Spreeuwenberg PM, van der Zee J. Disaster and subsequent healthcare utilization: a longitudinal study among victims, their family members, and control subjects. Med Care 2006; 44(6):581-589.

Dorn T, Yzermans CJ, Guijt H, van der Zee J. Disaster-related stress as a prospective risk factor for hypertension in parents of adolescent disaster victims. American Journal of Epidemiology 2007; 165(4):410-117.

Dougall AL, Baum A. Psychoneuroimmunology and trauma. In: Green BL, Schnurr PP, editors. Trauma and health: Physical health consequences of exposure to extreme stress. Washington, DC: American Psychological Association, 2004; 129-155.

Duignan JP, McEntee GP, Scully B, Corrigan TP. Report of a fire disaster-management of burns and complications. Ir Med J 1984; 77(1):8-10.

Dyregrov A, Frykholm AM, Lilled L, Broberg AG, Holmberg I. The Goteborg discotheque fire, 1998. Scand J Psychol 2003; 44(5):449-457.

Edgar DW, Wood F, Goodwin-Walters A. First response, rehabilitation, and outcomes of hand and upper limb function: survivors of the Bali bombing disaster. A case series report. J Hand Ther 2006; 19(3):283-297.

Eisenberg JM. Physician utilization: the state of research about physicians' practice patterns. Med Care. 2002; 40:1016-35.

El Hamaoui Y, Yaalaoui S, Chihabeddine K, Boukind E, Moussaoui D. Depression in mothers of burned children. Arch Womens Ment Health 2006; 9:117-119.

Ellemers JE. Rampen in Nederland. [Disasters in the Netherlands] Sociologische Gids 2001; 48(3):231-252.

Engel CC. Somatization and multiple idiopathic physical symptoms: Relationship to traumatic events and posttraumatic stress disorder. In: Schnurr PP, Green BL, editors. Trauma and health - physical health consequences of exposure to extreme stress. Washington, DC: American Psychological Association, 2003; 191-216.

Figley CR. Burnout as systemic traumatic stress: A model for helping traumatized family members. In: Figley CR. The systemic costs of caring. Boca Raton, FL, US: CRC Press, $1998 ; 15-28$.

Figley CR. Burnout in families: The systemic costs of caring. Boca Raton, FL, US: CRC Press; 1998. 
Florentinus SR. New drugs in general practice - Prescribing patterns and external influences. Dissertation, University of Utrecht, the Netherlands, 2006.

Ford DE. Depression, trauma, and cardiovascular health. In: Green BL, Schnurr PP, editors. Trauma and health: Physical health consequences of exposure to extreme stress. Washington, DC: American Psychological Association, 2004; 73-97.

Fukunishi I. Posttraumatic stress symptoms and depression in mothers of children with severe burn injuries. Psychol Rep 1998; 83(1):331-335.

Fullerton CS, Ursano RJ, Norwood AE, Holloway HH. Trauma, terrorism and disaster. In: Ursano RJ, Fullerton CS, Norwood AE, editors. Terrorism and disaster - individual and community mental health interventions. New York: Cambridge University Press, 2003; $1-22$.

Gene-Badia J, Blay-Pueyo C, Soler-Vila M. Risk factors in the use of benzodiazepines. Fam Pract 1988; 5(4):283-88.

Gerin W, Chaplin W, Schwartz JE, et al. Sustained blood pressure increase after an acute stressor: the effects of the 11 September 2001 attack on the New York City World Trade Center. J Hypertens 2005; 23:279-84.

Gezondheidsraad. Gevolgen van rampen voor de gezondheid op middellange en lange termijn. [The medium and long-term health impact of disasters] Den Haag: Gezondheidsraad, 2006.

Gewalli F, Fogdestam I. Triage and initial treatment of burns in the Gothenburg fire disaster 1998. On-call plastic surgeons' experiences and lessons learned. Scand J Plast Reconstr Surg Hand Surg 2003; 37(3):134-139.

GGD Zaanstreek-Waterland. Het psychosociaal welbevinden van jongeren 4,5 jaar na de cafébrand. [Psychosocial wellbeing of young people 4, 5 years after the café fire] Zaandam: GGD Zaanstreek-Waterland, 2006.

GGD Zaanstreek-Waterland. Psychosociaal welbevinden van jongeren na de cafébrand. [Psychosocial wellbeing of young people after the café fire] Signaleringsonderzoek middelbare scholieren Volendam. Zaandam: GGD Zaanstreek-Waterland, 2003.

Giaconia RM, Reinherz HZ, Silverman AB, Pakiz B, Frost AK, Cohen E. Traumas and posttraumatic stress disorder in a community population of older adolescents. J Am Acad Child Adolesc Psychiatry 1995; 34(10):1369-1380.

Gill JR, Goldfeder LB, Stajic M. The happy land homicides: 87 deaths due to smoke inhalation. J Forensic Sci 2003; 48(1):161-163.

Gillock KL, Zayfert C, Hegel MT, Ferguson RJ. Posttraumatic stress disorder in primary care: prevalence and relationships with physical symptoms and medical utilization. Gen Hosp Psychiatry 2005; 27(6):392-399.

Goenjian AK, Molina L, Steinberg AM, Fairbanks LA, Alvarez ML, Goenjian HA et al. Posttraumatic stress and depressive reactions among Nicaraguan adolescents after hurricane Mitch. Am J Psychiatry 2001; 158(5):788-794.

Goenjian AK, Walling D, Steinberg AM, Karayan I, Najarian LM, Pynoos R. A prospective study of posttraumatic stress and depressive reactions among treated and untreated adolescents 5 years after a catastrophic disaster. Am J Psychiatry 2005; 162(12):23022308.

Goldstein H. Multilevel models in education and social research. Oxford: Oxford University Press; 1987. 
Gordis L. Epidemiolgy. Philadelphia: Saunders, 2000.

Gorgels WJ, Oude Voshaar RC, Mol AJ, Breteler MH, van de Lisdonk EH, Zitman FG. (Longterm use of benzodiazepines). Ned Tijdschr Geneeskd 2001; 145(28):1342-46.

Green BL, Kimerling R. Trauma, posttraumatic stress disorder, and health status. In: Green BL, Schnurr PP, editors. Trauma and health: Physical health consequences of exposure to extreme stress. Washington, DC: American Psychological Association, 2004; 13-42.

Groenewegen PP, Leufkens HG, Spreeuwenberg P, Worm W. Neighbourhood characteristics and use of benzodiazepines in The Netherlands. Soc Sci Med 1999; 48(12):1701-11.

Grootenhuis MA, Last BF. Adjustment and coping by parents of children with cancer: a review of the literature. Support Care Cancer 1997; 5(6):466-484.

Haines VA, Hurlbert JS, Beggs JJ. Exploring the determinants of support provision: Provider characteristics, personal networks, community contexts, and support following life events. J Health Soc Behav 1996; 37:252-264.

Hall E, Saxe G, Stoddard F, Kaplow J, Koenen K, Chawla N et al. Posttraumatic stress symptoms in parents of children with acute burns. J Pediatr Psychol 2006; 31(4):403-412.

Hall M, Irwin M. Physiological indices of functioning in bereavement. In: Stroebe MS, editor. Handbook of bereavement research: Consequences, coping, and care. Washington, DC: American Psychological Association; 2001; 473-492.

Harms LM, Schellevis FG, van Eijk JT, Donker AJ, Bouter LM. Cardiovascular morbidity and mortality among hypertensive patients in general practice: the evaluation of long-term systematic management. J Clin Epidemiol 1997; 50(7):779-786.

Havenaar J, Rumyantzeva G, Kasyanenko A, Kaasjager K, Westermann A, van den Brink W et al. Health effects of the Chernobyl disaster: illness or illness behavior? A comparative general health survey in two former Soviet regions. Environ Health Perspect 1997; 105 Suppl 6:1533-1537.

Health Council of the Netherlands: Committee on Medical Technology Assessment. Towards the effective use of benzodiazepines. The Hague: Health Council of the Netherlands, 1998.

Herbert TB, Cohen S. Stress and immunity in humans: a meta-analytic review. Psychosom Med 1993; 55(4):364-379.

Herz M. Benzodiazepine prescribing in a community in crisis. Fam Pract 1993; 10(3):317-19.

Heywood PL, Blackie GC, Cameron IH, Dowell AC. An assessment of the attributes of frequent attenders to general practice. Fam Pract. 1998; 15:198-204.

Hobfoll SE, Lilly RS. Resource conservation as a strategy for community psychology. J Community Psychol 1993; 21(2):128-148.

Hobfoll SE. Conservation of resources: a new attempt at conceptualizing stress. Am Psychol 1989; 44:513-524.

Hobfoll SE. The ecology of stress. New York: Hemisphere, 1988.

Hobfoll SE. Traumatic stress: A theory based on rapid loss of resources. Anxiety Research 1991; 4(3):187-197.

Hofmans-Okkes IM, Lamberts H. The International Classification of Primary Care (ICPC): new applications in research and computer-based patient records in family practice. Fam Pract 1996; 13(3):294-302. 
Isacson D, Carsjo K, Bergman U, Blackburn JL. Long-term use of benzodiazepines in a Swedish community: an eight-year follow-up. J Clin Epidemiol 1992; 45(4):429-36.

Janssen M, van der Velden P, Kleber R. Was alles maar weer normaal. Over leven na de brand in Volendam. Zaltbommel: Instituut voor Psychotrauma, 2002.

Jonas BS, Franks P, Ingram DD. Are symptoms of anxiety and depression risk factors for hypertension? Longitudinal evidence from the National Health and Nutrition Examination Survey I Epidemiological Follow-up Study. Arch Fam Med 1997; 6:43-9.

Jonas BS, Lando JF. Negative affect as a prospective risk factor for hypertension. Psychosom Med 2000; 62:188-96.

Kario K, McEwen BS, Pickering TG. Disasters and the heart: a review of the effects of earthquake-induced stress on cardiovascular disease. Hypertens Res 2003; 26:355-67.

Kennedy PJ, Haertsch PA, Maitz PK. The Bali burn disaster: implications and lessons learned. J Burn Care Rehabil 2005; 26(2):125-131.

Kent L, King H, Cochrane R. Maternal and child psychological sequelae in paediatric burn injuries. Burns 2000; 26(4):317-322.

Kersnik J, Svab I, Vegnuti M. Frequent attenders in general practice: quality of life, patient satisfaction, use of medical services and GP characteristics. Scand J Prim Health Care. 2001; 19:174-77.

Kiecolt-Glaser JK, Dura JK, Speicher CE, Traks OJ, Glaser R. Spousal caregivers of dementia victims: longitudinal changes in immunity and health. Psychosom Med 1991; 53:345-342.

Kimerling R, Clum G, McQuery J, Schnurr PP. PTSD and medical comorbidity. In: Ouimette P, et al, editors. Gender and PTSD. New York, NY, US: Guilford Press, 2002; 271-302.

Klein Beernink M. Support in Volendam. Houten: Bohn Stafleu van Loghum, 2006.

Klungel OH, de Boer A, Paes AH, Herings RM, Seidell JC, Bakker A. Influence of question structure on the recall of self-reported drug use. J Clin Epidemiol 2000; 53(3):273-77.

Knottnerus JA. Role of the electronic patient record in the development of general practice in The Netherlands. Methods Inf Med 1999; 38(4-5):350-54.

Korthuis PT, Asch S, Mancewicz M, Shapiro MF, Mathews WC, Cunningham WE et al. Measuring medication: do interviews agree with medical record and pharmacy data? Med Care 2002; 40(12):1270-82.

Kroenke K, Spitzer RL, Williams JB, Linzer M, Hahn SR, deGruy FV, III et al. Physical symptoms in primary care. Predictors of psychiatric disorders and functional impairment. Arch Fam Med 1994; 3(9):774-779.

Kroenke K. Patients presenting with somatic complaints: epidemiology, psychiatric comorbidity and management. Int J Methods Psychiatr Res 2003; 12(1):34-43.

Kuster PA, Merkle CJ. Caregiving stress, immune function, and health: implications for research with parents of medically fragile children. Issues Compr Pediatr Nurs 2004; 27(4):257276.

Lamberts H, Wood M. ICPC: International Classification of Primary Care. Oxford, United Kingdom: Oxford University Press, 1987.

Lamberts H, Wood M. International Classification of Primary Care. Oxford: Oxford University Press, 1987. 
Landelijk Informatienetwerk Huisartsenzorg. Feiten en cijfers over huisartsenzorg in Nederland [LINH web-site]. Verheij, R. A. Jabaaij L. Abrahamse H. Van den Hoogen H. Braspenning J. and Van Althuis T. http://www.linh.nl. Accessed 06-24-2005.

Landelijk Informatienetwerk Huisartsenzorg. Feiten en cijfers over huisartsenzorg in Nederland (LINH web-site). Verheij R., editor. http://www.linh.nl. Accessed 3-4-2006.

Landolt MA, Grubenmann S, Meuli M. Family impact greatest: predictors of quality of life and psychological adjustment in pediatric burn survivors. J Trauma 2002; 53(6):1146-1151.

Landolt MA, Vollrath M, Ribi K, Gnehm HE, Sennhauser FH. Incidence and associations of parental and child posttraumatic stress symptoms in pediatric patients. J Child Psychol Psychiatry 2003; 44(8):1199-1207.

LeDoux J, Meyer WJ, III, Blakeney PE, Herndon DN. Relationship between parental emotional states, family environment and the behavioural adjustment of pediatric burn survivors. Burns 1998; 24(5):425-432.

Lehman DR, Wortman CB, Williams AF. Long-term effects of losing a spouse or child in a motor vehicle crash. J Pers Soc Psychol 1987; 52(1):218-231.

Levenstein S, Smith MW, Kaplan GA. Psychosocial predictors of hypertension in men and women. Arch Intern Med 2001; 161:1341-6.

Lewin K. Field theory in social science: Selected theoretical papers. New York: Harper \& Row, 1951.

Li J, Precht DH, Mortensen PB, Olsen J. Mortality in parents after death of a child in Denmark: a nationwide follow-up study. Lancet 2003; 361(9355):363-367.

Logue JN, Melick ME, Hansen H. Research issues and directions in the epidemiology of health effects of disasters. Epidemiol Rev 1981; 3:140-162.

Mahoney EJ, Harrington DT, Biffl WL, Metzger J, Oka T, Cioffi WG. Lessons learned from a nightclub fire: institutional disaster preparedness. J Trauma 2005; 58(3):487-491.

Mancuso MG, Bishop S, Blakeney P, Robert R, Gaa J. Impact on the family: psychosocial adjustment of siblings of children who survive serious burns. J Burn Care Rehabil 2003; 24(2):110-118.

Mason SA. Young, scarred children and their mothers - a short-term investigation into the practical, psychological and social implications of thermal injury to the preschool child. Part I: Implications for the mother. Burns 1993; 19(6):495-500.

McEwen BS. The neurobiology of stress: from serendipity to clinical relevance. Brain Res 2000; 886(1-2):172-189.

McFarlane AC. The effects of stressful life events and disasters: research and theoretical issues. Aust N Z J Psychiatry 1985; 19(4):409-421.

Mecocci P, Di Iorio AD, Pezzuto S, et al. Impact of the earthquake of September 26, 1997 in Umbria, Italy on the socioenvironmental and psychophysical conditions of an elderly population. Aging (Milano) 2000; 12:281-6.

Metsemakers JF, Hoppener P, Knottnerus JA, Kocken RJ, Limonard CB. Computerized health information in The Netherlands: a registration network of family practices. Br J Gen Pract 1992; 42(356):102-106.

Metsemakers JF, Knottnerus JA, van Schendel GJ, Kocken RJ, Limonard CB. Unlocking patients' records in general practice for research, medical education and quality assurance: the Registration Network Family Practices. Int J Biomed Comput 1996; 42(1-2):43-50. 
Meyer WJ, Blakeney P, Moore P, Murphy L, Robson M, Herndon D. Parental well-being and behavioral adjustment of pediatric survivors of burns. J Burn Care Rehabil 1994; 15(1):62-68.

Midence K, McManus C, Fuggle P, Davies S. Psychological adjustment and family functioning in a group of British children with sickle cell disease: preliminary empirical findings and a meta-analysis. Br J Clin Psychol 1996; 35(3):439-450.

Miranda J, Perez-Stable EJ, Munoz RF, Hargreaves W, Henke CJ. Somatization, psychiatric disorder, and stress in utilization of ambulatory medical services. Health Psychol 1991; 10(1):46-51.

Morse JM, Mitcham C. The experience of agonizing pain and signals of disembodiment. J Psychosom Res 1998; 44(6):667-680.

Munninger K, Ravenholt O. Lessons from Las Vegas: the MGM Hotel fire. JEMS 1981; 6(2):3740.

Neal RD, Wickenden G, Cottrell D, Mason J, Rugiano J, Clarkson P et al. The use of primary, secondary, community and social care by families who frequently consult their general practitioner. Health Soc Care Community. 2001; 9:375-82.

$\mathrm{Ng}$ DM, Jeffery RW. Relationships between perceived stress and health behaviors in a sample of working adults. Health Psychol 2003; 22(6):638-642.

Noji E.K. The nature of disaster: general characteristics and public health effects. In: Noji E.K., ed. The public health consequences of disaster. New York: Oxford University Press; 1997: 3-20.

Noji EK. Disaster epidemiology and disease monitoring. J Med Syst 1995; 19(2):171-174.

Noji EK. Disasters: introduction and state of the art. Epidemiol Rev 2005; 27:3-8.

Noji EK. The nature of disaster: general characteristics and public health effects. In: Noji EK, editor. The public health consequences of disasters. New York: Oxford University Press, 1997: 3-20.

Norris F. Epidemiology of trauma: Frequency and impact of different potentially traumatic events on different demographic groups. J Consult Clin Psychol 1992; 60(3):409-418.

Norris FH, Friedman MJ, Watson PJ, Byrne CM, Diaz E, Kaniasty K. 60,000 disaster victims speak: Part I. An empirical review of the empirical literature, 1981-2001. Psychiatry 2002; 65(3):207-239.

Norris FH, Friedman MJ, Watson PJ, et al. 60,000 disaster victims speak: part I. An empirical review of the empirical literature, 1981-2001. Psychiatry 2002; 65:207-39.

Norris FH, Friedman MJ, Watson PJ. 60,000 disaster victims speak: Part II. Summary and implications of the disaster mental health research. Psychiatry 2002; 65(3):240-260.

Norris FH, Kaniasty K. Received and perceived social support in times of stress: A test of the social support deterioration deterrence model. J Pers Soc Psychol 1996; 71(3):498-511.

Norris FH. Disaster research methods: past progress and future directions. J Trauma Stress 2006; 19(2):173-184.

Norris FH. Psychosocial consequences of disaster. PTSD Research Quarterly 2002; 13(2):1-8.

O'Connor MF, Allen JJ, Kaszniak AW. Autonomic and emotion regulation in bereavement and depression. J Psychosom Res 2002; 52:183-5. 
Ohayon MM, Caulet M, Priest RG, Guilleminault C. Psychotropic medication consumption patterns in the UK general population. J Clin Epidemiol 1998; 51(3):273-83.

Okkes IM, Groen A, Oskam SK, Lamberts H. Advantages of long observation in episodeoriented electronic patient records in family practice. Methods Inf Med 2001; 40(3):229235.

Parati G, Antonicelli R, Guazzarotti F, et al. Cardiovascular effects of an earthquake: direct evidence by ambulatory blood pressure monitoring. Hypertension 2001; 38:1093-5.

Patterson DR, Everett JJ, Bombardier CH, Questad KA, Lee VK, Marvin JA. Psychological effects of severe burn injuries. Psychol Bull 1993; 113(2):362-378.

Paulose-Ram R, Jonas BS, Orwig D, Safran MA. Prescription psychotropic medication use among the U.S. adult population: results from the third National Health and Nutrition Examination Survey, 1988-1994. J Clin Epidemiol 2004; 57(3):309-17.

Pennebaker JW. Accuracy of symptom perception. In: Baum A, Taylor SE, editors. Handbook of psychology and health. New York: Erlbaum, 1983: 189-218.

Phillips AC, Carroll D, Ring C, Sweeting H, West P. Life events and acute cardiovascular reactions to mental stress: a cohort study. Psychosom Med 2005; 67(3):384-392.

Pickering TG. Mental stress as a causal factor in the development of hypertension and cardiovascular disease. Curr Hypertens Rep 2001; 3(3):249-254.

Pirson J, Degrave E. Aeromedical transfer to Belgium of severely burned patients during the initial days following the Volendam fire. Mil Med 2003; 168(5):360-363.

Porteous T, Bond C, Robertson R, Hannaford P, Reiter E. Electronic transfer of prescriptionrelated information: comparing views of patients, general practitioners, and pharmacists. Br J Gen Pract 2003; 53(488):204-09.

Raikkonen K, Matthews KA, Kuller LH. Trajectory of psychological risk and incident hypertension in middle-aged women. Hypertension 2001; 38:798-802.

Raina P, O'Donnell M, Rosenbaum P, Brehaut J, Walter SD, Russell D et al. The health and wellbeing of caregivers of children with cerebral palsy. Pediatrics 2005; 115(6):e626-e636.

Ramos G, Flageat G, Queiroz G, Nacif G, Fiorentino R, Arata A et al. Massive Hospital Admission of Patients with Respiratory Failure Resulting from Smoke Inhalation Injury: The Cromagnon Republic Tragedy. J Burn Care Res 2006; 27(6):842-847.

Reijneveld SA, Crone MR, Schuller AA, Verhulst FC, Verloove-Vanhorick SP. The changing impact of a severe disaster on the mental health and substance misuse of adolescents: follow-up of a controlled study. Psychol Med 2005; 35:367-376.

Reijneveld SA, Crone MR, Verhulst FC, Verloove-Vanhorick SP. The effect of a severe disaster on the mental health of adolescents: a controlled study. Lancet 2003; 362(9385):691-696.

Rheingold AA, Acierno R, Resnick HS. Trauma, posttraumatic stress disorder, and health risk behaviors. In: Schnurr PP, Green BL, editors. Trauma and health: Physical health consequences of exposure to extreme stress. Washington, DC: American Psychological Association, 2004; 217-244.

Ritter PL, Stewart AL, Kaymaz H, Sobel DS, Block DA, Lorig KR. Self-reports of health care utilization compared to provider records. J Clin Epidemiol. 2001; 54:136-41.

Rizzone LP, Stoddard FJ, Murphy JM, Kruger LJ. Posttraumatic stress disorder in mothers of children and adolescents with burns. J Burn Care Rehabil 1994; 15(2):158-163. 
Roberts RO, Bergstralh EJ, Schmidt L, Jacobsen SJ. Comparison of self-reported and medical record health care utilization measures. J Clin Epidemiol. 1996; 49:989-95.

Roorda J, van Stiphout WA, Huijsman-Rubingh RR. Post-disaster health effects: strategies for investigation and data collection. Experiences from the Enschede firework disaster. J Epidemiol Community Health 2004; 58(12):982-987.

Rosenbaum JF. Attitudes toward benzodiazepines over the years. J Clin Psychiatry 2005; 66 Suppl 2:4-8.

Roussos A, Goenjian AK, Steinberg AM, Sotiropoulou C, Kakaki M, Kabakos C et al. Posttraumatic stress and depressive reactions among children and adolescents after the 1999 earthquake in Ano Liosia, Greece. Am J Psychiatry 2005; 162(3):530-537.

Rozanski A, Blumenthal JA, Kaplan J. Impact of psychological factors on the pathogenesis of cardiovascular disease and implications for therapy. Circulation 1999; 99(16):2192-2217.

Rubin SS, Malkinson R. Parental response to child loss across the life cycle: Clinical and research perspectives. In: Stroebe MS, editor. Handbook of bereavement research: Consequences, coping, and care. Washington DC: American Psychological Association, 2001: 219-240.

Rubonis AV, Bickman L. Psychological impairment in the wake of disaster: the disasterpsychopathology relationship. Psychol Bull 1991; 109:384-399.

Sadler C. Accident and emergency: the St Valentine's day disaster. Nurs Mirror 1982; 154(20):1416.

Saito K, Kim JI, Maekawa K, et al. The great Hanshin-Awaji earthquake aggravates blood pressure control in treated hypertensive patients. Am J Hypertens 1997; 10:217-21.

Salzman C. The APA Task Force report on benzodiazepine dependence, toxicity, and abuse. Am J Psychiatry 1991; 148(2):151-52.

Scaife B, Gill P, Heywood P, Neal R. Socio-economic characteristics of adult frequent attenders in general practice: secondary analysis of data. Fam Pract. 2000; 17:298-304.

Schneeweiss S, Avorn J. A review of uses of health care utilization databases for epidemiological research on therapeutics. J Clin Epidemiol 2005; 58(4):323-37.

Schnurr PP, Green BL. Trauma and health: Physical health consequences of exposure to extreme stress. Washington, DC: American Psychological Association, 2004.

Schnurr PP, Green BL. Trauma and health: Physical health consequences of exposure to extreme stress. Washington, DC, US: American Psychological Association UR, 2004.

Schnurr PP, Green BL. Understanding relationships among trauma, posttraumatic stress disorder, and health outcomes. In: Green BL, Schnurr PP, editors. Trauma and health: Physical health consequences of exposure to extreme stress. Washington, DC, US: American Psychological Association, 2004; 247-275.

Schnurr PP, Jankowski MK. Physical health and post-traumatic stress disorder: review and synthesis. Semin Clin Neuropsychiatry 1999; 4(4):295-304.

Seeman TE, Singer BH, Rowe JW, Horwitz RI, McEwen BS. Price of adaptation-allostatic load and its health consequences. MacArthur studies of successful aging. Arch Intern Med 1997; 157(19):2259-2268.

Selye H. The stress of life. New York: McGraw-Hill, 1956. 
Shelby J, Sullivan J, Groussman M, Gray R, Saffle J. Severe burn injury: effects on psychologic and immunologic function in noninjured close relatives. J Burn Care Rehabil 1992; 13(1):58-63.

Silva RR, Alpert M, Munoz DM, Singh S, Matzner F, Dummit S. Stress and vulnerability to posttraumatic stress disorder in children and adolescents. Am J Psychiatry 2000; 157(8):1229-1235.

Silverman WK, La Greca AM. Children experiencing disasters: Definitions, reactions, and predictors of outcomes. In: La Greca AM, editor. Helping children cope with disasters and terrorism. Washington, DC: American Psychological Association; 2002; 11-33.

Snijder TB, Bosker R. Multilevel analysis: an introduction to basic and advanced multilevel modeling. Thousand Oaks, CA: Sage Publications, 1999.

Solomon SD. Mobilizing social support networks in times of disaster. In: Figley CR, editor. Trauma and its wake. Vol II: Traumatic stress, theory, research and intervention. New York: Brunner Mazel, 1986; 232-263.

Spratt ML, Denney DR. Immune variables, depression, and plasma cortisol over time in suddenly bereaved parents. J Neuropsychiatry Clin Neurosci. 1991; 3:299-306.

Stange KC, Zyzanski SJ, Smith TF, Kelly R, Langa DM, Flocke SA et al. How valid are medical records and patient questionnaires for physician profiling and health services research? A comparison with direct observation of patients visits. Med Care. 1998; 36:851-67.

Stroebe W, Schut H. Risk factors in bereavement outcome: A methodological and empirical review. In: Stroebe MS, editor. Handbook of bereavement research: Consequences, coping, and care. Washington DC: American Psychological Association, 2001; 349-371.

Tarnow P, Gewalli F, Cassuto J. Fire disaster in Gothenburg 1998-surgical treatment of burns. Burns 2003; 29(5):417-421.

Tarnowski KJ, Brown RT. Burn injuries. In: Goreczny AJ, Hersen M, editors. Handbook of pediatric and adolescent health psychology. Boston: Allyn and Bacon, 1999; 115-126.

Tarnowski KJ, Rasnake LK, Gavaghan-Jones MP, Smith L. Psychological sequelae of pediatric burn injuries. Clin Psychol Rev 2002; 11(4):371-398.

Taylor A. A taxonomy of disasters and their victims. Journal of Psychosomatic Research 1987; 31(5):535-544.

Taylor SE, Repetti RL, Seeman T. Health psychology: what is an unhealthy environment and how does it get under the skin? Annu Rev Psychol 1997; 48:411-447.

Taylor SE. What is stress? In: Taylor SE, editor. Health psychology. New York: McGraw-Hill, 1995; 219-296.

Tessler R, Mechanic D, Dimond M. The effect of psychological distress on physician utilization: a prospective study. J Health Soc Behav 1976; 17(4):353-364.

Tierney KJ. Controversy and consensus in disaster mental health research. Prehospital and Disaster Medicine 2000; 15(4):181-187.

Tong HC, Haig AJ, Nelson VS, Yamakawa KS, Kandala G, Shin KY. Low back pain in adult female caregivers of children with physical disabilities. Arch Pediatr Adolesc Med 2003; 157(11):1128-1133 
Tong HC, Kandala G, Haig AJ, Nelson VS, Yamakawa KS, Shin KY. Physical functioning in female caregivers of children with physical disabilities compared with female caregivers of children with a chronic medical condition. Arch Pediatr Adolesc Med 2002; 156(11):1138-1142.

Trevisan M, Jossa F, Farinaro E, et al. Earthquake and coronary heart disease risk factors: a longitudinal study. Am J Epidemiol 1992; 135:632-7.

van Bemmel JH, Musen MA. Handbook of Medical Informatics. Houten: Bohn Stafleu Van Loghum, 1997.

van der Lei J, Duisterhout JS, Westerhof HP, van der DE, Cromme PV, Boon WM et al. The introduction of computer-based patient records in The Netherlands. Ann Intern Med 1993; 119(10):1036-1041.

van der Waals FW, Mohrs J, Foets M. Sex differences among recipients of benzodiazepines in Dutch general practice. BMJ 1993; 307(6900):363-66.

van Eijk JT. Serious illness and family dynamics. 1. Changes in consulting patterns of the unafflicted family members. Fam Pract 1985; 2(2):61-69.

van Eijk JT. Serious illness and family dynamics. 2. Changes in consulting patterns of the afflicted family members. Fam Pract 1985; 2(2):70-75.

van Eijk JT. The role of Dutch general practitioners in clinical health promotion. Patient Educ Couns 1995; 25(3):269-276.

van Harten SM, Welling L, Perez RS, Patka P, Kreis RW. Management of multiple burn casualties from the Volendam disaster in the emergency departments of general hospitals. Eur J Emerg Med 2005; 12(6):270-274.

van Hulten R, Isacson D, Bakker A, Leufkens HG. Comparing patterns of long-term benzodiazepine use between a Dutch and a Swedish community. Pharmacoepidemiol Drug Saf 2003; 12(1):49-53.

van Loey NE, Van Son MJ. Psychopathology and psychological problems in patients with burn scars: epidemiology and management. Am J Clin Dermatol 2003; 4(4):245-272.

van Mil JW. Pharmaceutical care in community pharmacy: practice and research in the Netherlands. Ann Pharmacother 2005; 39(10):1720-1725.

van Vugt AB. [Disaster medicine: lessons from Enschede and Volendam]. Ned Tijdschr Geneeskd 2001; 145(48):2309-2312.

Vedhara K, McDermott MP, Evans TG, Treanor JJ, Plummer S, Tallon D et al. Chronic stress in nonelderly caregivers: psychological, endocrine and immune implications. J Psychosom Res 2002; 53(6):1153-1161.

Vedhara K, Shanks N, Anderson S, Lightman S. The role of stressors and psychosocial variables in the stress process: a study of chronic caregiver stress. Psychosom Med 2000; 62(3):374385.

Vernberg EM. Children's responses to disaster: Family and systems approaches. In: Gist R, Lubin B, editors. Response to disaster: Psychosocial, community, and ecological approaches. Philadelphia: Brunner/Mazel, 1999; 193-210.

Vitaliano PP, Zhang J, Scanlan JM. Is caregiving hazardous to one's physical health? A metaanalysis. Psychol Bull 2003,129:946-972. 
Vlahov D, Galea S, Resnick H, Ahern J, Boscarino JA, Bucuvalas M et al. Increased use of cigarettes, alcohol, and marijuana among Manhattan, New York, residents after the September 11th terrorist attacks. Am J Epidemiol 2002; 155(11):988-996.

Walker EA, Newman E, Koss MP. Costs and health care utilization associated with traumatic experiences. In: Green BL, Schnurr PP, editors. Trauma and health: Physical health consequences of exposure to extreme stress. Washington, DC: American Psychological Association, 2004; 43-69.

Watkins PN, Cook EL, May SR, Still JM, Jr., Luterman A, Purvis RJ. Postburn psychologic adaptation of family members of patients with burns. J Burn Care Rehabil 1996; 17(1):7892.

Welling L, van Harten SM, Patka P, Bierens JJ, Boers M, Luitse JS et al. The café fire on New Year's Eve in Volendam, the Netherlands: description of events. Burns 2005; 31(5):548554.

Welling L, van Harten SM, Patka P, Bierens JJ, Boers M, Luitse JS et al. Medical management after indoor fires: a review. Burns 2005; 31(6):673-678

WHO Collaborating Centre for Drug Statistics Methodology, Norwegian Institute of Public Health. About the ATC/DDD system. Oslo, Norway: WHO Collaborating Centre for Drug Statistics Methodology, 2006. (http://www.whocc.no/atcddd/).

WHO Regional Office for Europe. Highlights on health in the Netherlands. Copenhagen: 1997.

Williams R, Zyzanski SJ, Wright AL. Life events and daily hassles and uplifts as predictors of hospitalization and outpatient visitation. Social Science and Medicine. 1992; 34:763-68.

Wills TA, Sandy JM, Yaeger AM. Stress and smoking in adolescence: a test of directional hypotheses. Health Psychol 2002; 21(2):122-130.

Yule W, Bolton D, Udwin O, Boyle S, O'Ryan D, Nurrish J. The long-term psychological effects of a disaster experienced in adolescence: I: The incidence and course of PTSD. J Child Psychol Psychiatry 2000; 41(4):503-511.

Yzermans CJ, Donker GA, Kerssens JJ, Dirkzwager AJ, Soeteman RJ, Ten Veen PM. Health problems of victims before and after disaster: a longitudinal study in general practice. Int J Epidemiol 2005; 34:810-819.

Yzermans J, Gersons BPR. The chaotic aftermath of an airplane crash in Amsterdam: A second disaster. In: Havenaar JM, Cwikel JG, Bromet EJ, editors. Toxic turmoil: Psychological and societal consequences of ecological disasters. New York, NY, US: Kluwer Academic /Plenum Publishers, 2002: 85-99.

Zwaanswijk M, Verhaak PF, van der EJ, Bensing JM, Verhulst FC. Consultation for and identification of child and adolescent psychological problems in Dutch general practice. Fam Pract. 2005; 22:498-506. 
Literature 
Dankwoord 


\section{Dankwoord}

Zonder de hulp van anderen kan een proefschrift nooit tot stand komen. Er zijn veel mensen aan wie ik dank verschuldigd ben.

Allereerst wil ik mijn promotor Jouke van der Zee en mijn copromotor Joris IJzermans bedanken. Ik heb het erg goed getroffen met jullie. Jullie hebben altijd vertrouwen in mij gehad. En dat gaf vleugels!

Jouke, het is heel leuk dat je niet alleen mijn scriptieonderzoek hebt begeleid, maar ook bereid was mij de weg te wijzen naar mijn promotie. Ik heb graag met je samengewerkt. Je was altijd goed op de hoogte van waar ik mee bezig was. Je hebt niet alleen een vinger aan de pols gehouden, maar je was ook altijd bereikbaar voor mij. Daardoor heb je ervoor gezorgd dat er vaart in het onderzoek zat. Hiervoor ben ik je erg dankbaar. Ik heb veel van je geleerd en er zijn zeker nog dingen die ik in de toekomst van je zou willen leren - bijvoorbeeld hoe je die fantastische toespraken van je in elkaar zet!

Joris, je was niet alleen mijn copromotor, maar ook een soort mentor voor mij. Je vond het niet erg dat ik tijd nodig had voor de beslissing of ik wel of niet wilde promoveren (tenminste heb je me dat nooit laten voelen). In 2003 heb ik de knoop doorgehakt en ben ik met een concreet voorstel gekomen hoe mijn proefschrift eruit zou kunnen zien. Met alle vakinhoudelijke vragen kon ik bij jou terecht, maar ik kon ook op moeilijke momenten op je rekenen. Je hebt me door dik en dun gesteund en begeleid. Je weet niet hoe belangrijk dit voor mij was. Bedankt voor je steun en alles wat je voor mij hebt gedaan.

Natuurlijk wil ik ook de huisartsen en apothekers in Volendam bedanken voor hun inbreng in dit onderzoek. Zonder hun gegevens en hun bereidschap om aan dit onderzoek deel te nemen had dit proefschrift nooit geschreven kunnen worden. Bijzondere dank gaat ook uit naar de wetenschappelijke adviescommissie die het onderzoek al die jaren in de gaten heeft gehouden. Het onderzoek is hierdoor alleen maar beter geworden. 
Verder wil ik de leden van de beoordelingscommissie, prof. dr. G. Kok, prof. dr. W. van den Brink, prof. dr. J. Th. M. van Eijk, prof. dr. T. Fydrich en prof. dr. J.F.M. Metsemakers bedanken voor het lezen en beoordelen van het manuscript.

Daarnaast zijn er nog vele collega's die ik graag wil bedanken. Petra, jij was verantwoordelijk voor het databeheer - en er was veel data! Zonder jouw inbreng en kennis had dit proefschrift nooit tot stand kunnen komen. Ook ben je een erg leuke kamergenote geweest!

Jan, je hebt mijn eerste stappen in het onderzoek meegemaakt. Dankzij jou kan ik tegenwoordig heel veel grafiekjes in korte tijd produceren (een uiterst nuttige vaardigheid) en door jouw goede voorbeeld ben ik goed geworden in het verbouwen van grote databestanden met SPSS.

Peter, jij kwam later in beeld. Van jou heb ik geleerd hoe je variabelen voor een regressie-analyse op een handige manier codeert. Je vond het niet erg om dingen steeds opnieuw uit te leggen tot bij mij het muntje was gevallen en dankzij jou zijn bij mij heel veel muntjes gevallen in de laatste jaren! Dat ik nu met Mlwin zelfstandig kan omgaan heb ik aan jou te danken.

Anja, Dirk-Jan, ik denk met veel plezier terug aan 'the good old days' toen we in de Drieharingstraat nog op dezelfde verdieping zaten. Ik vind het heel leuk dat jullie als paranimfen naast mij willen staan tijdens mijn verdediging. Anja, jou wil ik ook bedanken voor de tijd die je in mijn artikelen hebt gestopt. Ik heb aan jouw advies altijd veel gehad (aan je lachzak ook, trouwens).

Karin en Karin, Pauline, Annemarie, Mattijn, op het eind hebben jullie nog de laatste fouten uit mijn manuscript gehaald - heel erg bedankt! Marion, Ruth, Celina en Rik, mijn (ex-)kamergenoten: bedankt voor alle gezelligheid.

Marina, jij hebt mijn proefschrift opgemaakt voor het drukken. Het was heel fijn dat je mij zo goed en snel hebt geholpen, tussen alle bedrijven door. 
Richard, dat de omslag van het boekje zo mooi oogt heb ik aan jou te danken. Je hebt een bijzonder kaft in elkaar gezet!

Mieke, fijn dat jij even bijsprong op het moment waar ik met de samenvatting dreigde vast te lopen.

Mijn lieve vrienden in Amsterdam, en daarbuiten, ik kan altijd bij jullie terecht, voor zo ongeveer alle levensvragen! Jullie zijn een kostbaar bezit. Ik verheug me op al de feesten die wij nog samen gaan vieren.

Tenslotte wil ik Arjan bedanken. Tien jaar geleden ben ik je op een kruispunt in Salt Lake City tegengekomen. Ik duwde twee fietsen tegelijk een steile helling omhoog. Dat heeft blijkbaar indruk op je gemaakt. Misschien was je ook een beetje jaloers omdat je op dat moment zelf geen fiets had. In ieder geval heb ik op die manier je aandacht getrokken, we raakten aan de praat. En nog steeds praat ik heel graag met je! Als wij geen stel waren geworden, had ik dan ooit voor de keuze gestaan om een proefschrift te schrijven over een ramp in Nederland? Ik weet het niet. Maar een ding weet ik zeker: dat je trots op me bent - en dat is zo een fijn gevoel. 
Dankwoord 
About the author 


\begin{abstract}
About the author
Tina Dorn was born in Speyer, Germany, on the $1^{\text {st }}$ of June, 1973. She followed her secondary education at the Carl-Friedrich-Gauß-Gymnasium in Hockenheim, Germany, from which she graduated in 1992. Following this, she started to study French and German literature at the University of Heidelberg, Germany. In 1993, she changed her major into psychology. From 1996 to 1997, she pursued her studies at the University of Utah, Salt Lake City, Utah, USA, supported by a grant from the university's academic exchange office. In 2000, she graduated from the University of Heidelberg, with Clinical and Developmental Psychology as majors. Hereafter, she received a grant from the German Academic Exchange Service (DAAD) for postgraduate studies at the University of Maastricht, the Netherlands. In 2001, she obtained her Master of Public Health degree (MPH) from this university. Since 2002 she has been employed at the Netherlands Institute for Health Services Research (NIVEL), conducting research on the Volendam fire which resulted in this $\mathrm{PhD}$ thesis.
\end{abstract}


